\title{
Discovery of Novel Triazolothiadiazines as Fungicidal Leads Targeting Pyruvate Kinase
}

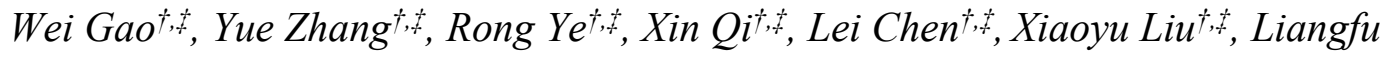
Tang ${ }^{\dagger, t}$, Lai Chen $\$$, Hongyu Chen ${ }^{\natural *}$, Zhijin Fan ${ }^{\dagger, *^{*}}$

$\dagger$ State Key Laboratory of Elemento-Organic Chemistry, College of Chemistry, Nankai University, Tianjin 300071, P. R. China

$\$$ Frontiers Science Center for New Organic Matter, College of Chemistry, Nankai University, Tianjin 300071, P. R. China

$\S$ College of Plant Protection, Hebei Agricultural University, Baoding 071001, P. R. China

^The Second Medical Center \& National Clinical Research Center for Geriatric Diseases, Chinese PLA General Hospital, Beijing 100853, China

* Address correspondence to these authors at State Key Laboratory of ElementoOrganic Chemistry, College of Chemistry, Nankai University, Frontiers Science Center for New Organic Matter, College of Chemistry, Nankai University, No. 94, Weijin Road, Nankai District, Tianjin 300071, P. R. China (Tel: +86-13920714666; Fax: +86 022-23503620; e-mail: fanzj@nankai.edu.cn for Zhijin Fan or chenhy0528@163.com for Hongyu Chen). 


\section{Supporting Information}

Figure A. The Ramachandran plot of pyruvate kinase of Rhizoctonia solani. .................................3

Figure B. The pyruvate kinase of Rhizoctonia solani with binding domain......................................4

Table S1. The bond energy between compounds and pyruvate kinase of Rhizoctonia solani. ........5

Table S2. The bond energy of compound $\mathbf{6 m}$ with pyruvate kinase of different species................5

Table S3. Crystal data and structure refinement for compound $\mathbf{6 m}$. ...........................................6

Copies of ${ }^{1} \mathrm{H}$ NMR, ${ }^{13} \mathrm{C}$ NMR and HRMS of compounds 6 . ................................................ 


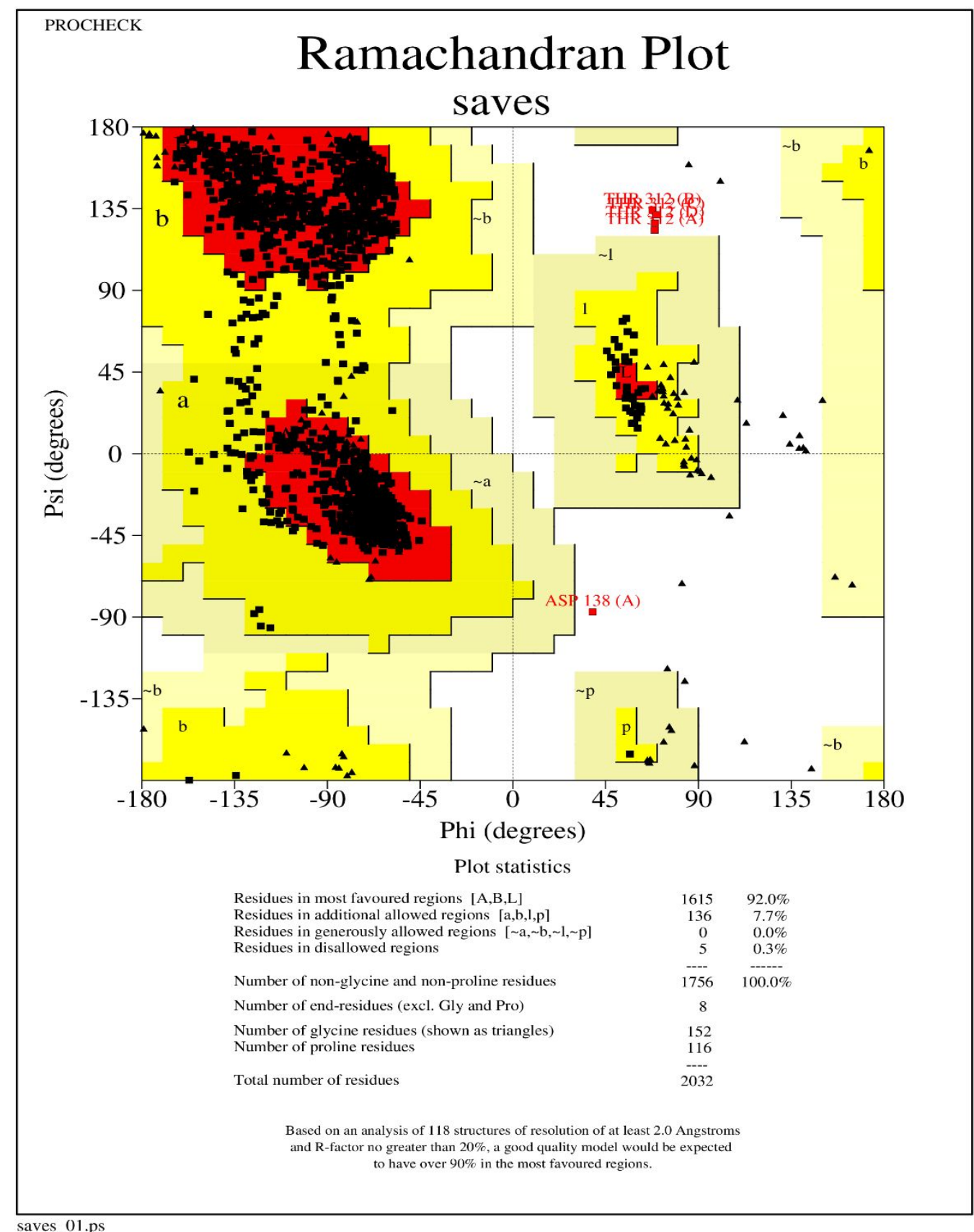

Figure A. The Ramachandran plot of pyruvate kinase of Rhizoctonia solani. 


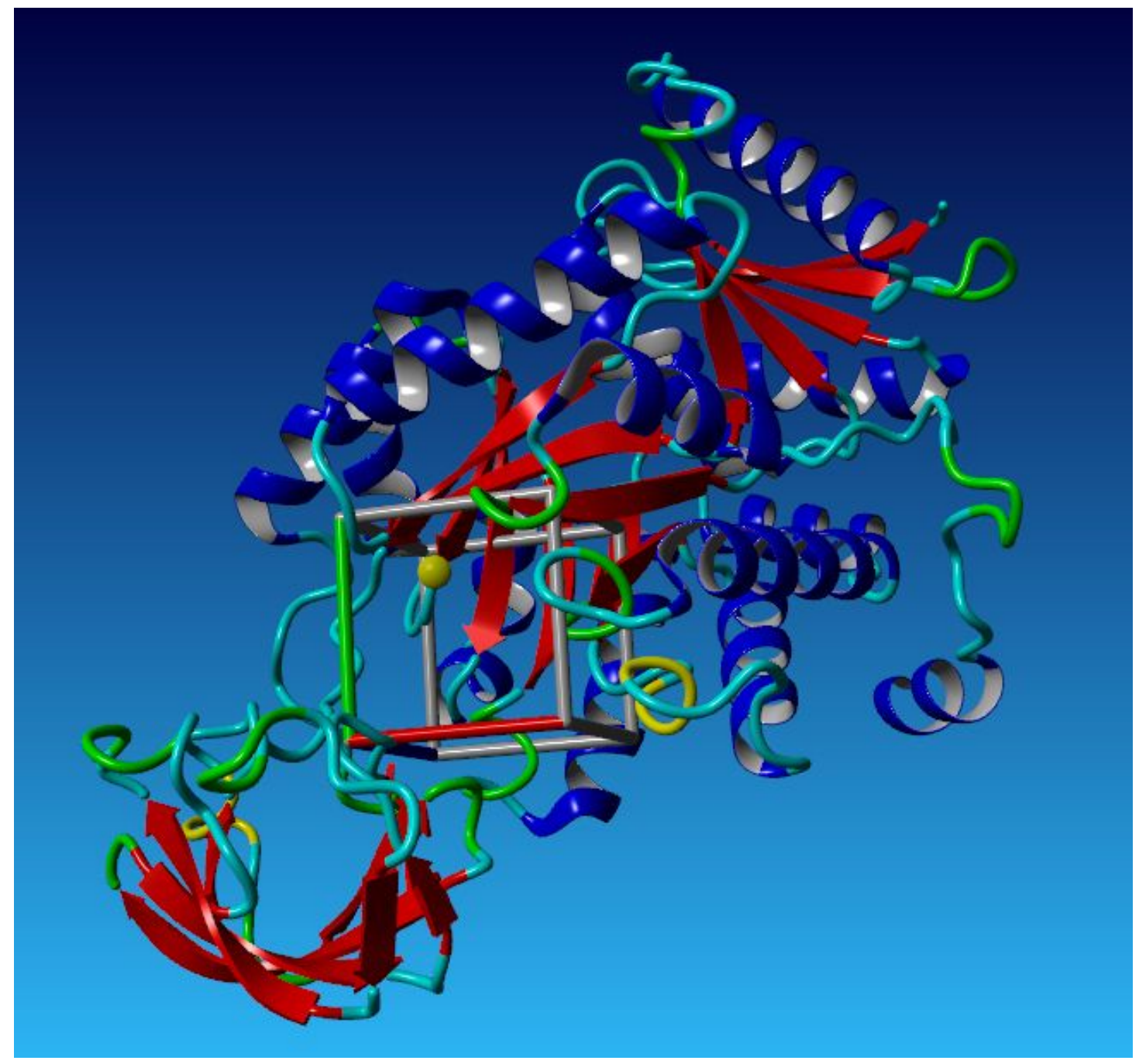

Figure B. The pyruvate kinase of Rhizoctonia solani with binding domain. 
Table S1. The bond energy between compounds and pyruvate kinase of Rhizoctonia solani. $(\mathrm{Kcal} / \mathrm{mol})$

\begin{tabular}{cccc}
\hline Compounds & Bond energy & Compounds & Bond energy \\
\hline YZK-C22 & 6.484 & $\mathbf{6 k}$ & 7.753 \\
$\mathbf{6 a}$ & 7.698 & $\mathbf{6}$ & 6.996 \\
$\mathbf{6 b}$ & 7.505 & $\mathbf{6 m}$ & 6.519 \\
$\mathbf{6 c}$ & 7.761 & $\mathbf{6 n}$ & 6.267 \\
$\mathbf{6 d}$ & 6.582 & $\mathbf{6 o}$ & 6.235 \\
$\mathbf{6 e}$ & 8.332 & $\mathbf{6 p}$ & 7.189 \\
$\mathbf{6 f}$ & 7.440 & $\mathbf{6 q}$ & 6.200 \\
$\mathbf{6 g}$ & 6.702 & $\mathbf{6 r}$ & 6.161 \\
$\mathbf{6 h}$ & 6.682 & $\mathbf{6 s}$ & 6.141 \\
$\mathbf{6 i}$ & 7.293 & $\mathbf{6 t}$ & 6.489 \\
$\mathbf{6 j}$ & 7.417 & $\mathbf{6 u}$ & 5.490 \\
\hline
\end{tabular}

Note: The larger the bond energy value, the better its potential fungicidal activity.

Table S2. The bond energy of compound $\mathbf{6 m}$ with pyruvate kinase of different species. $(\mathrm{Kcal} / \mathrm{mol})$

\begin{tabular}{ccc}
\hline Compound & Organisms & Bond energy \\
\hline \multirow{2}{*}{$\mathbf{6 m}$} & Homo sapiens & 6.296 \\
& Rhizoctonia solani & 6.519 \\
\hline
\end{tabular}

Note: The larger the bond energy value, the better its affinity. 
Table S3. Crystal data and structure refinement for compound $\mathbf{6 m}$.

\begin{tabular}{ll}
\hline Compound & $\mathbf{6 m}$ \\
\hline Empirical formula & $\mathrm{C}_{10} \mathrm{H}_{12} \mathrm{~N}_{6} \mathrm{~S}_{2}$ \\
Formula weight & 280.38 \\
Temperature & $113.15 \mathrm{~K}$ \\
Wavelength & $0.71073 \mathrm{~A}$ \\
Unit cell dimensions & $\mathrm{a}=10.2997(4) \mathrm{A}$; alpha $=90 \mathrm{deg}$. \\
& $\mathrm{b}=16.9802(5) \mathrm{A} ;$ beta $=97.565(3) \mathrm{deg}$. \\
& $\mathrm{c}=14.8168(5) \mathrm{A}$; gamma $=90 \mathrm{deg}$. \\
Volume & $2568.77(15) \mathrm{A}^{3}$ \\
Z, Calculated density & $8,1.450 \mathrm{~g}^{3} \mathrm{~cm}^{3}$ \\
Absorption coefficient & $0.406 \mu / \mathrm{mm}^{-1}$ \\
F(000) & 1168.0 \\
Crystal size & $0.22 \times 0.20 \times 0.17 \mathrm{~mm}$ \\
Theta range for data & 4.656 to 65.906 deg. \\
collection & \\
Limiting indices & $-15 \leq \mathrm{h} \leq 15,-24 \leq \mathrm{k} \leq 25,-22 \leq 1 \leq 20$ \\
Reflections collected / & $31903 / 8818[\mathrm{R}(\mathrm{int})=0.0624, \mathrm{R}(\mathrm{sigma})=0.0596]$ \\
unique & \\
Data / restraints / parameters & $8818 / 0 / 331$ \\
Goodness - of-fit on $\mathrm{F}^{2}$ & 1.036 \\
Final R indices [I $>$ (I) $]$ & $\mathrm{R}_{1}=0.0465, \mathrm{wR}_{2}=0.1017$ \\
$\mathrm{R}$ indices (all data) & $\mathrm{R}_{1}=0.0707, \mathrm{wR}_{2}=0.1144$ \\
Largest diff. peak and hole & 0.37 and $-0.45 \mathrm{e} . \mathrm{A}^{-3}$ \\
\hline
\end{tabular}


Copies of ${ }^{1} \mathrm{H}$ NMR, ${ }^{13} \mathrm{C}$ NMR and HRMS of compounds 6.

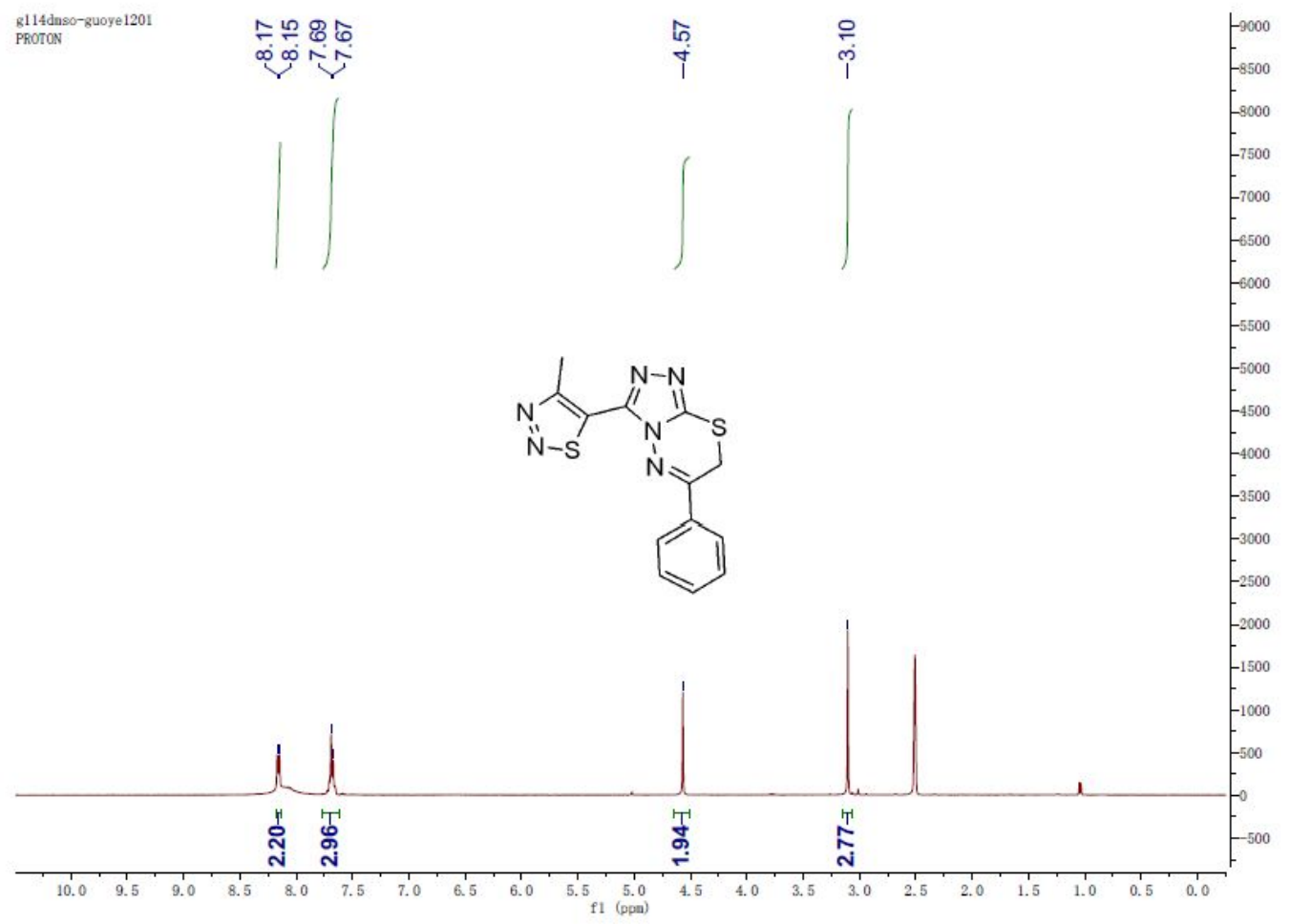

Figure $C 1$. The ${ }^{1} \mathrm{H}$ NMR (400MHz, DMSO- $d_{6}$ ) of compound $6 \mathbf{a}$.

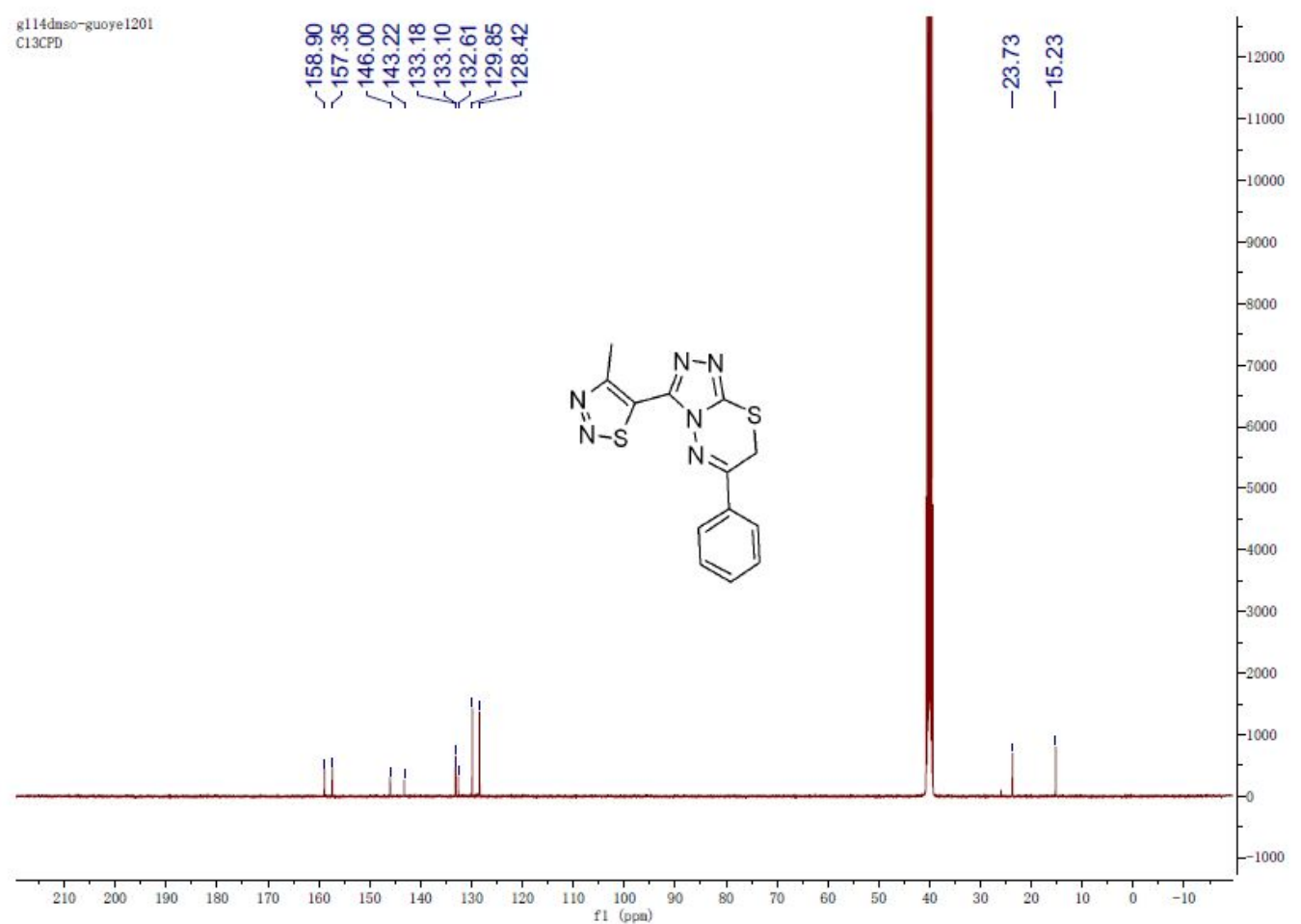


Figure $C 2$. The ${ }^{13} \mathrm{C}$ NMR $\left(400 \mathrm{MHz}, \mathrm{DMSO}-d_{6}\right)$ of compound 6 a. 


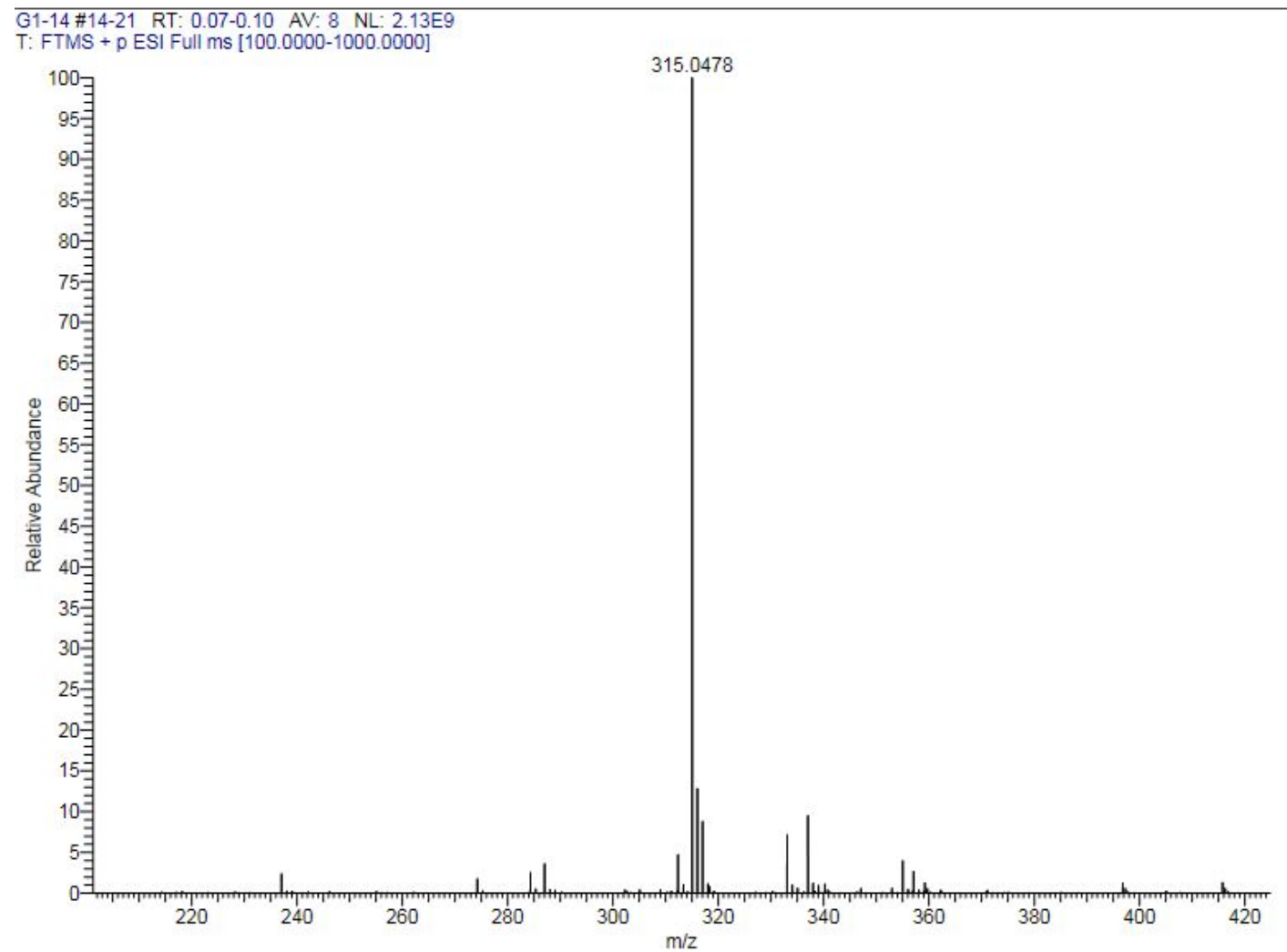

Figure C3. The HRMS of compound $\mathbf{6 a}$.

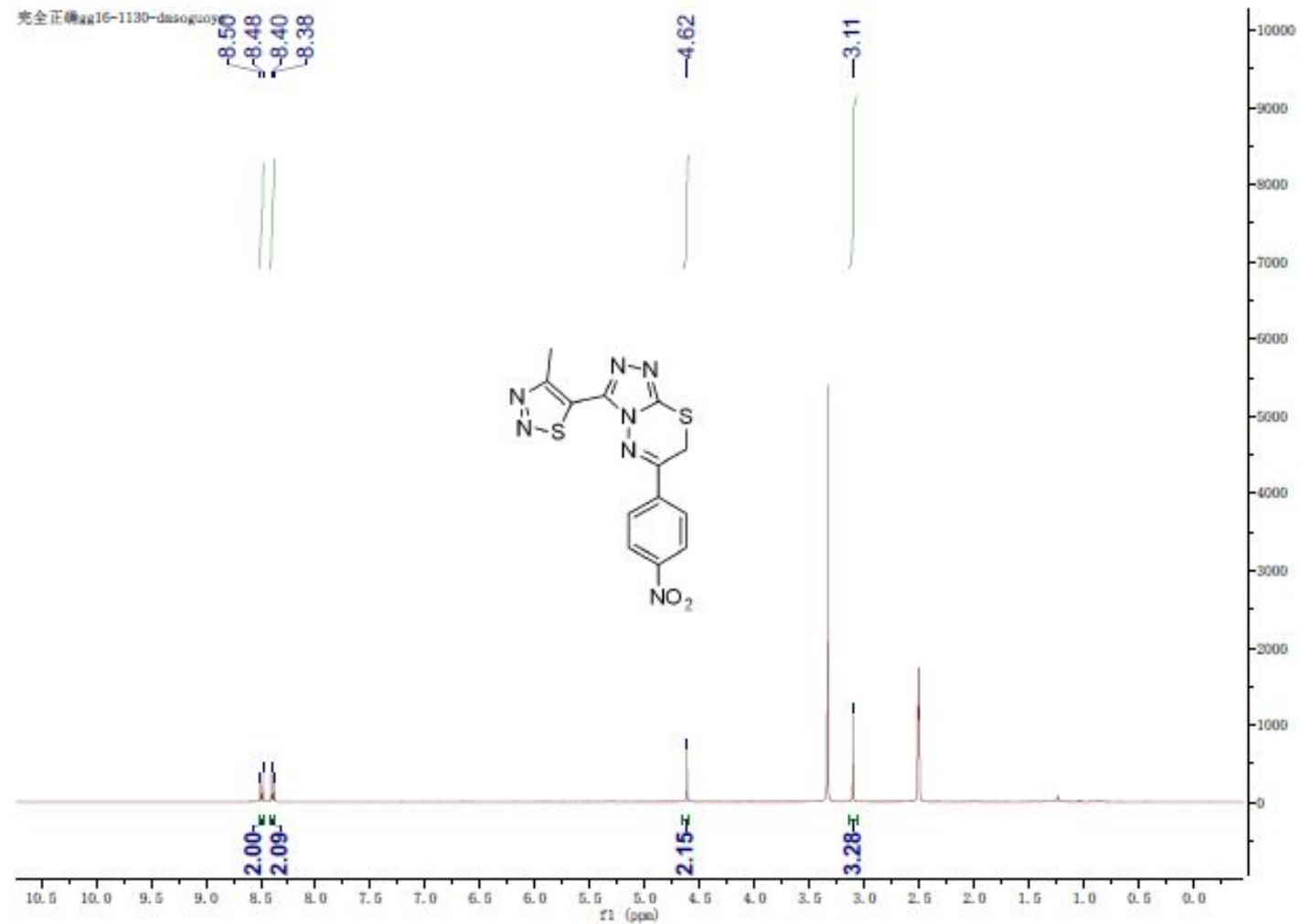

Figure C4. The ${ }^{1} \mathrm{H}$ NMR $\left(400 \mathrm{MHz}, \mathrm{DMSO}-d_{6}\right)$ of compound $\mathbf{6 b}$. 


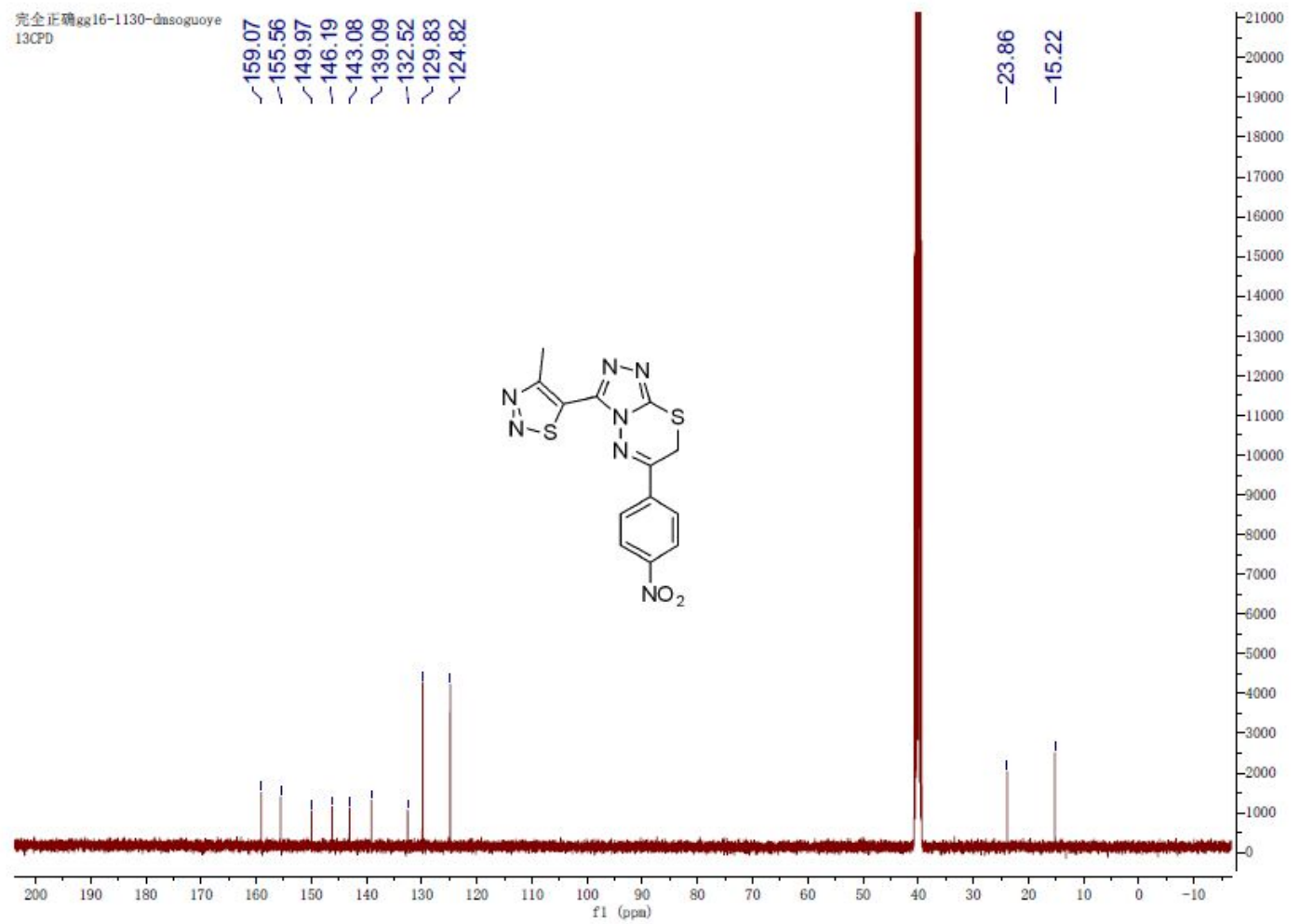

Figure $C 5$. The ${ }^{13} \mathrm{C}$ NMR $\left(400 \mathrm{MHz}\right.$, DMSO- $\left.d_{6}\right)$ of compound $\mathbf{6 b}$.

G1-16\#13-18 RT: 0.06-0.09 AV: 6 NL: 8.07E7

T: FTMS + p ESI Full ms [100.0000-1000.0000]

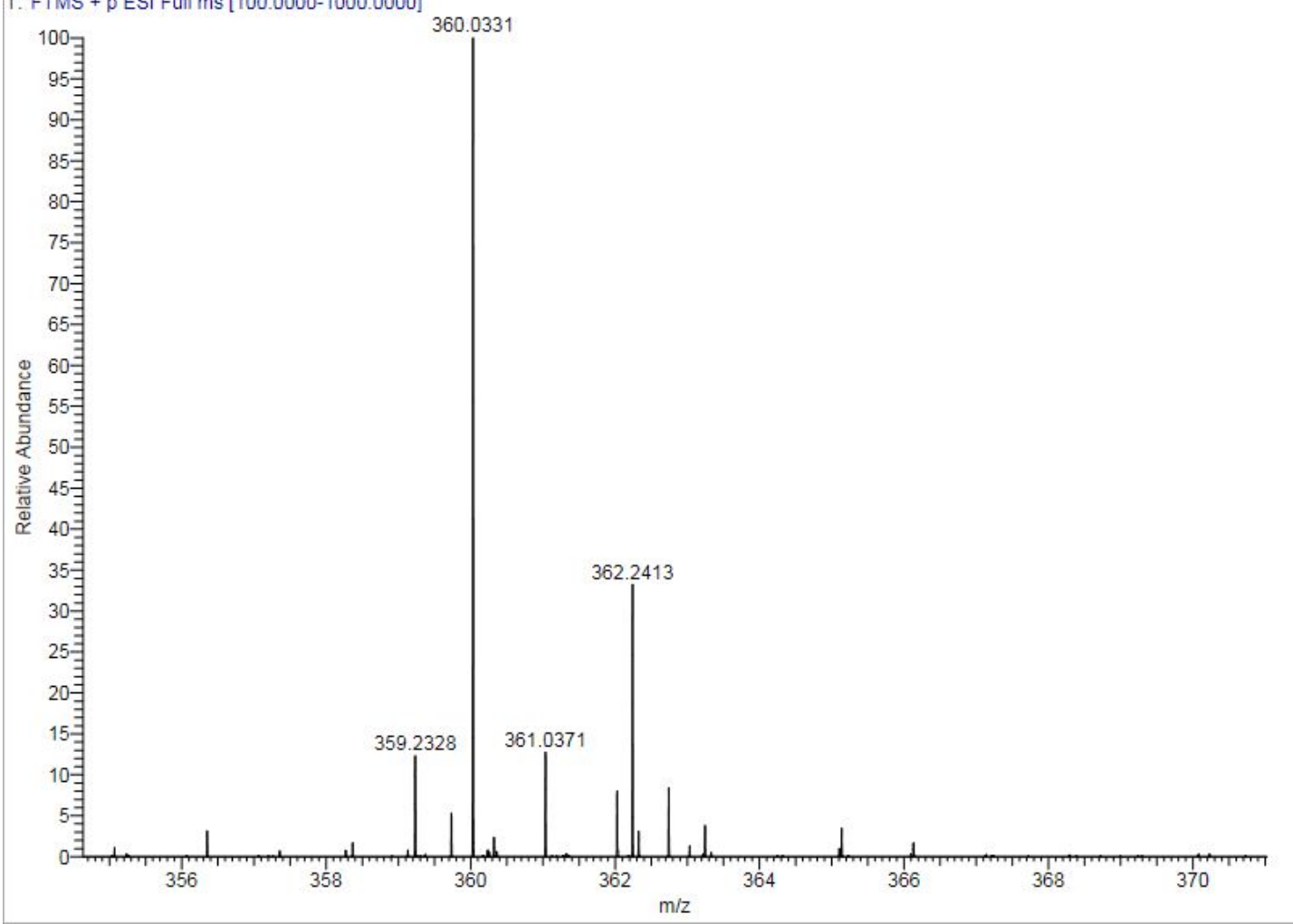

Figure C6. The HRMS of compound $\mathbf{6 b}$. 


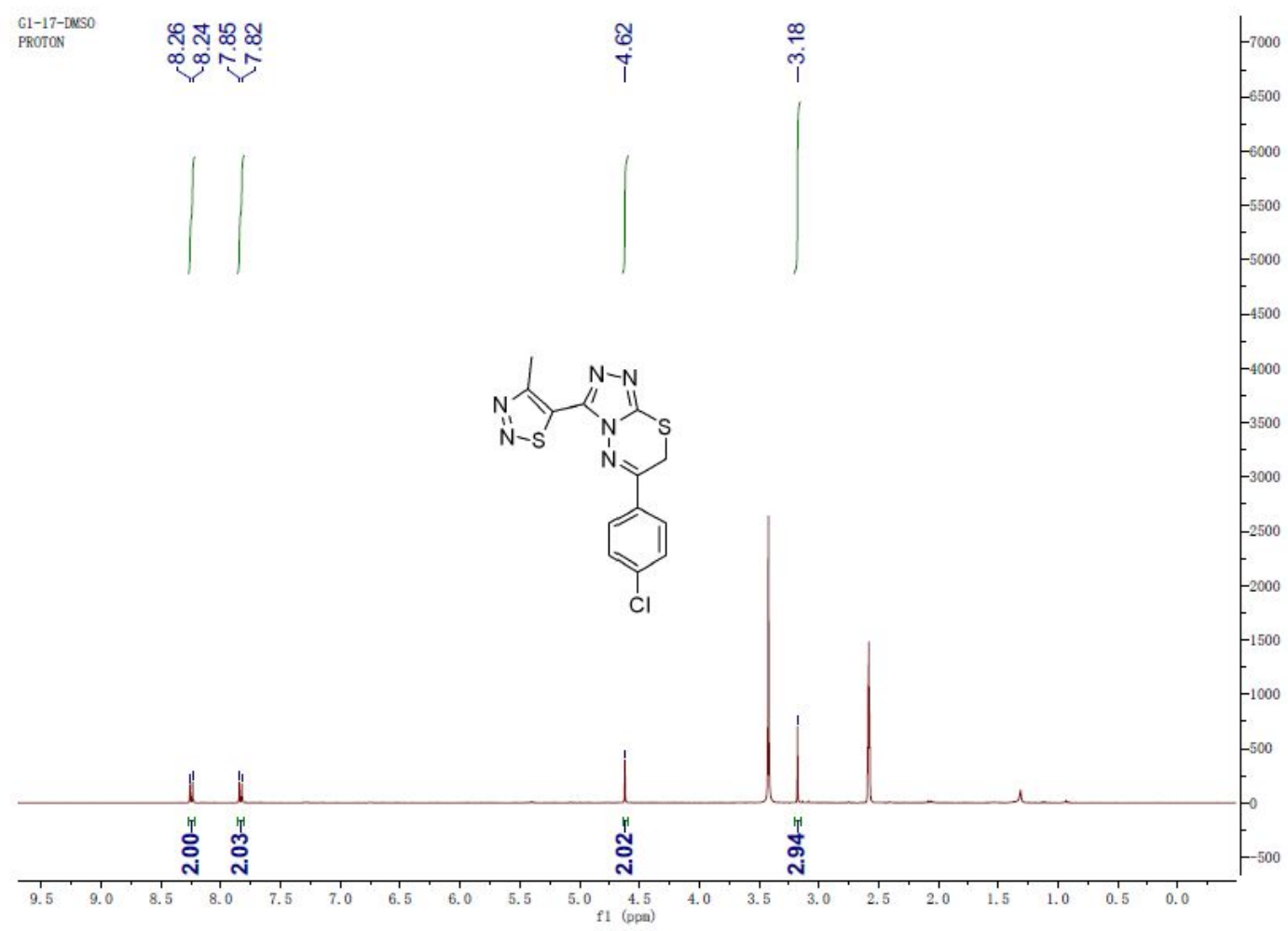

Figure $C 7$. The ${ }^{1} \mathrm{H}$ NMR (400MHz, DMSO- $d_{6}$ ) of compound $\mathbf{6 c}$.

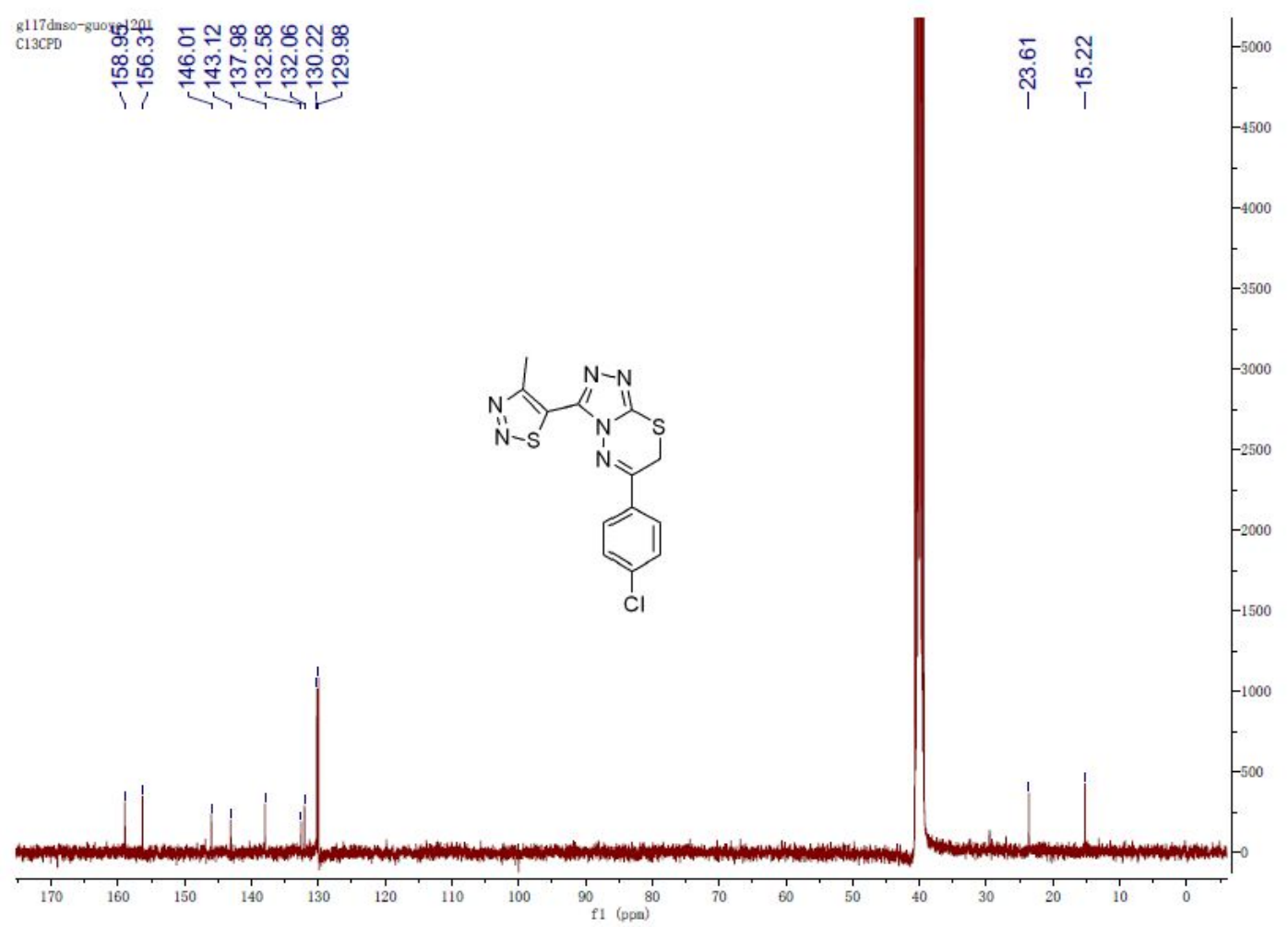

Figure C8. The ${ }^{13} \mathrm{C}$ NMR $\left(400 \mathrm{MHz}, \mathrm{DMSO}-d_{6}\right)$ of compound $\mathbf{6 c}$. 


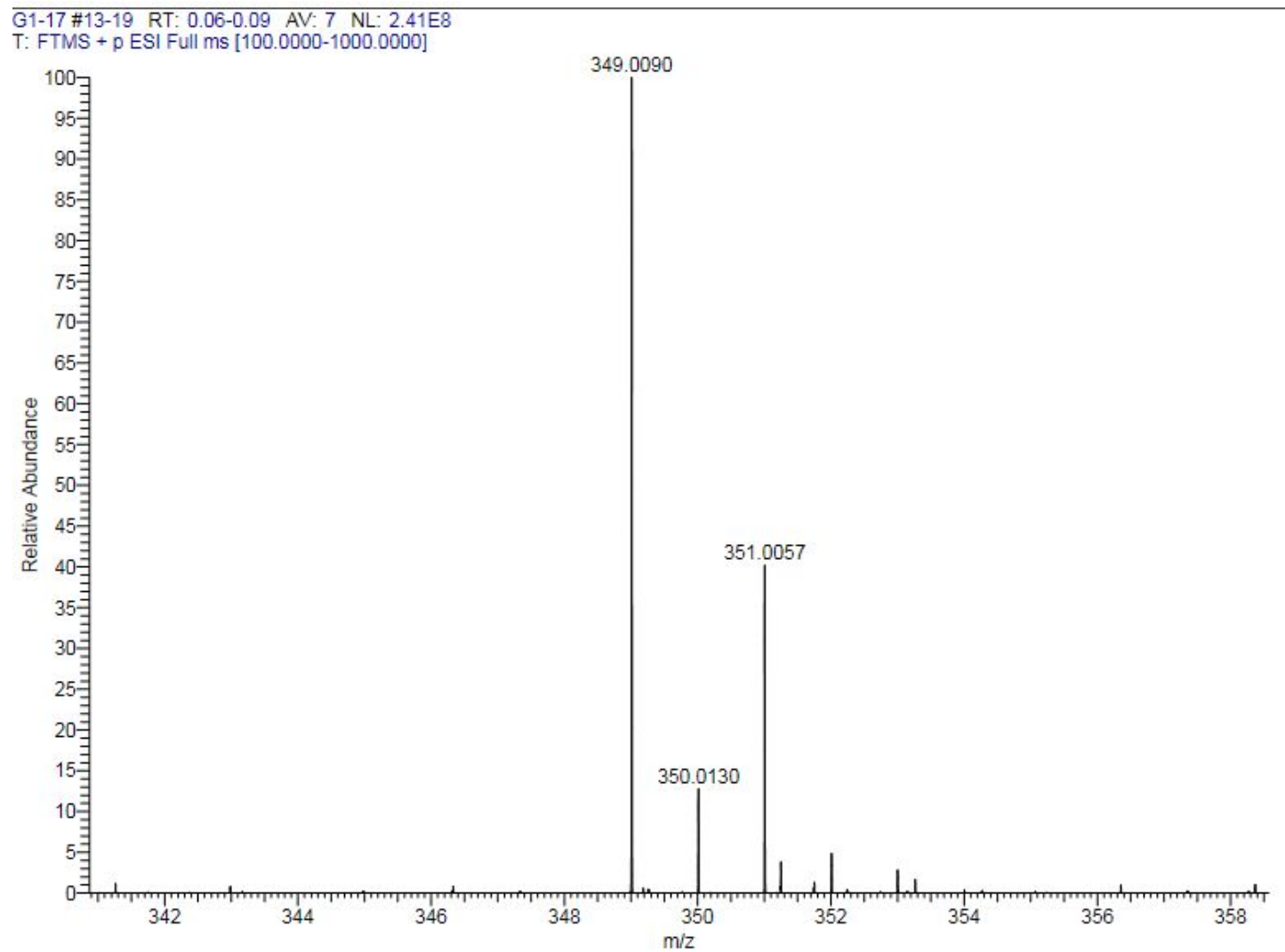

.Figure C9. The HRMS of compound $\mathbf{6 c}$.

G1-21
PROTON

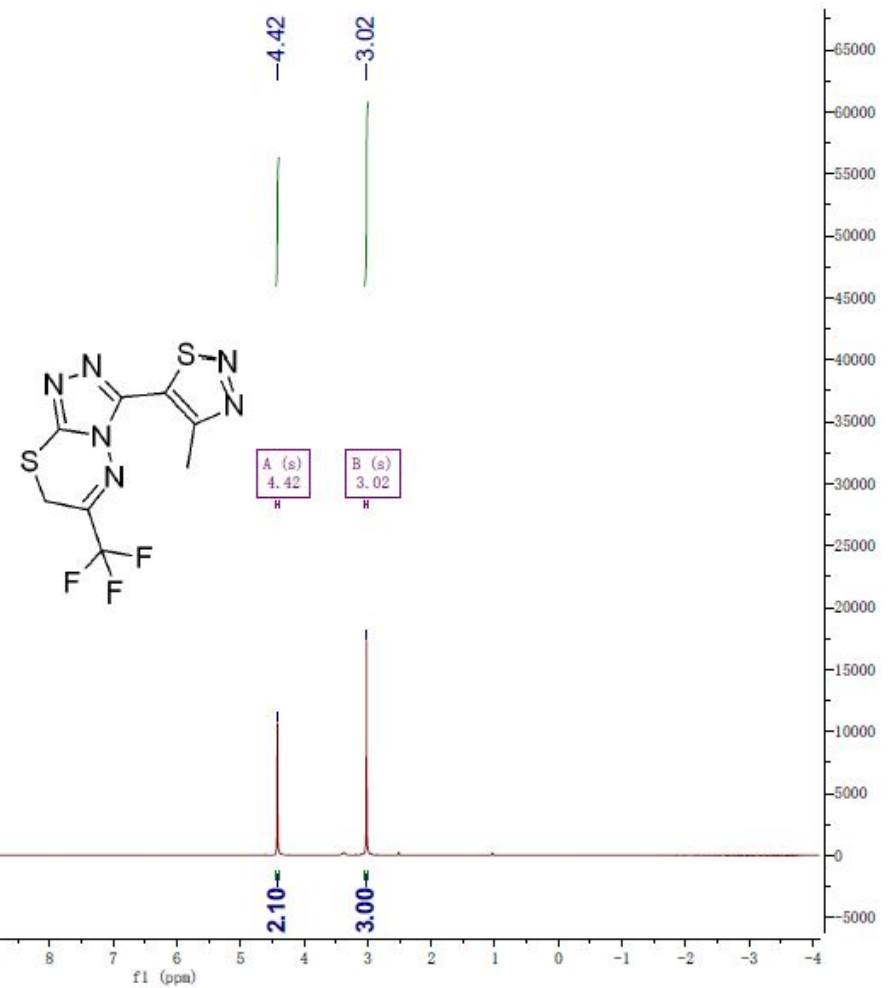

Figure C10. The ${ }^{1} \mathrm{H}$ NMR $\left(400 \mathrm{MHz}\right.$, DMSO- $d_{6}$ ) of compound $\mathbf{6 d}$. 


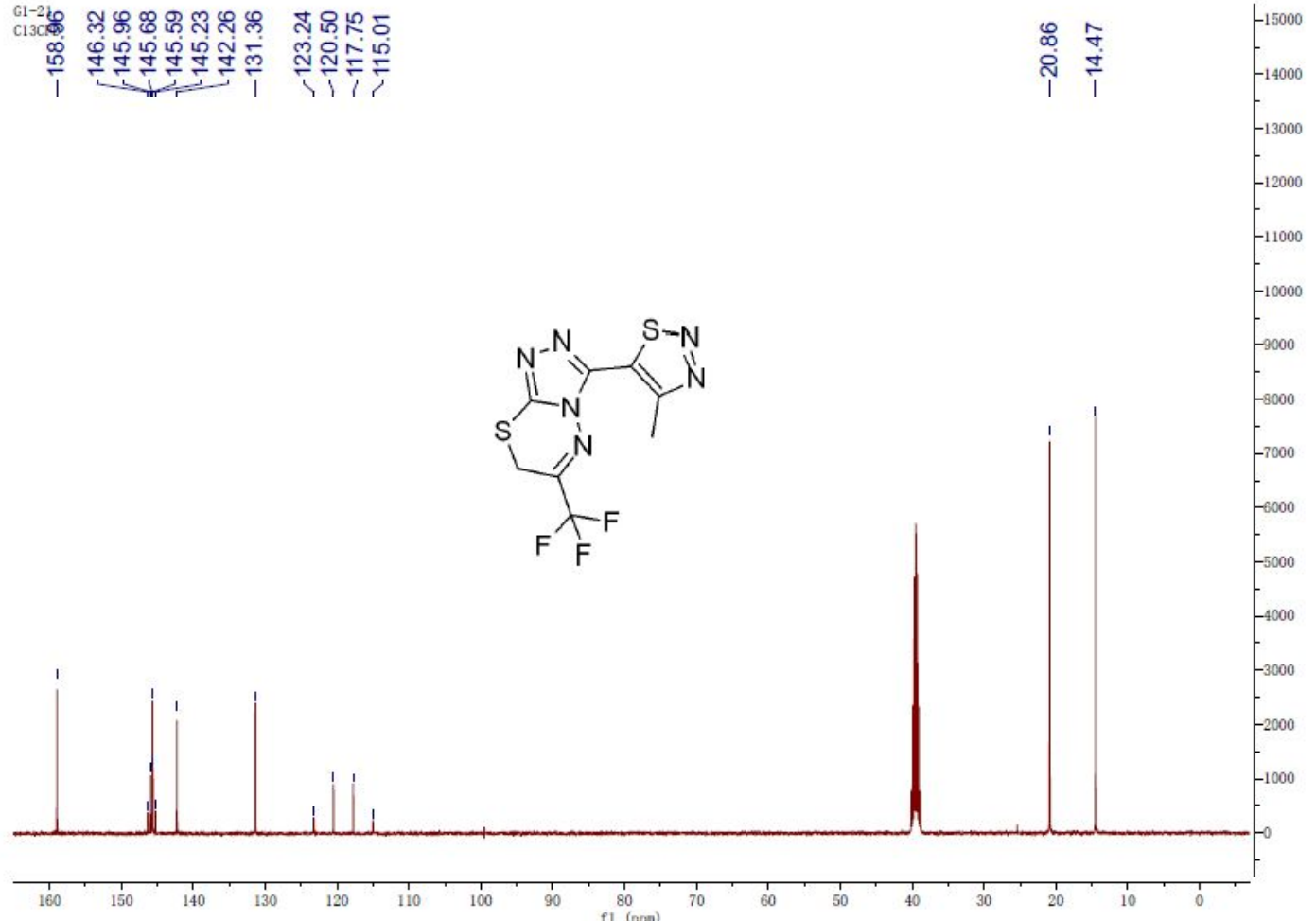

Figure $C 11$. The ${ }^{13} \mathrm{C}$ NMR $\left(400 \mathrm{MHz}\right.$, DMSO- $\left.d_{6}\right)$ of compound $\mathbf{6 d}$.

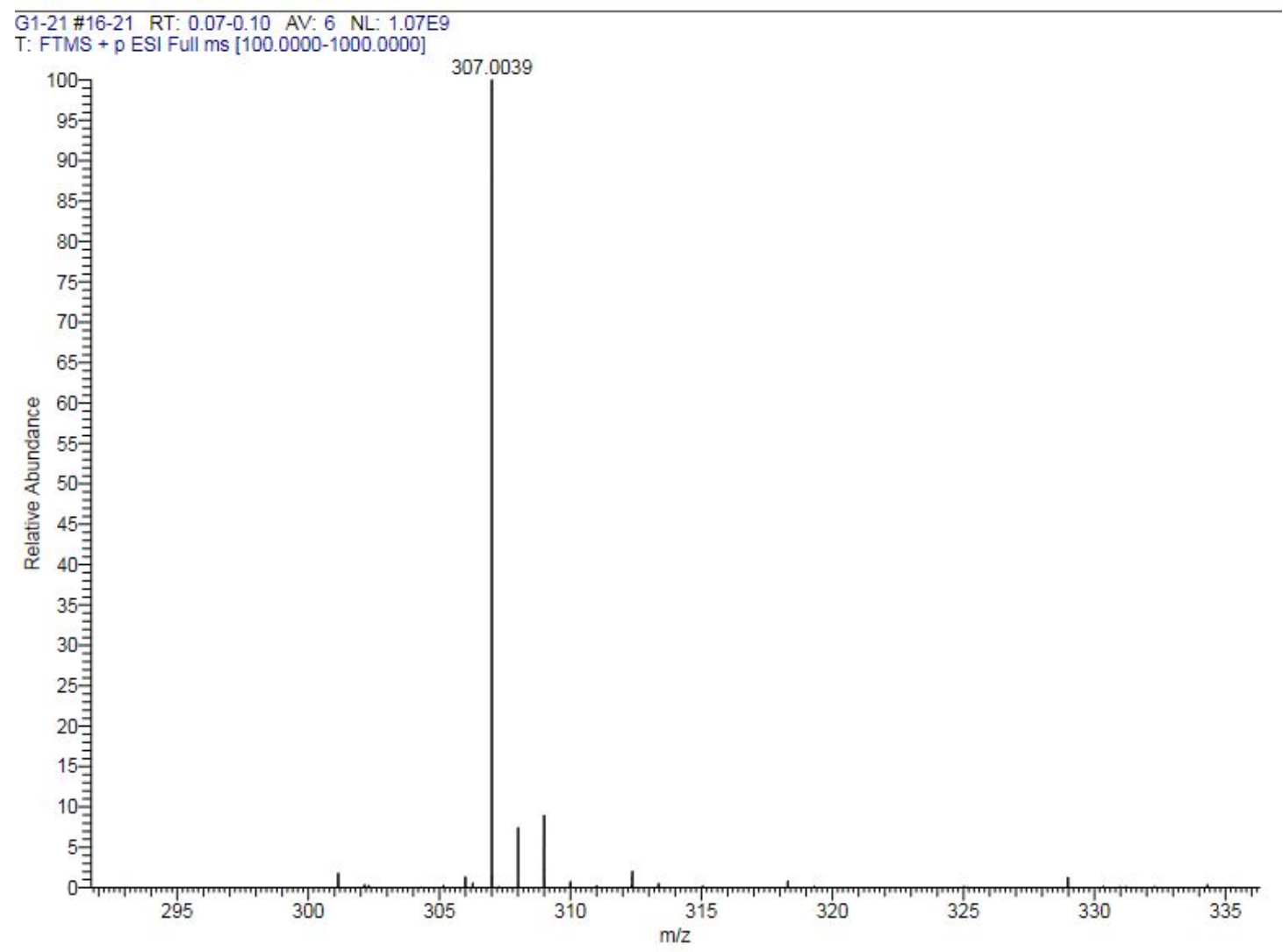

.Figure C12. The HRMS of compound $\mathbf{6 d}$. 


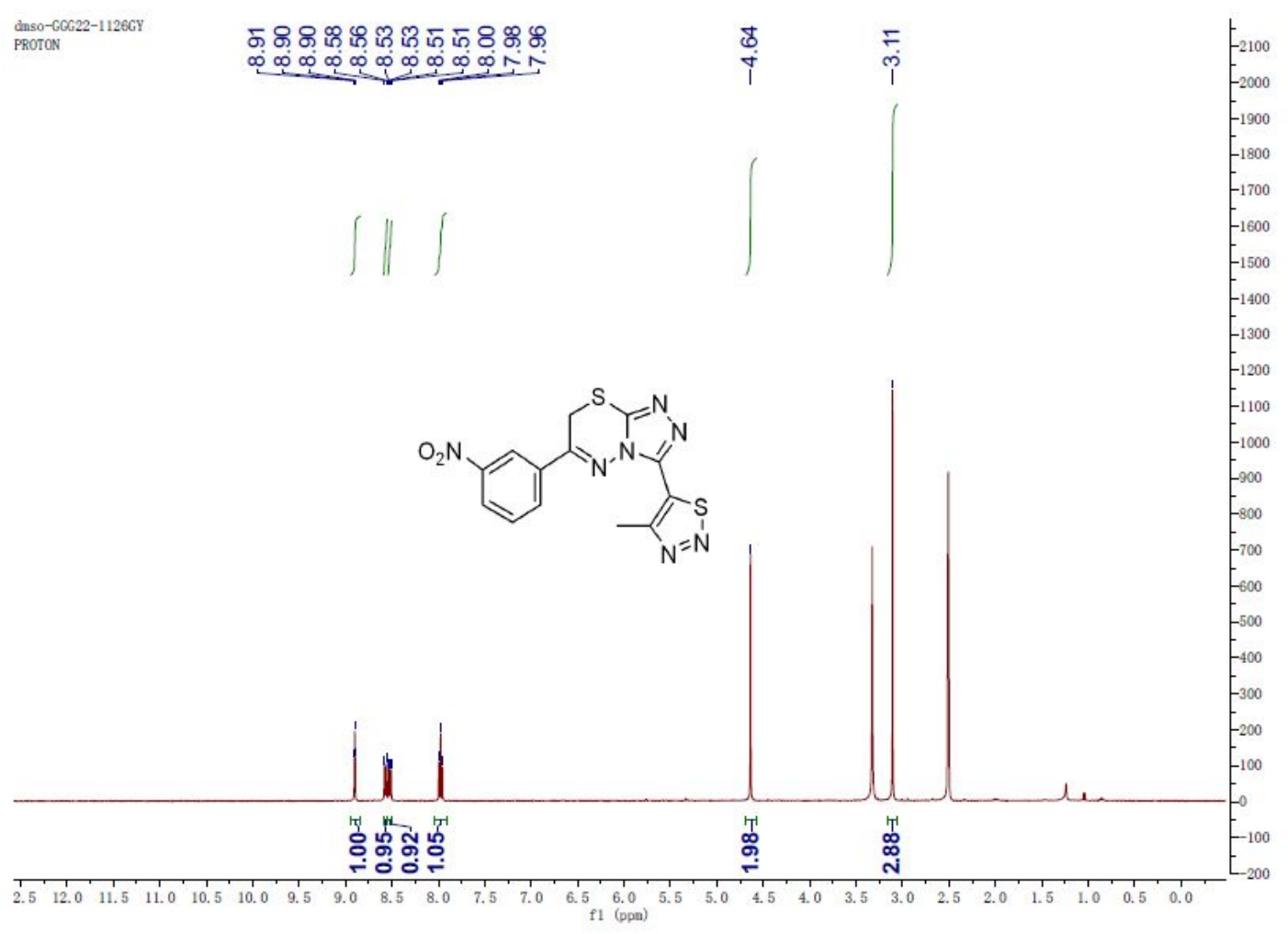

Figure $C 13$. The ${ }^{1} \mathrm{H}$ NMR $\left(400 \mathrm{MHz}, \mathrm{DMSO}-d_{6}\right)$ of compound $6 \mathrm{e}$.

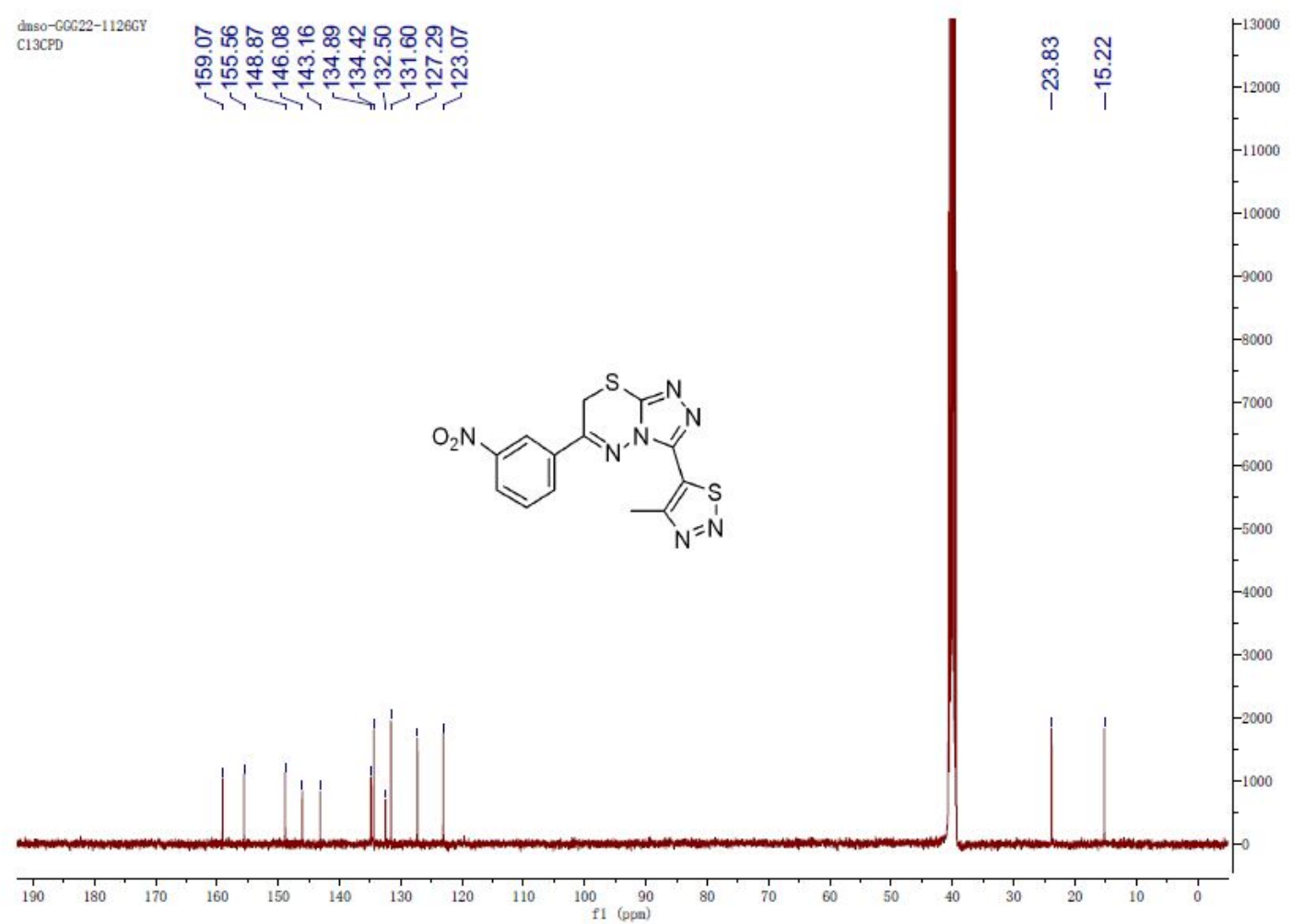

Figure C14. The ${ }^{13} \mathrm{C}$ NMR $\left(400 \mathrm{MHz}, \mathrm{DMSO}-d_{6}\right)$ of compound $6 \mathrm{e}$. 


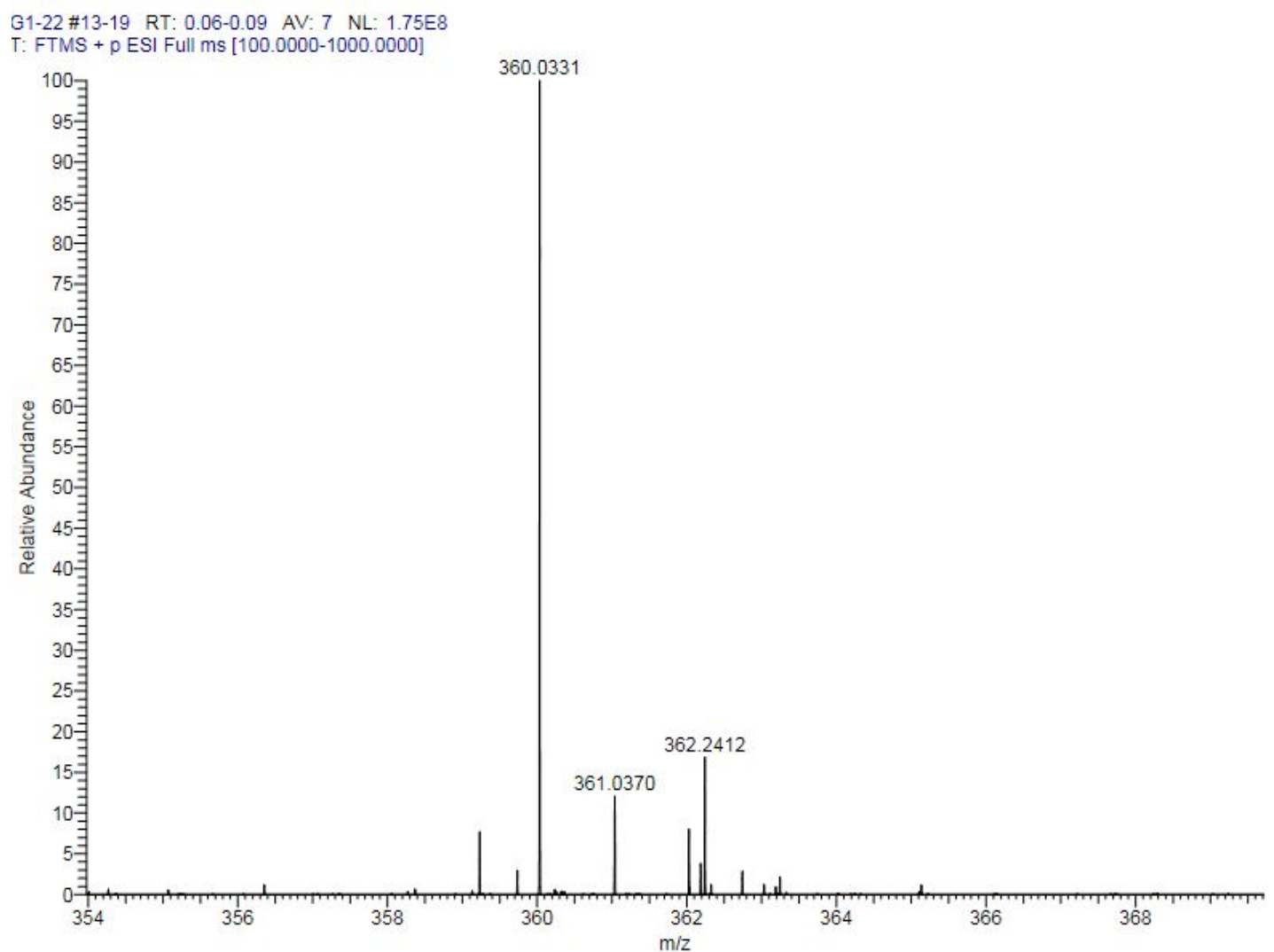

Figure C15. The HRMS of compound $\mathbf{6 e}$.

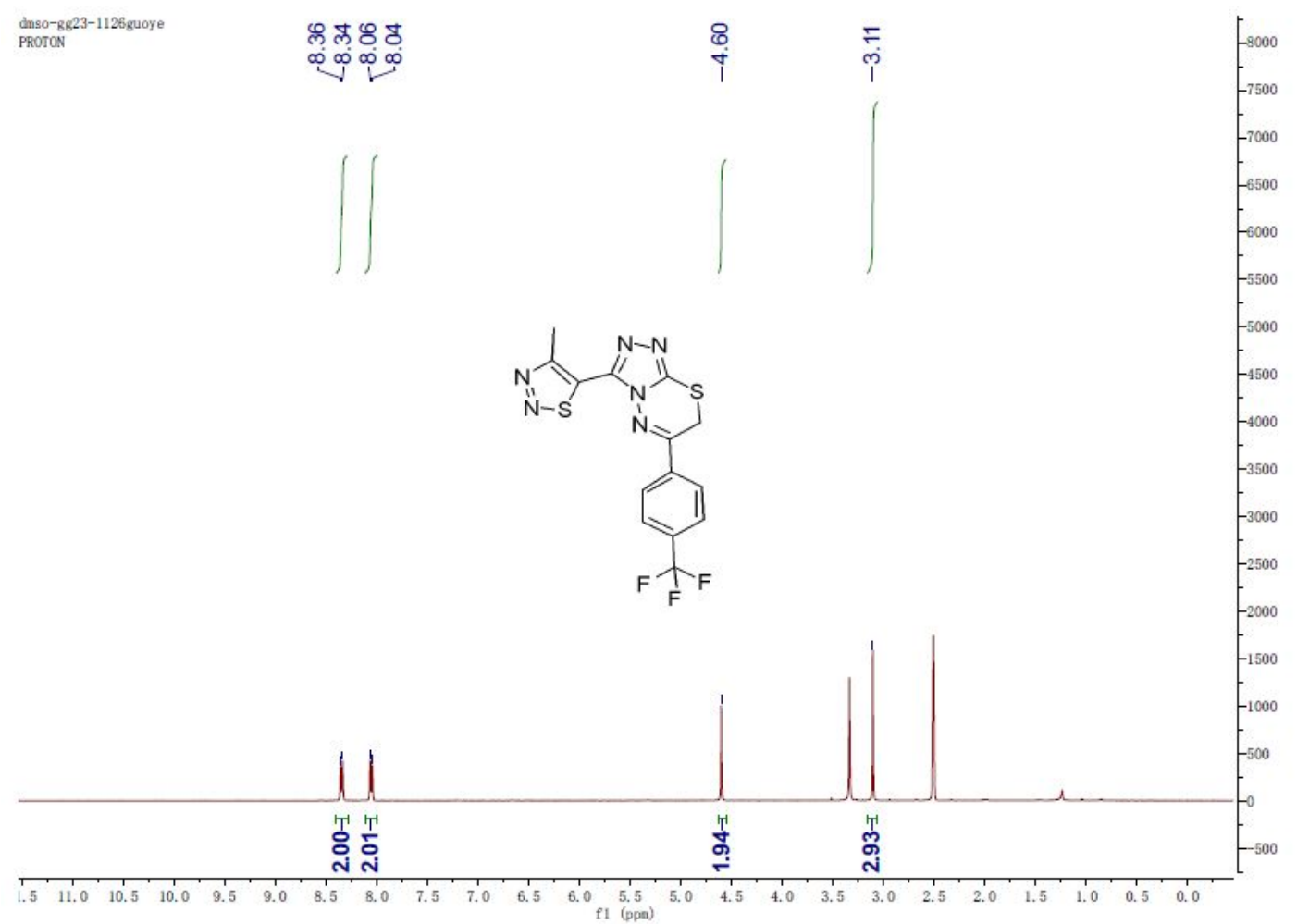

Figure C16. The ${ }^{1} \mathrm{H}$ NMR $\left(400 \mathrm{MHz}\right.$, DMSO- $\left.d_{6}\right)$ of compound $\mathbf{6 f}$. 


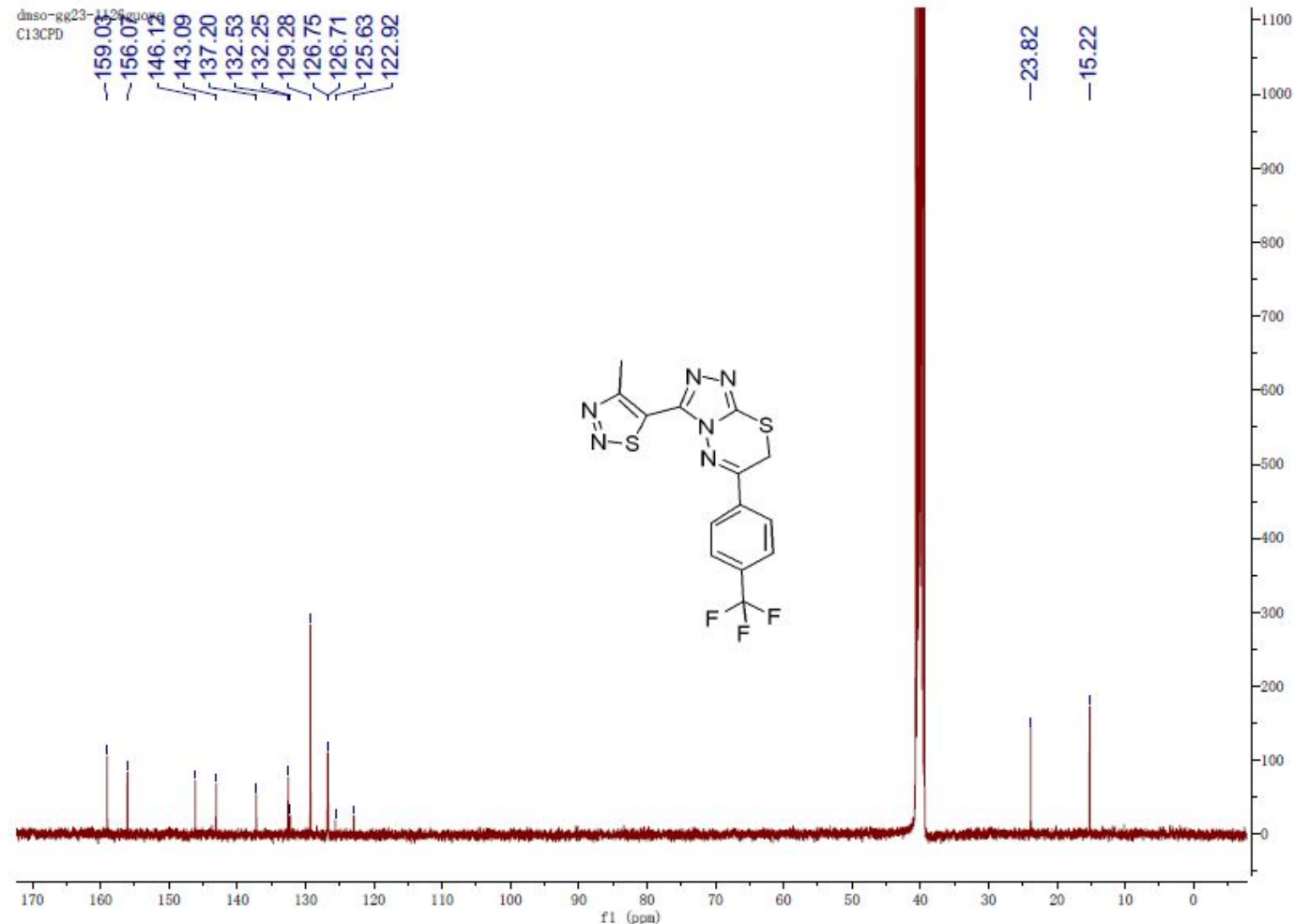

Figure C17. The ${ }^{13} \mathrm{C}$ NMR (400MHz, DMSO- $d_{6}$ ) of compound $\mathbf{6 f}$.

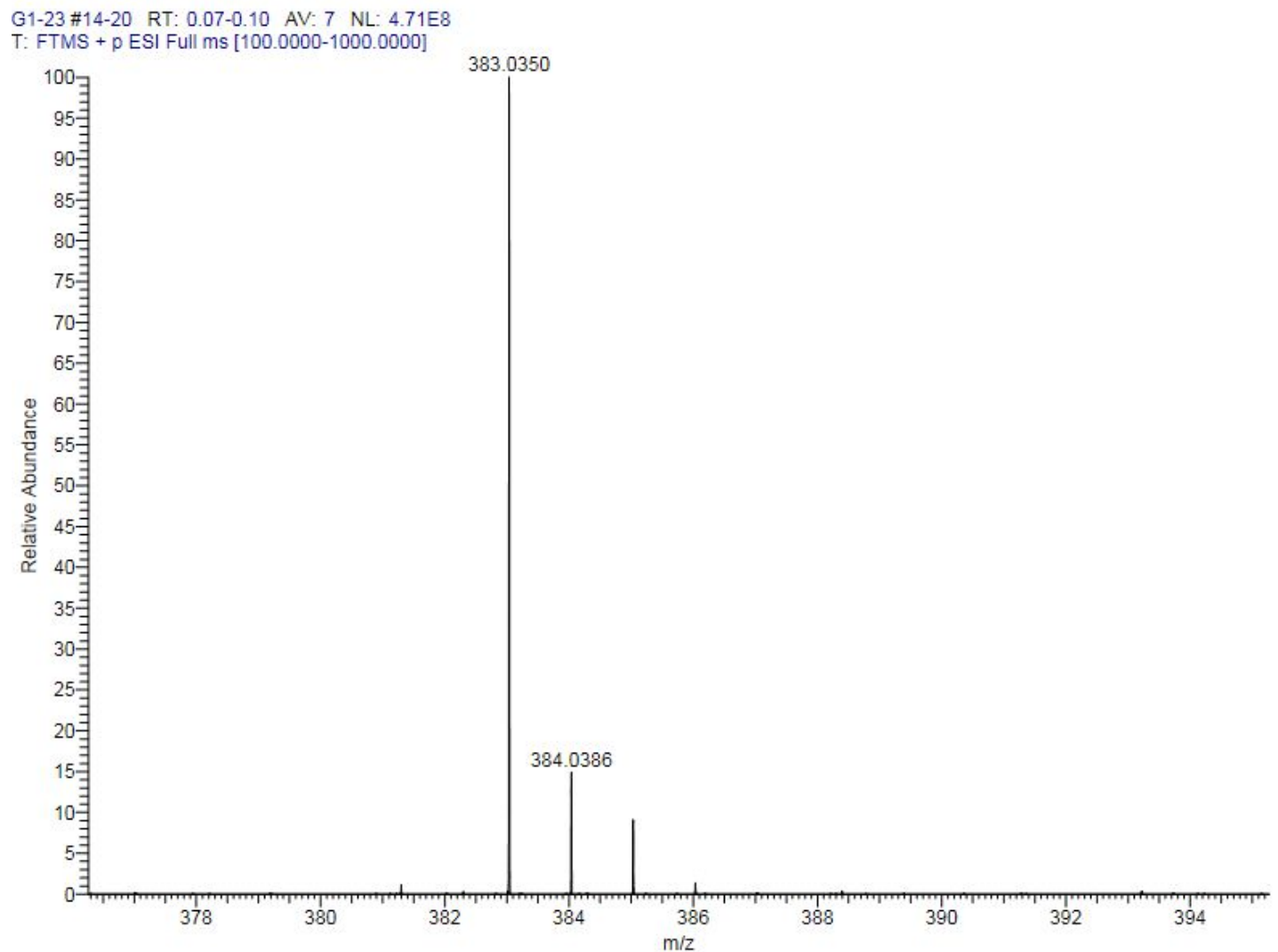

Figure C18. The HRMS of compound $\mathbf{6 f}$. 


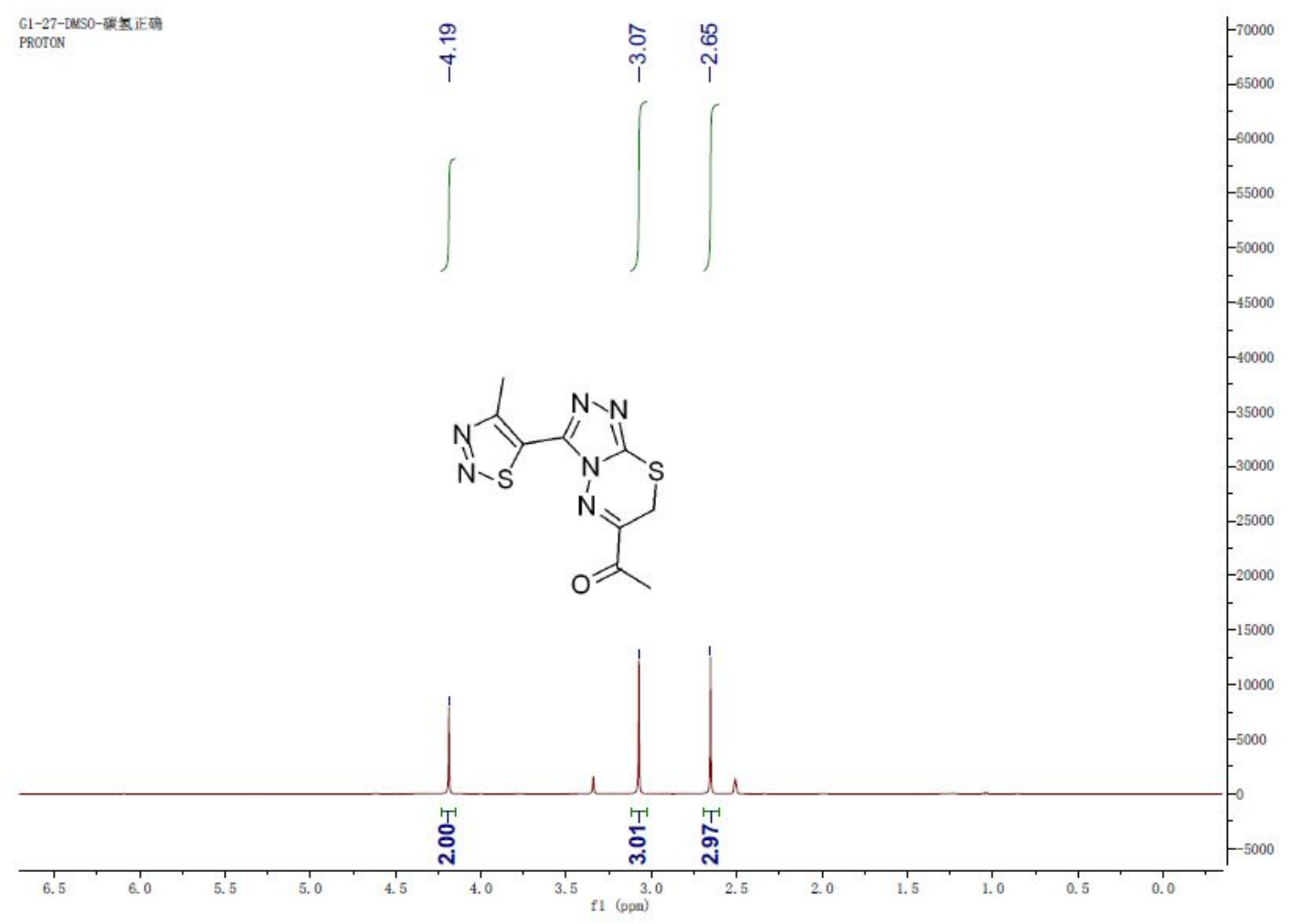

Figure C19. The ${ }^{1} \mathrm{H}$ NMR $\left(400 \mathrm{MHz}\right.$, DMSO- $d_{6}$ ) of compound $\mathbf{6 g}$.

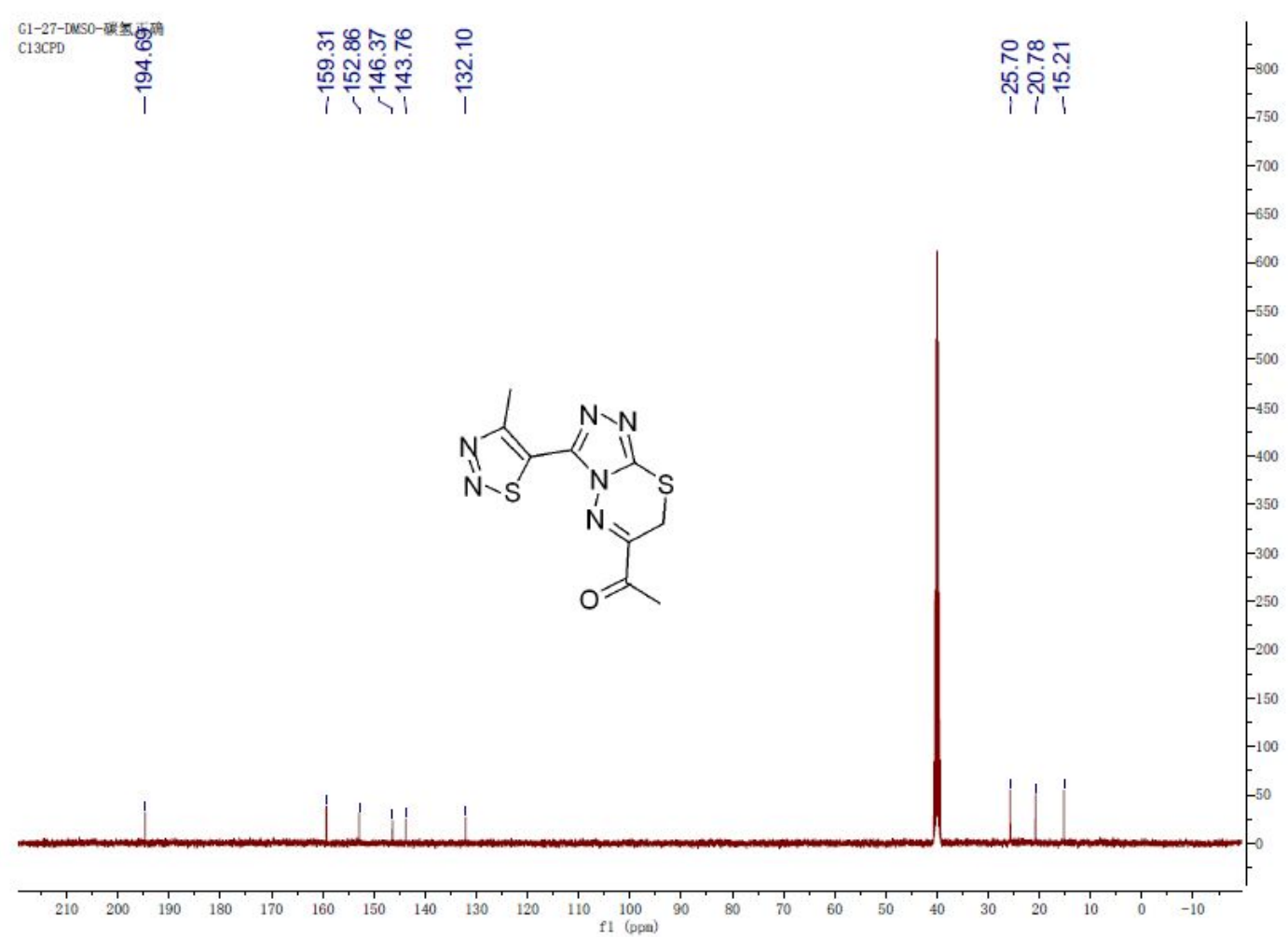

Figure $C 20$. The ${ }^{13} \mathrm{C}$ NMR (400MHz, DMSO- $d_{6}$ ) of compound $\mathbf{6 g}$. 
G1-27 \#15-21 RT: 0.07-0.10 AV: 7 NL: 9.98E8

T: FTMS + p ESI Full ms [100.0000-1000.0000]

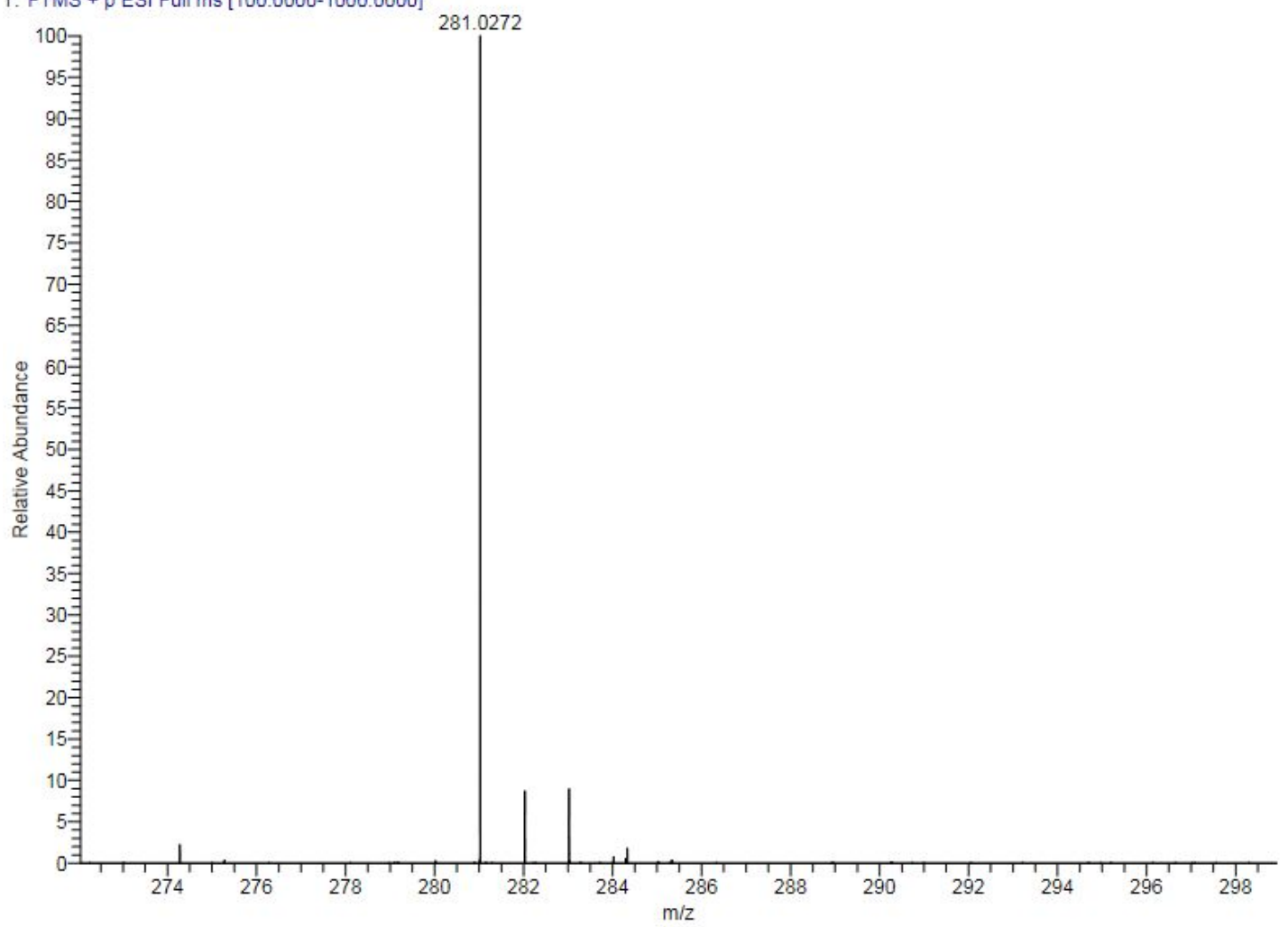

Figure C21. The HRMS of compound $\mathbf{6 g}$.

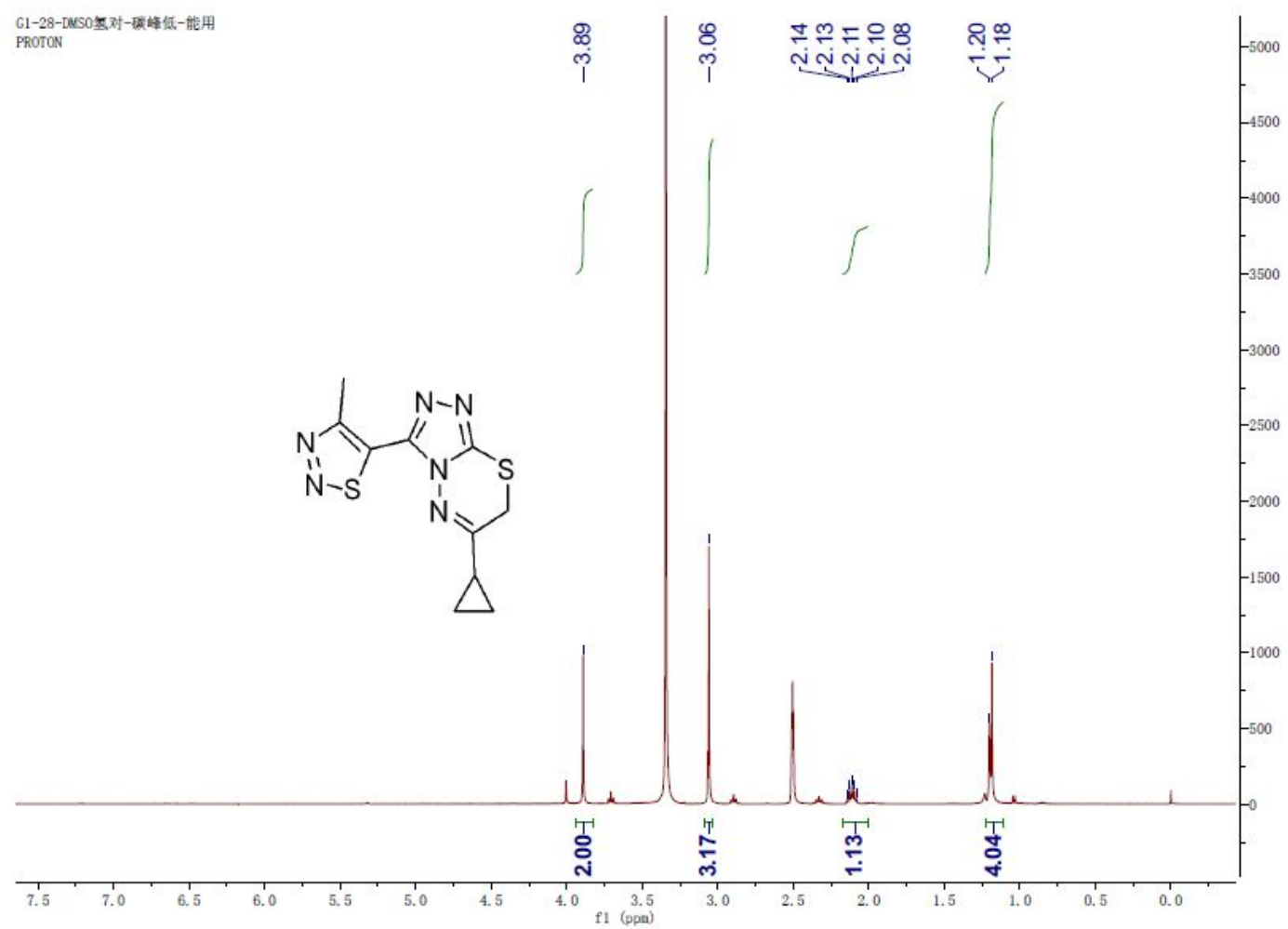

Figure $C 22$. The ${ }^{1} \mathrm{H}$ NMR $\left(400 \mathrm{MHz}, \mathrm{DMSO}-d_{6}\right)$ of compound $\mathbf{6 h}$. 


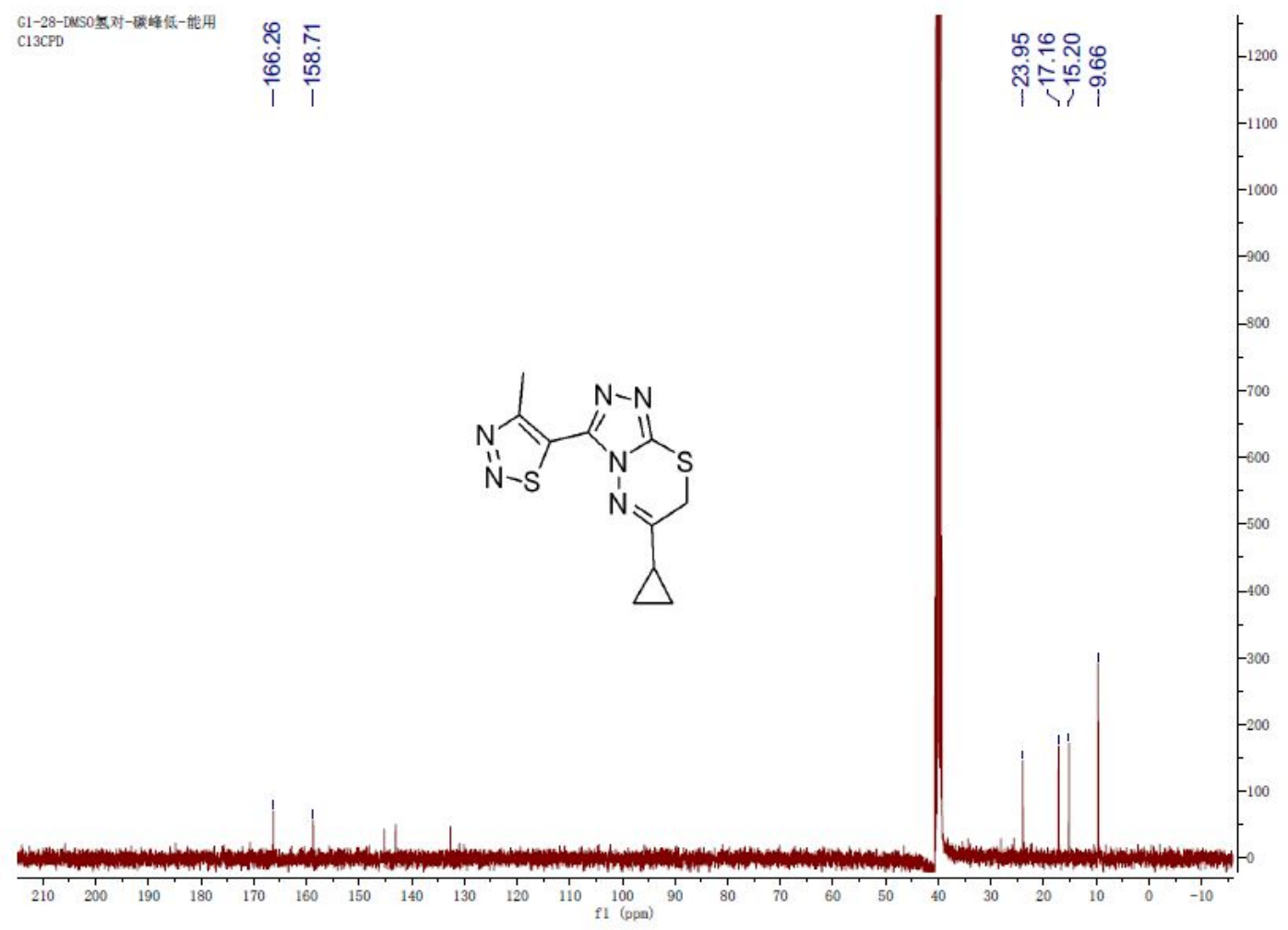

Figure $C 23$. The ${ }^{13} \mathrm{C}$ NMR (400MHz, DMSO- $d_{6}$ ) of compound $\mathbf{6 h}$.

G1-28 \#16-22 RT: 0.08-0.10 AV: 7 NL: $3.83 E 9$

T: FTMS + p ESI Full ms [100.0000-1000.0000]

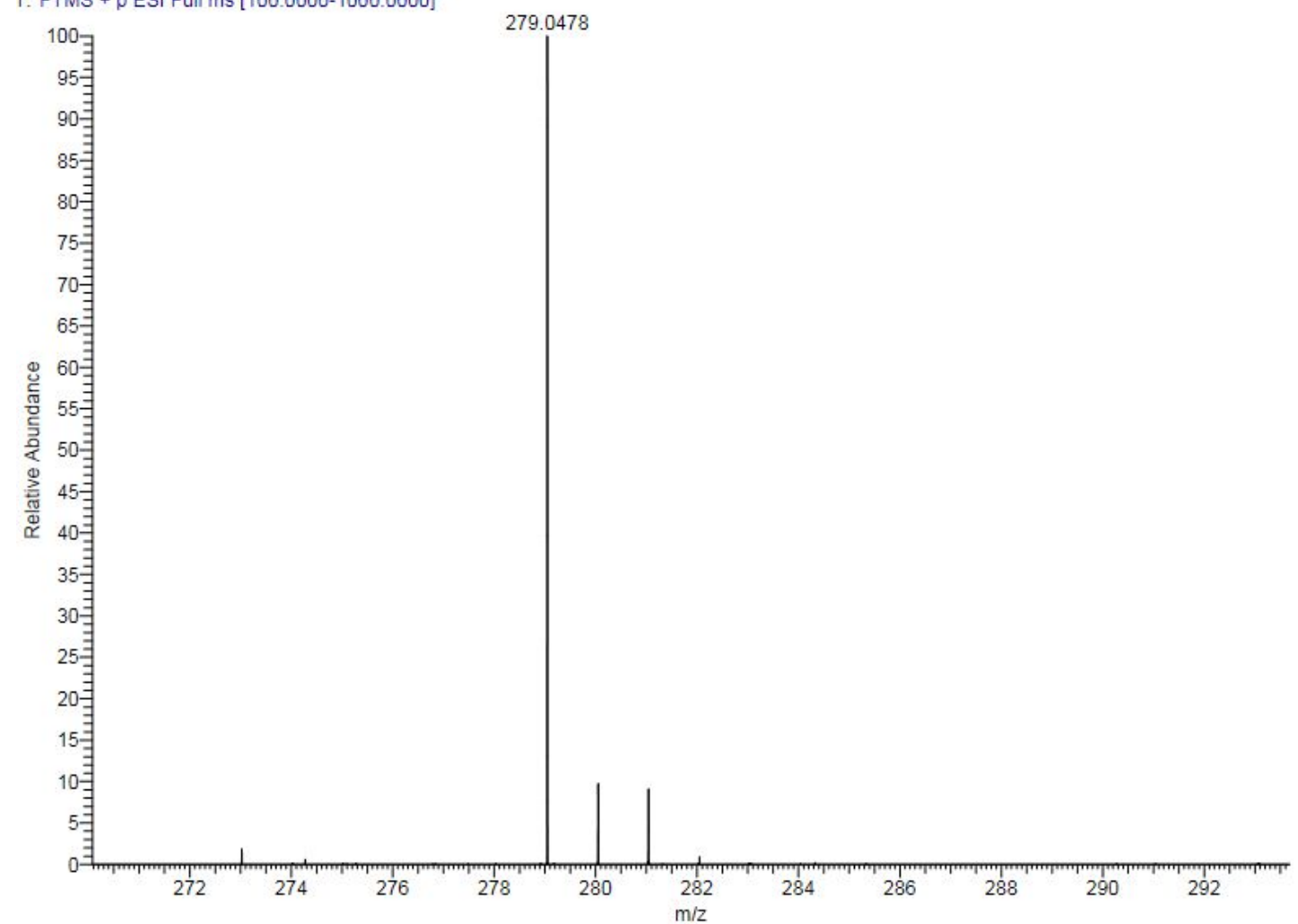

Figure C24. The HRMS of compound $\mathbf{6 h}$. 


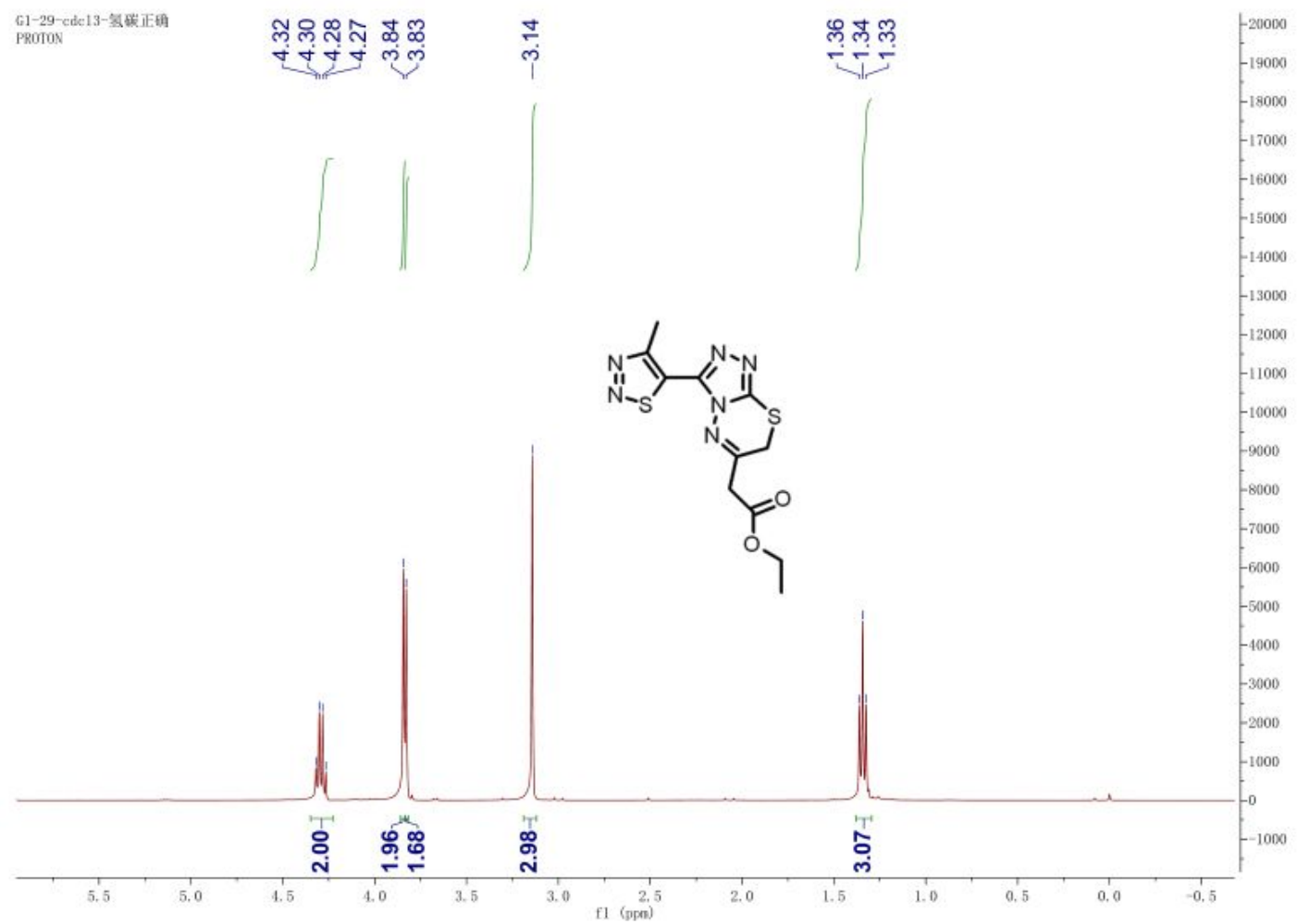

Figure C25. The ${ }^{1} \mathrm{H}$ NMR $\left(400 \mathrm{MHz}, \mathrm{CDCl}_{3}\right)$ of compound $\mathbf{6 i}$.

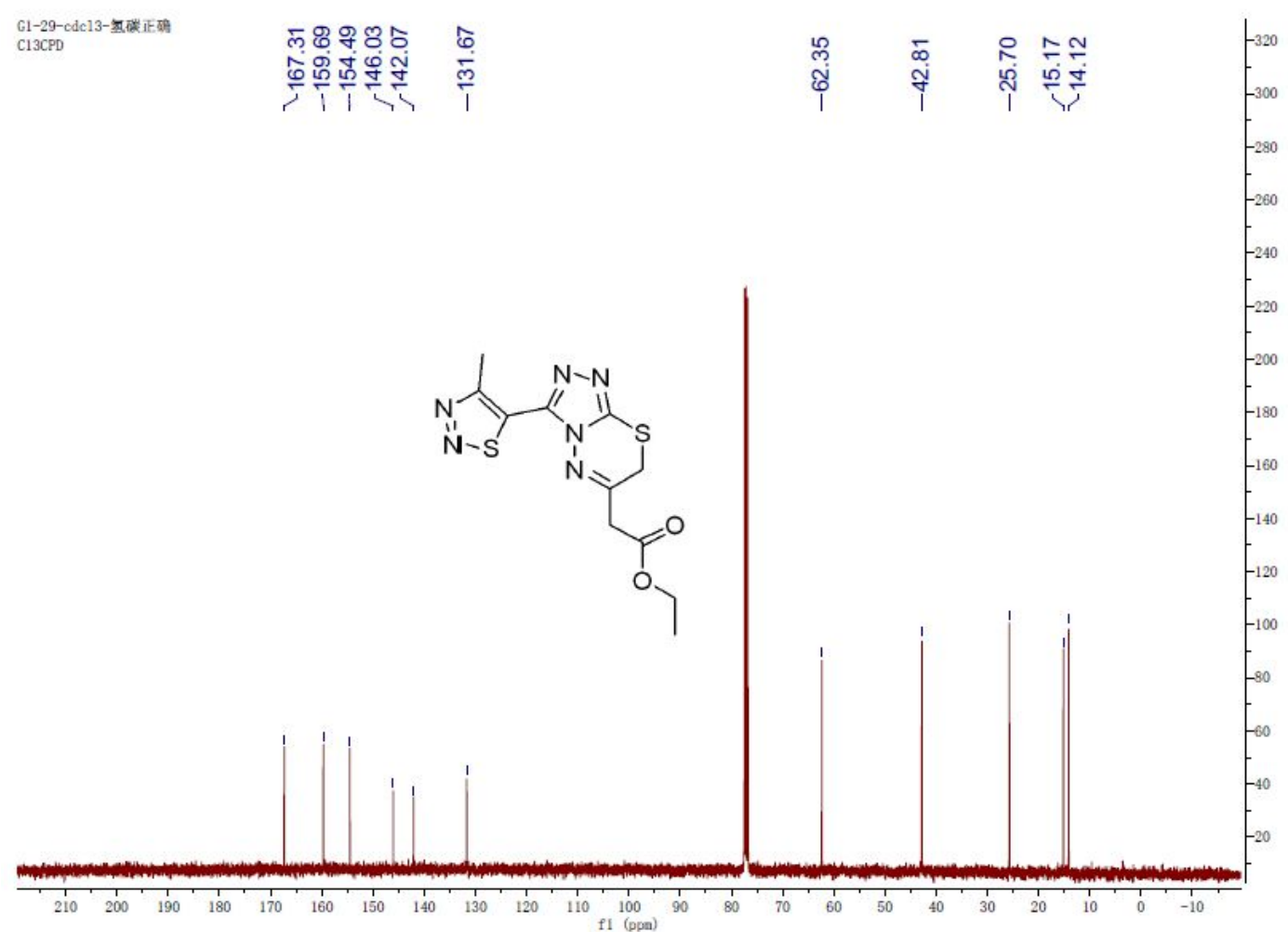

Figure C26. The ${ }^{13} \mathrm{C}$ NMR $\left(400 \mathrm{MHz}, \mathrm{CDCl}_{3}\right)$ of compound $\mathbf{6 i}$. 


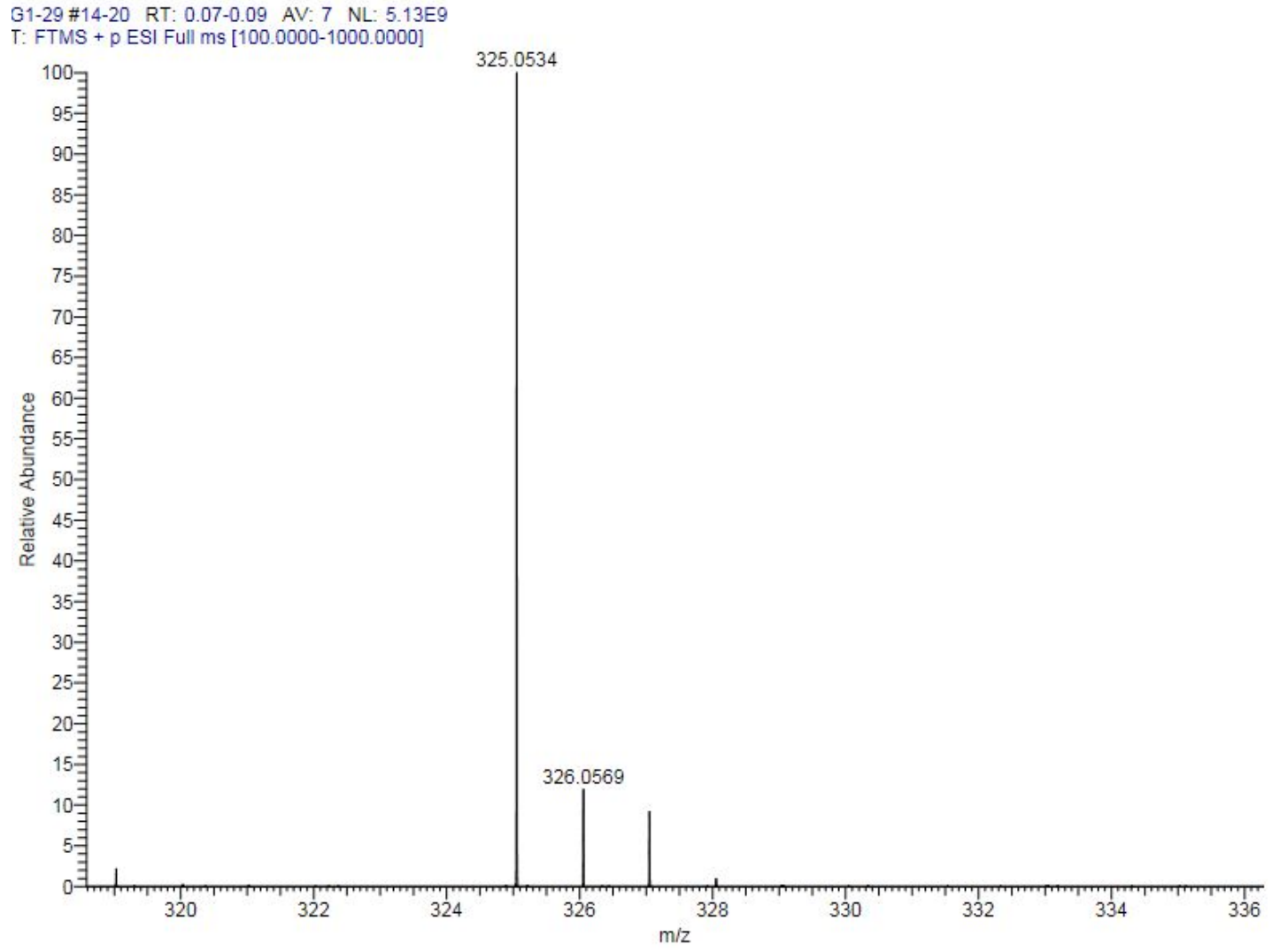

Figure C27. The HRMS of compound $\mathbf{6 i}$.

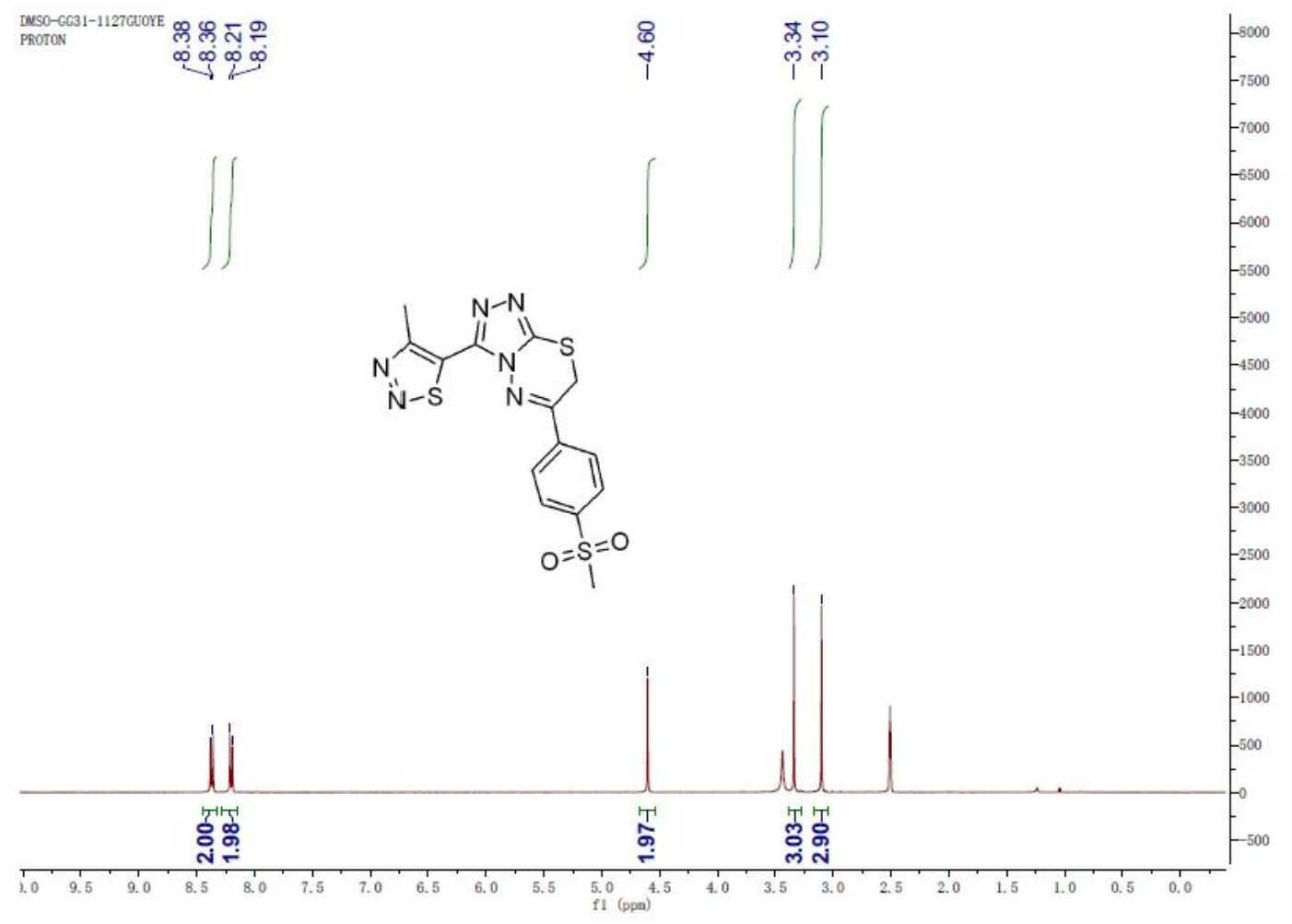

Figure $C 28$. The ${ }^{1} \mathrm{H}$ NMR (400MHz, DMSO- $d_{6}$ ) of compound $\mathbf{6 j}$. 


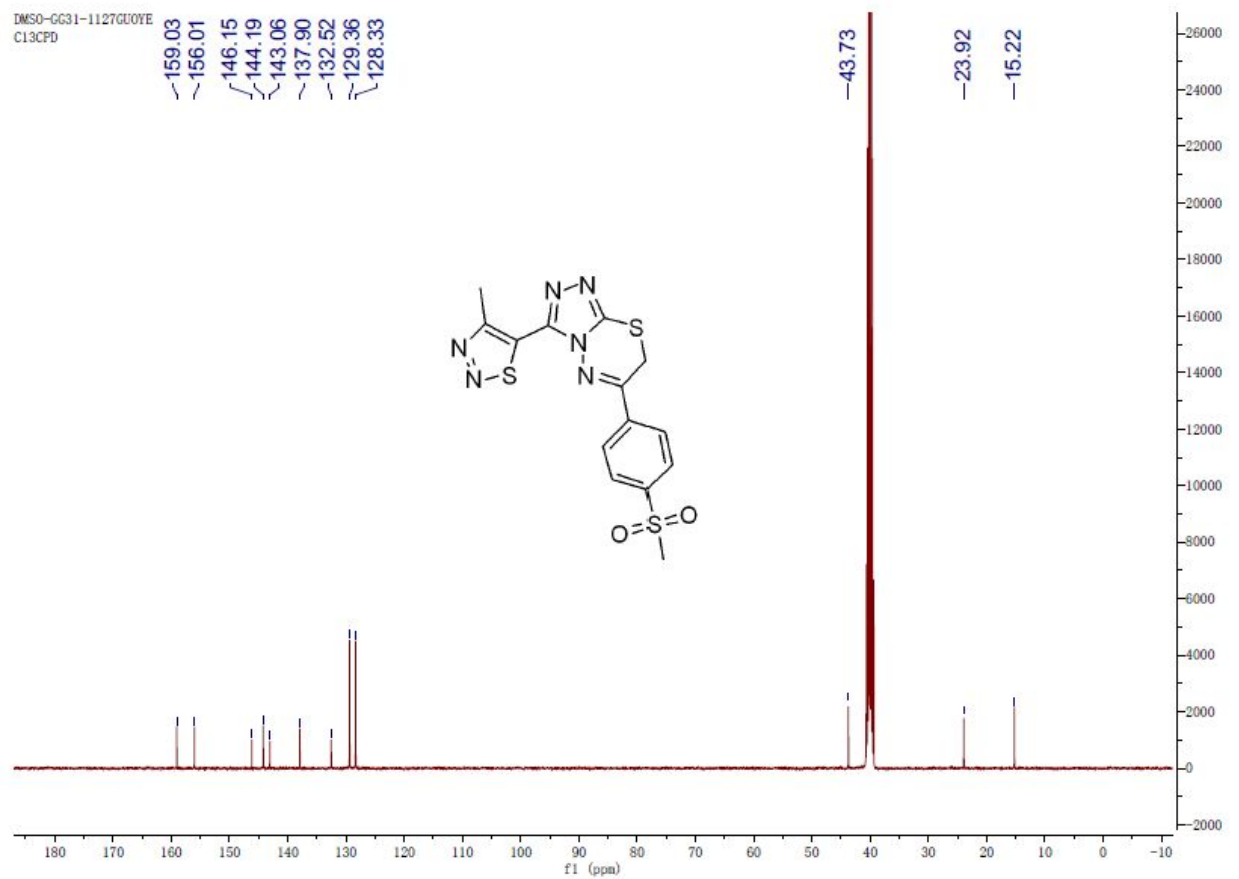

Figure C29. The ${ }^{13} \mathrm{C}$ NMR (400MHz, DMSO- $\left.d_{6}\right)$ of compound $\mathbf{6 j}$.

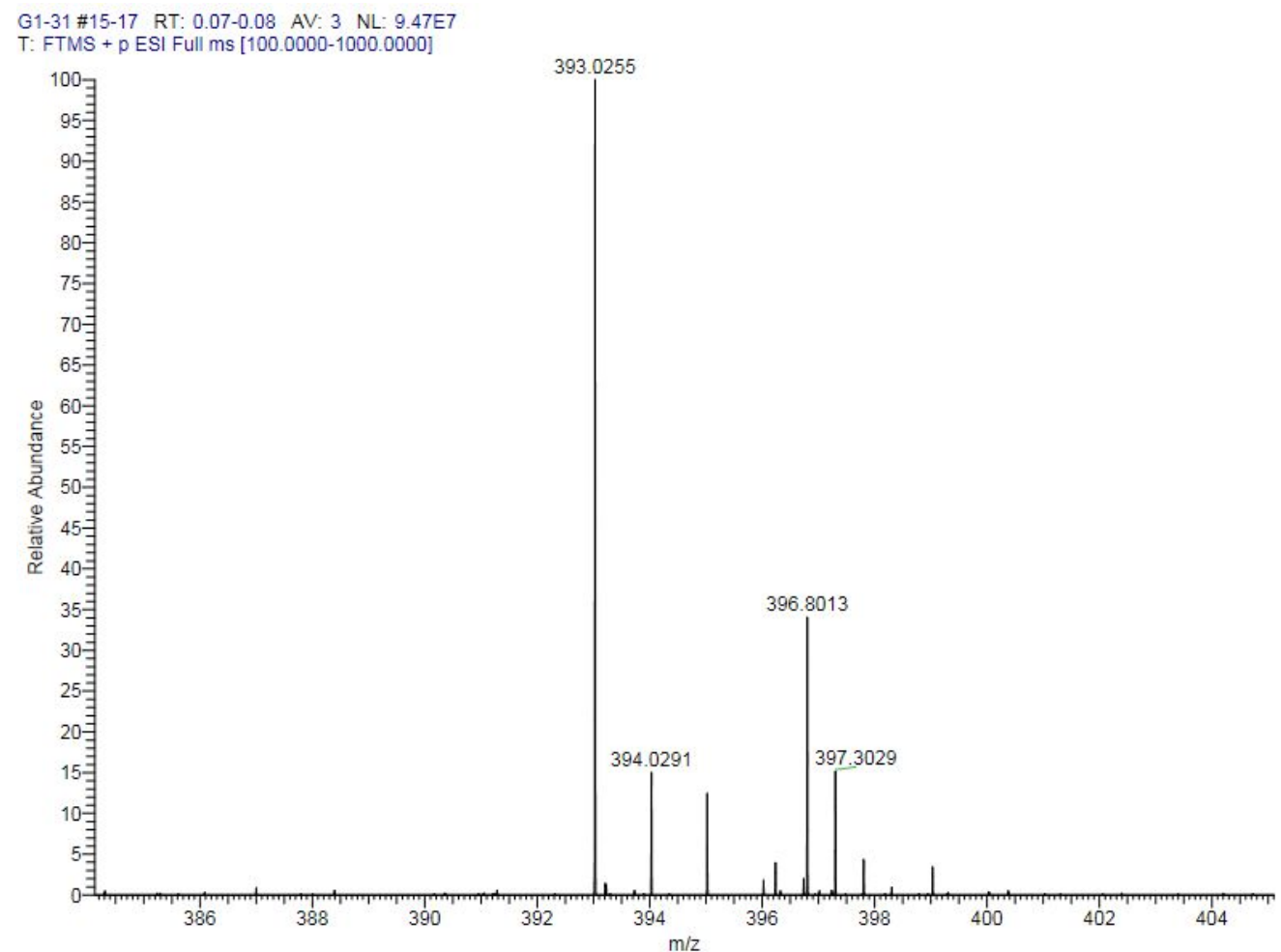

Figure C30. The HRMS of compound $\mathbf{6 j}$. 


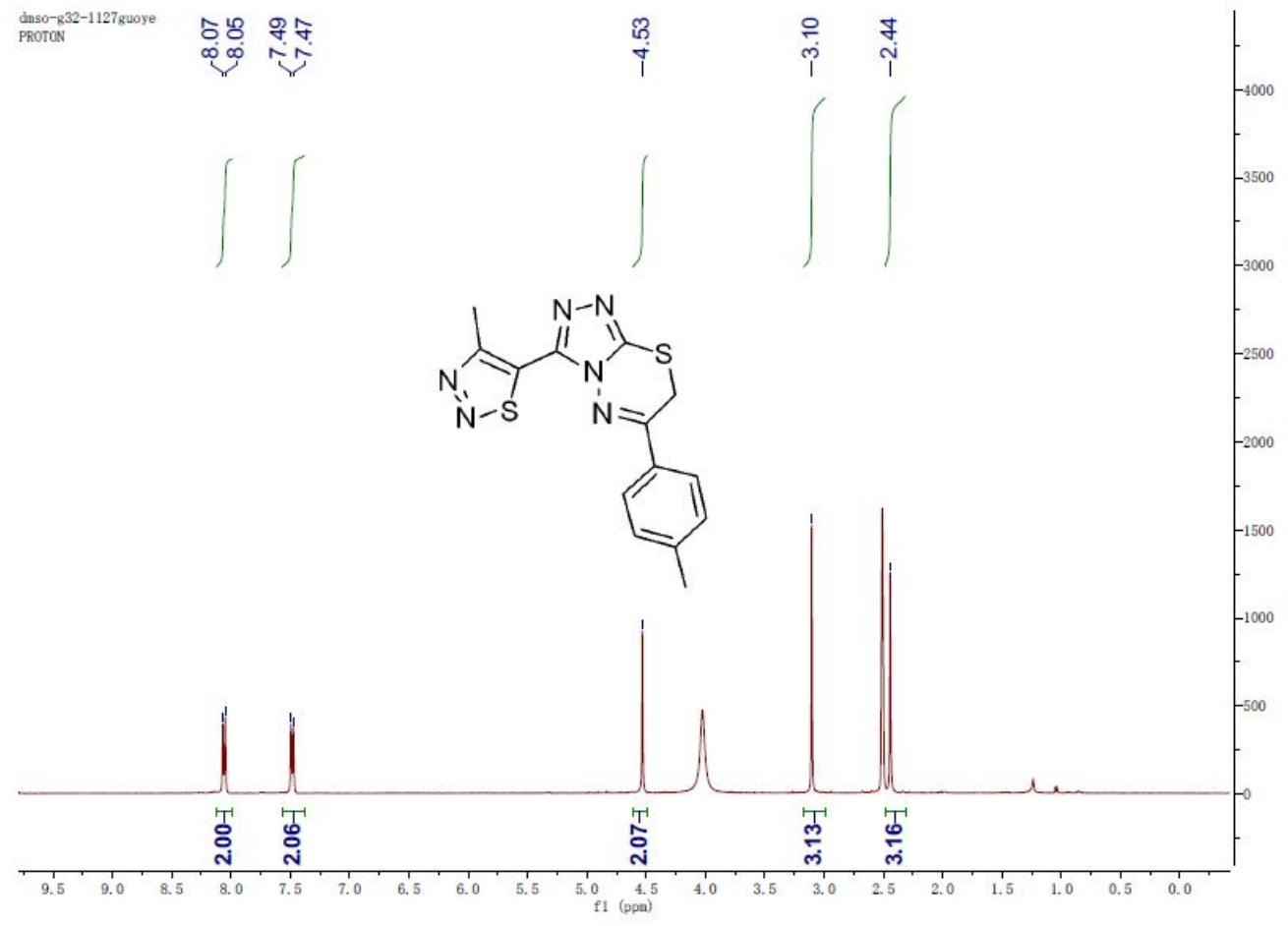

Figure C31. The ${ }^{1} \mathrm{H}$ NMR (400MHz, DMSO- $d_{6}$ ) of compound $6 \mathbf{k}$.

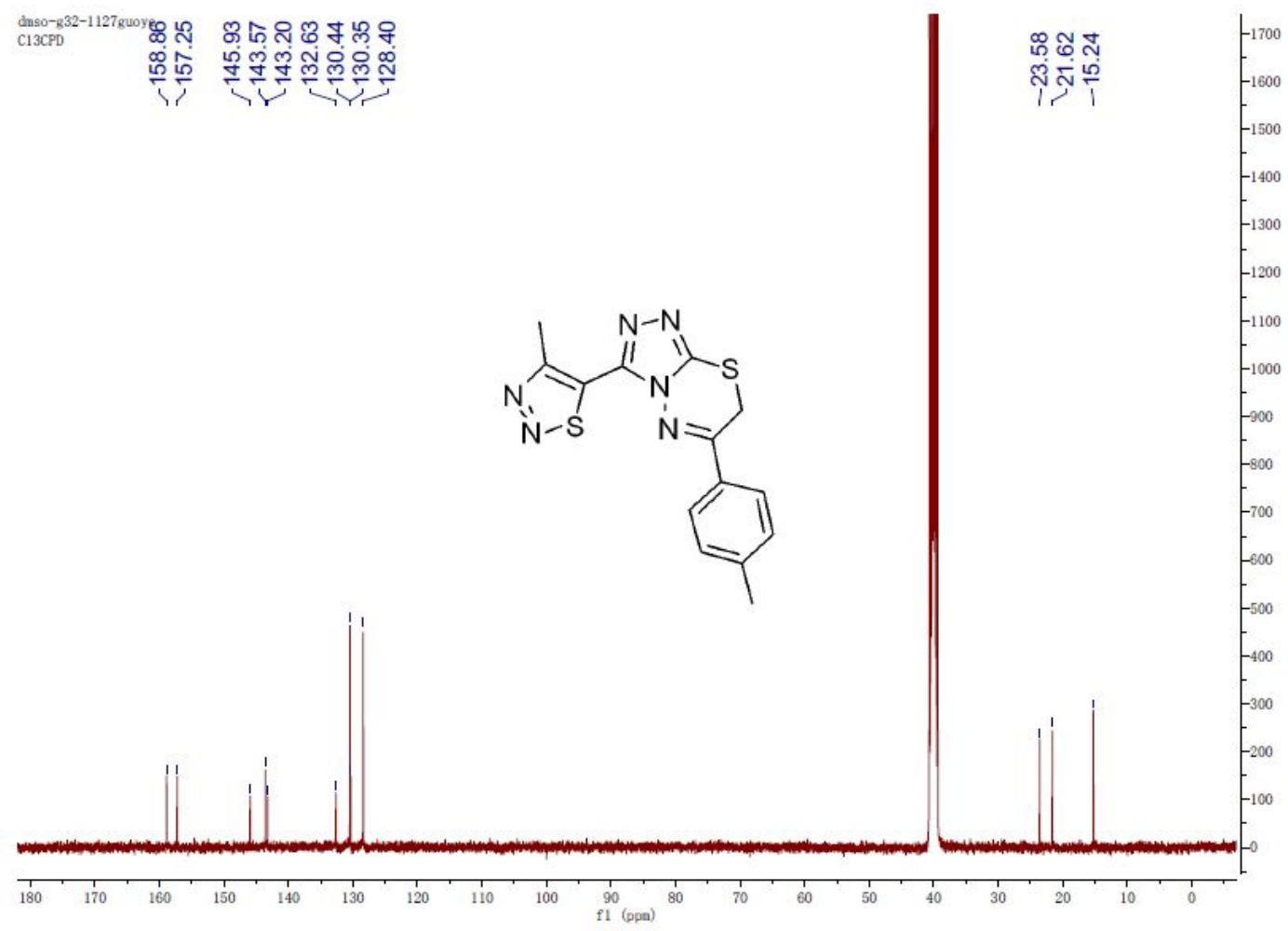

Figure C32. The ${ }^{13} \mathrm{C}$ NMR (400MHz, DMSO- $d_{6}$ ) of compound $6 \mathbf{k}$. 


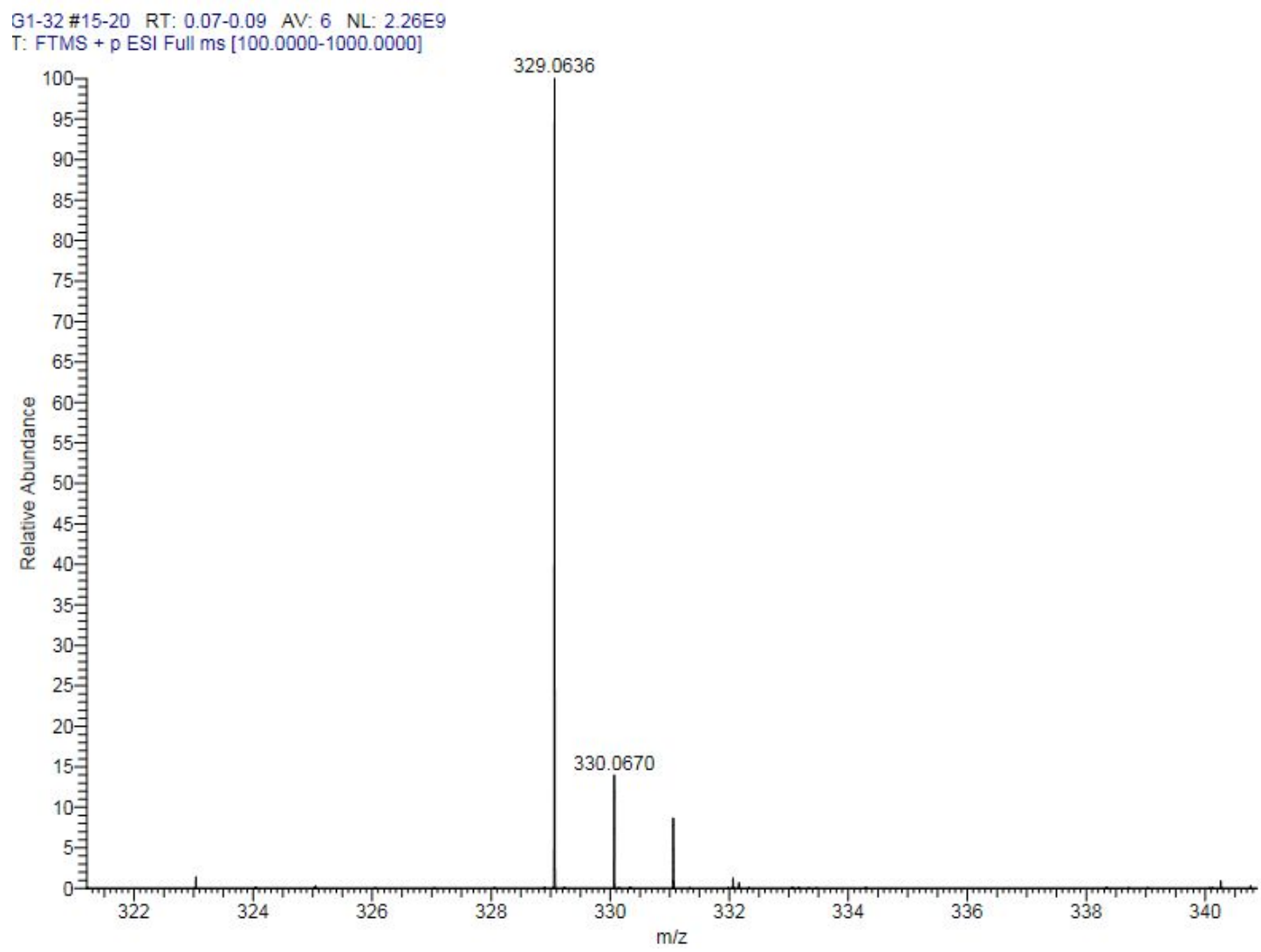

Figure C33. The HRMS of compound $6 \mathbf{k}$.

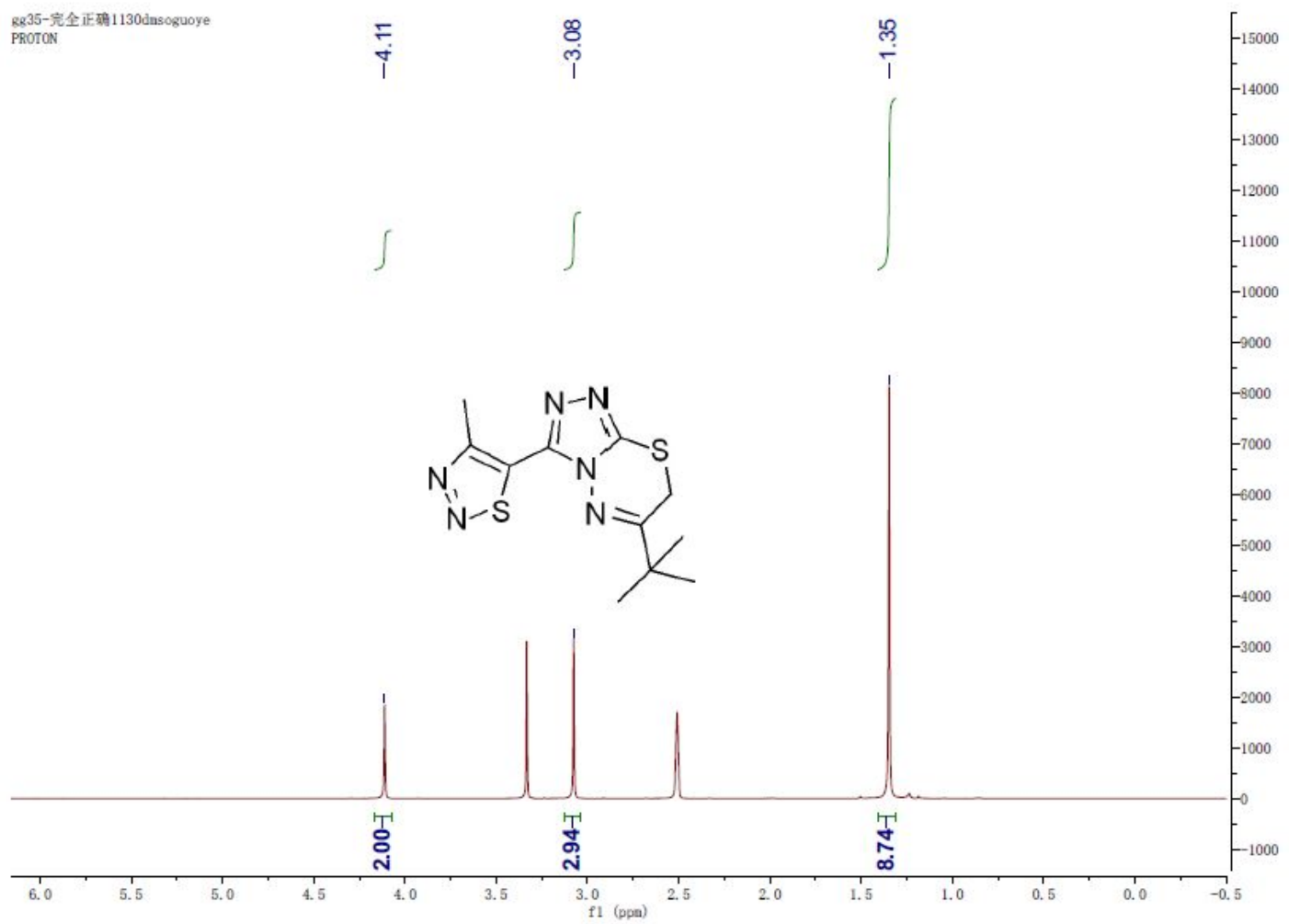

Figure C34. The ${ }^{1} \mathrm{H}$ NMR (400MHz, DMSO- $d_{6}$ ) of compound $6 \mathbf{l}$. 


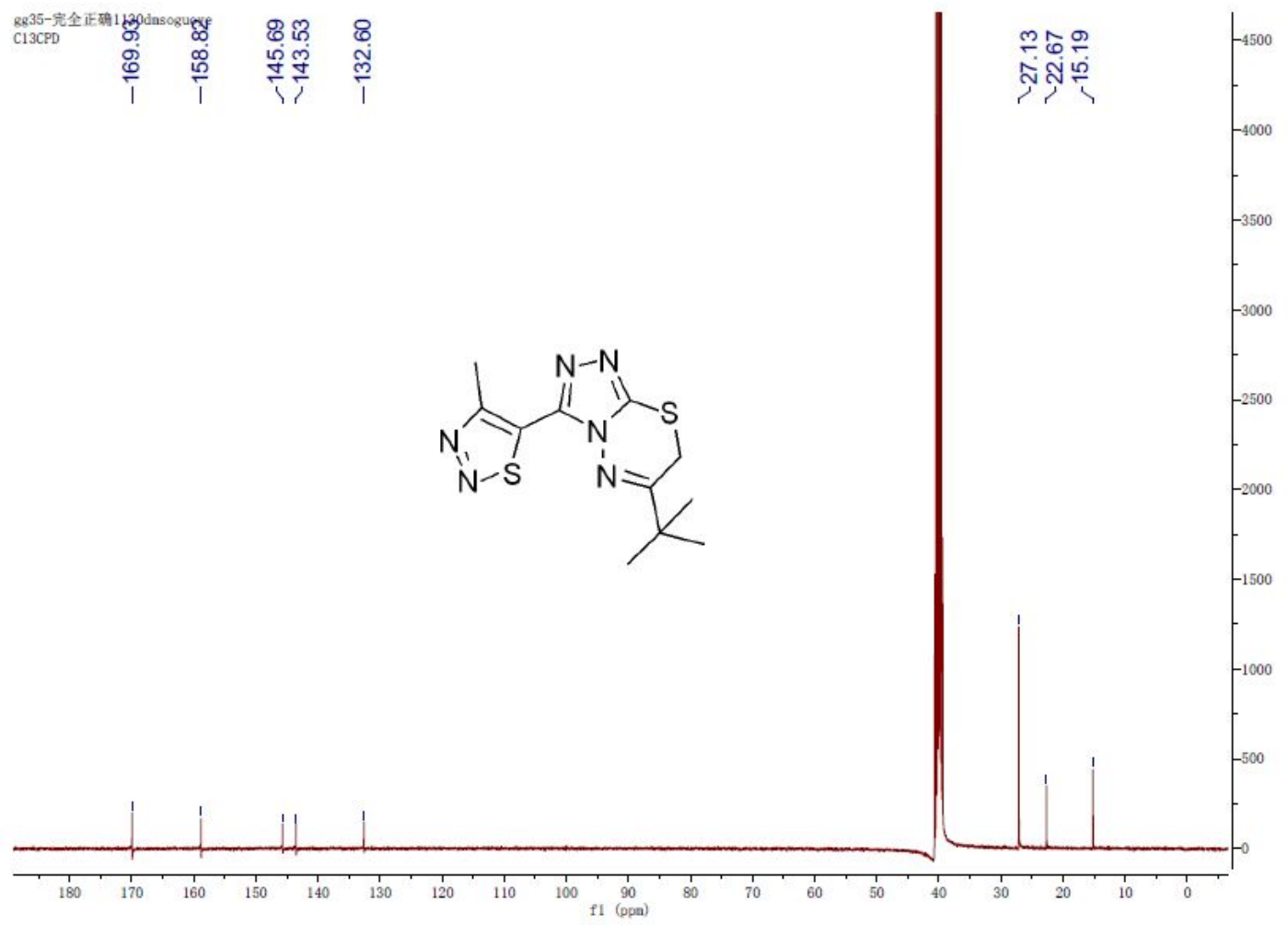

Figure C35. The ${ }^{13} \mathrm{C}$ NMR (400MHz, DMSO- $d_{6}$ ) of compound $6 \mathbf{l}$.

G1-35\#15-19 RT: 0.07-0.09 AV: 5 NL: 5.52E9

T: FTMS + p ESI Full ms [100.0000-1000.0000]

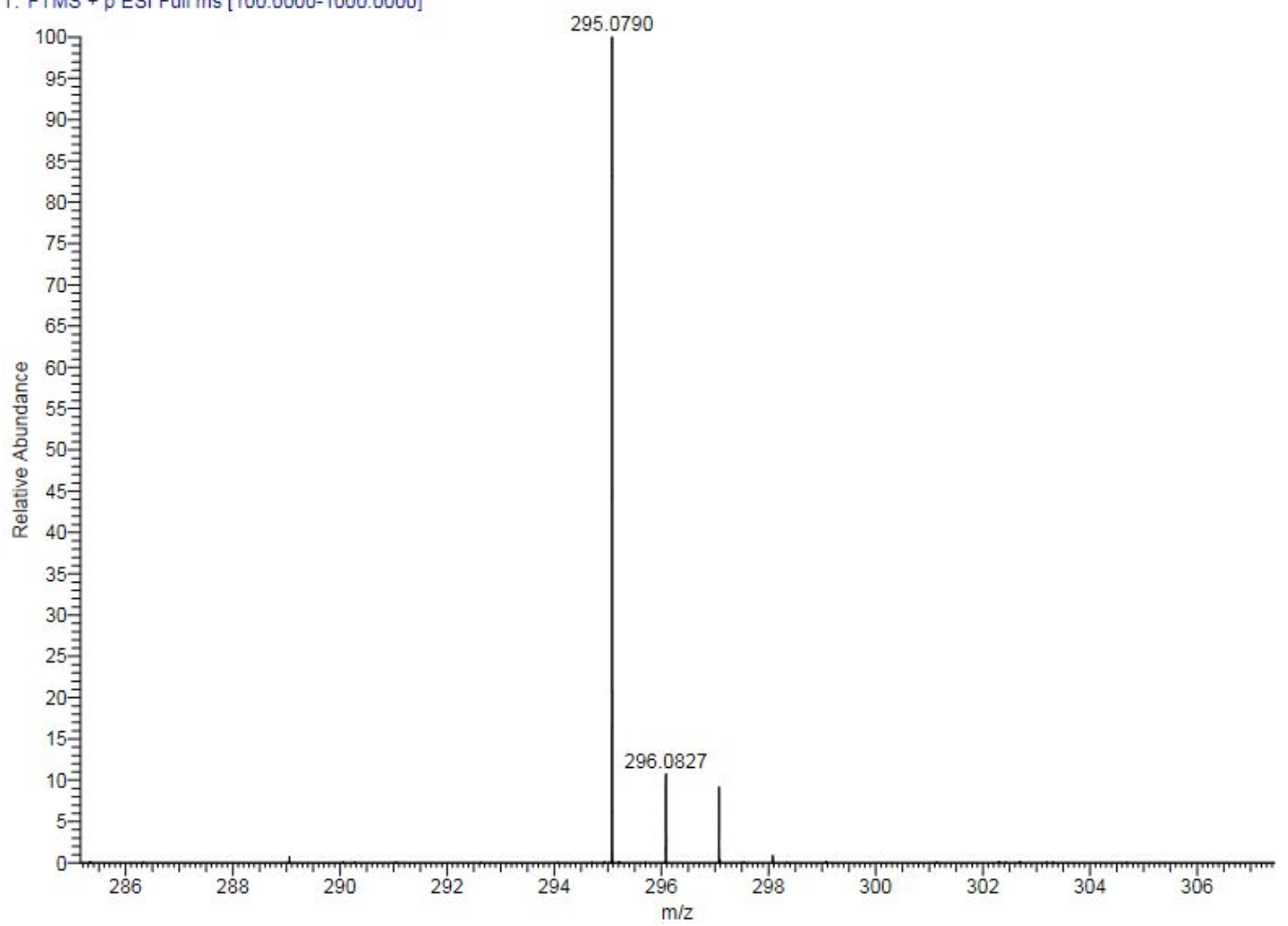

Figure C36. The HRMS of compound 61. 


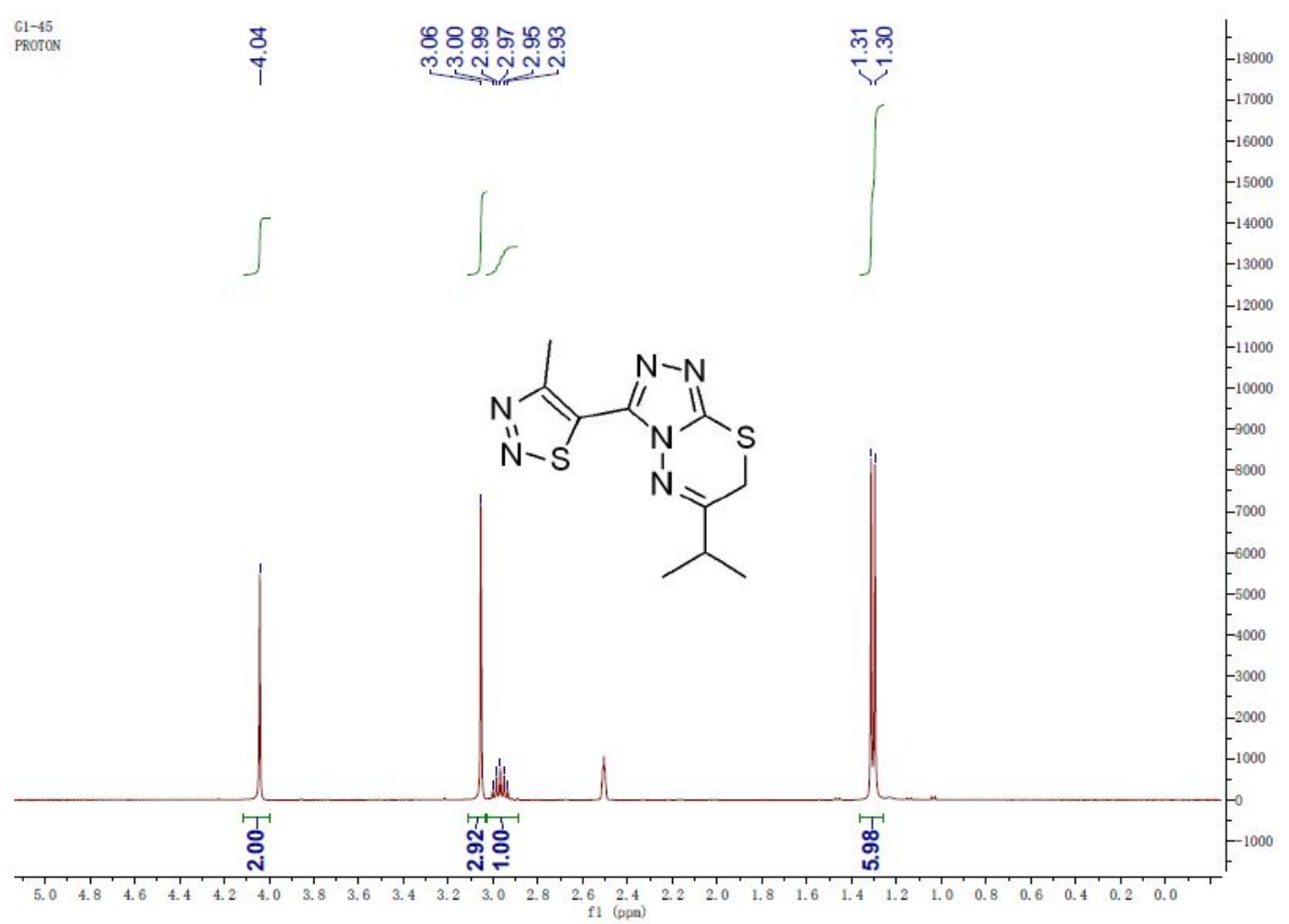

Figure C37. The ${ }^{1} \mathrm{H}$ NMR (400MHz, DMSO- $d_{6}$ ) of compound $\mathbf{6 m}$.

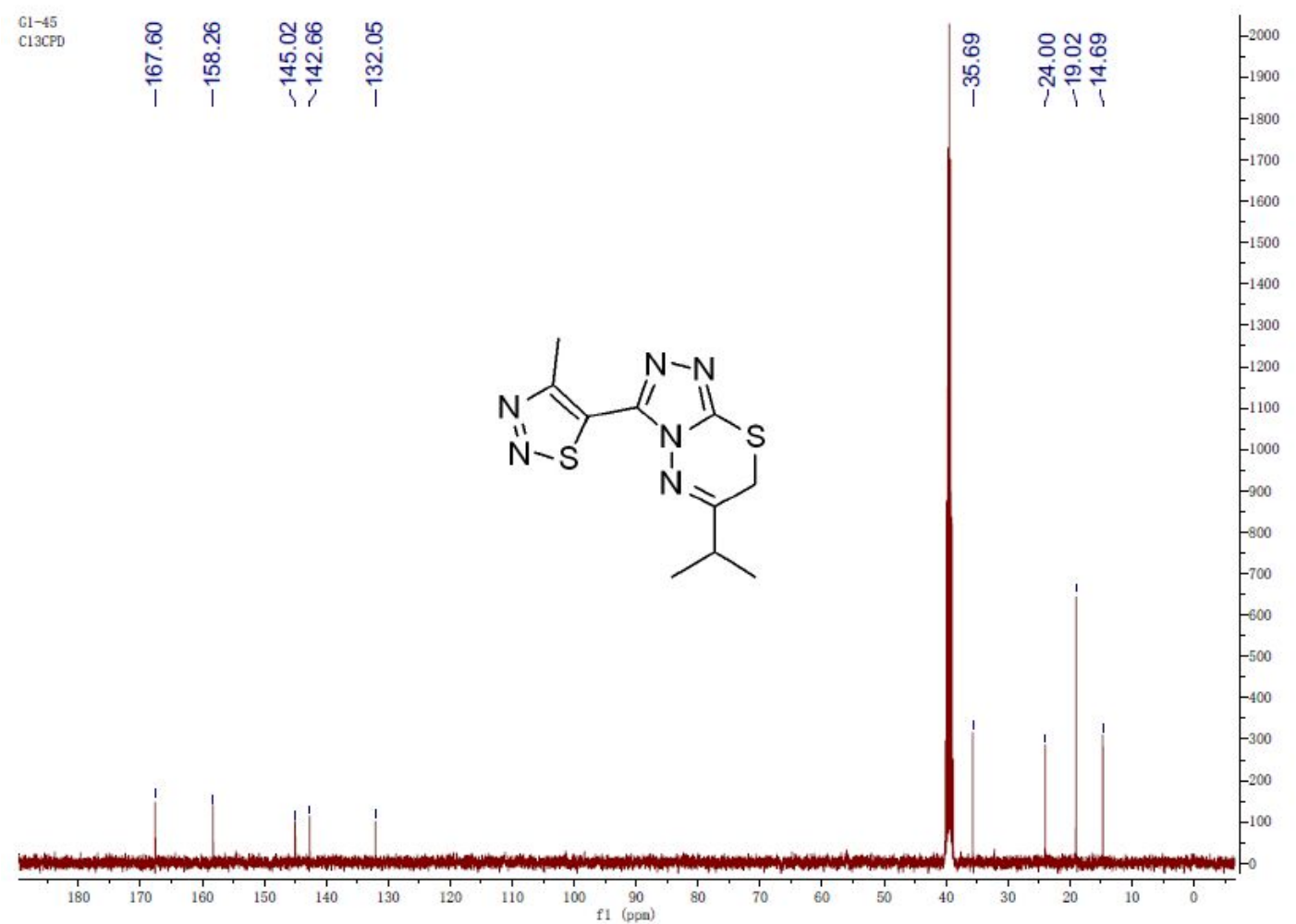

Figure $C 38$. The ${ }^{13} \mathrm{C}$ NMR $\left(400 \mathrm{MHz}\right.$, DMSO- $d_{6}$ ) of compound $\mathbf{6 m}$. 


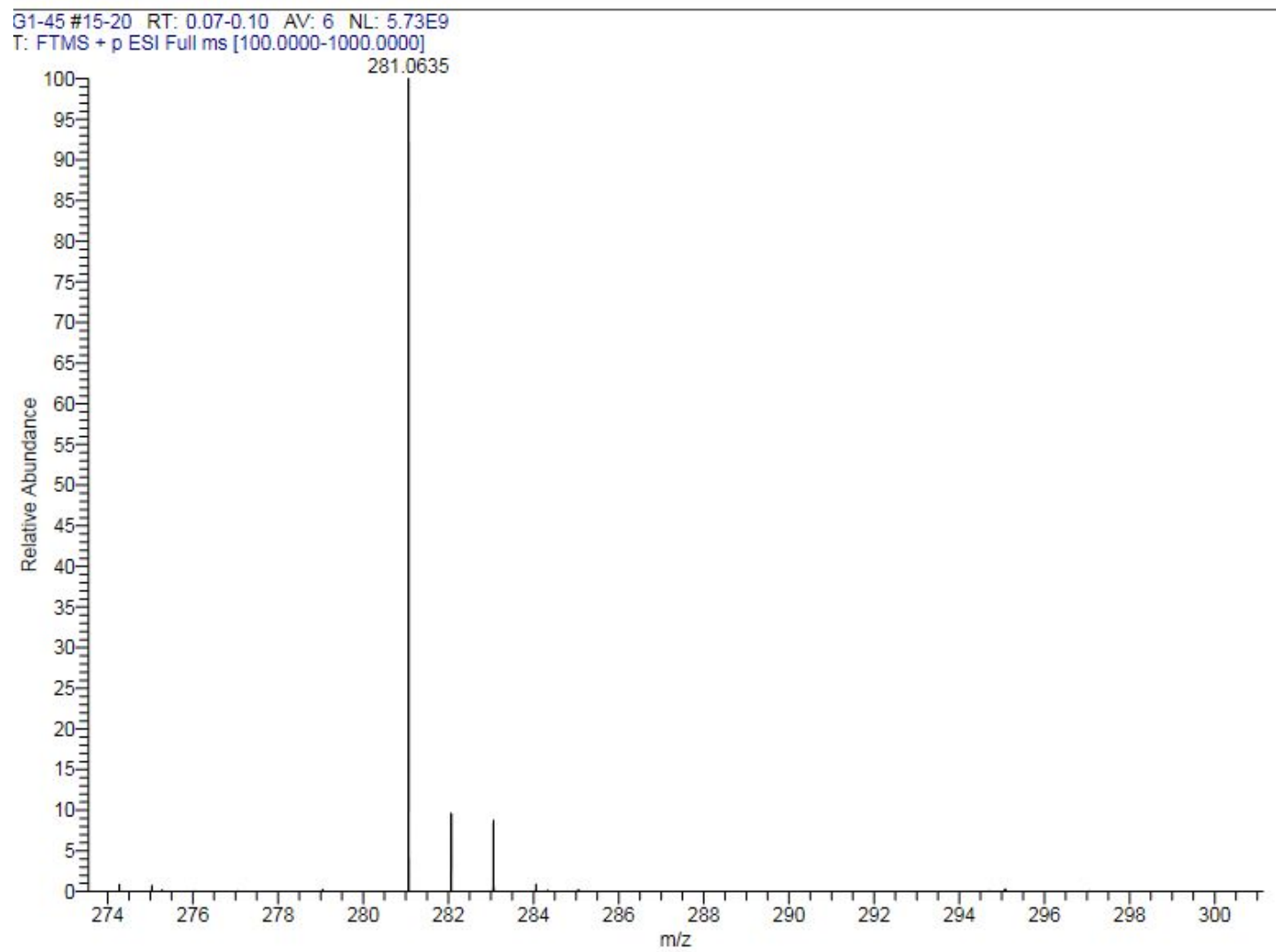

Figure C39. The HRMS of compound $\mathbf{6 m}$.

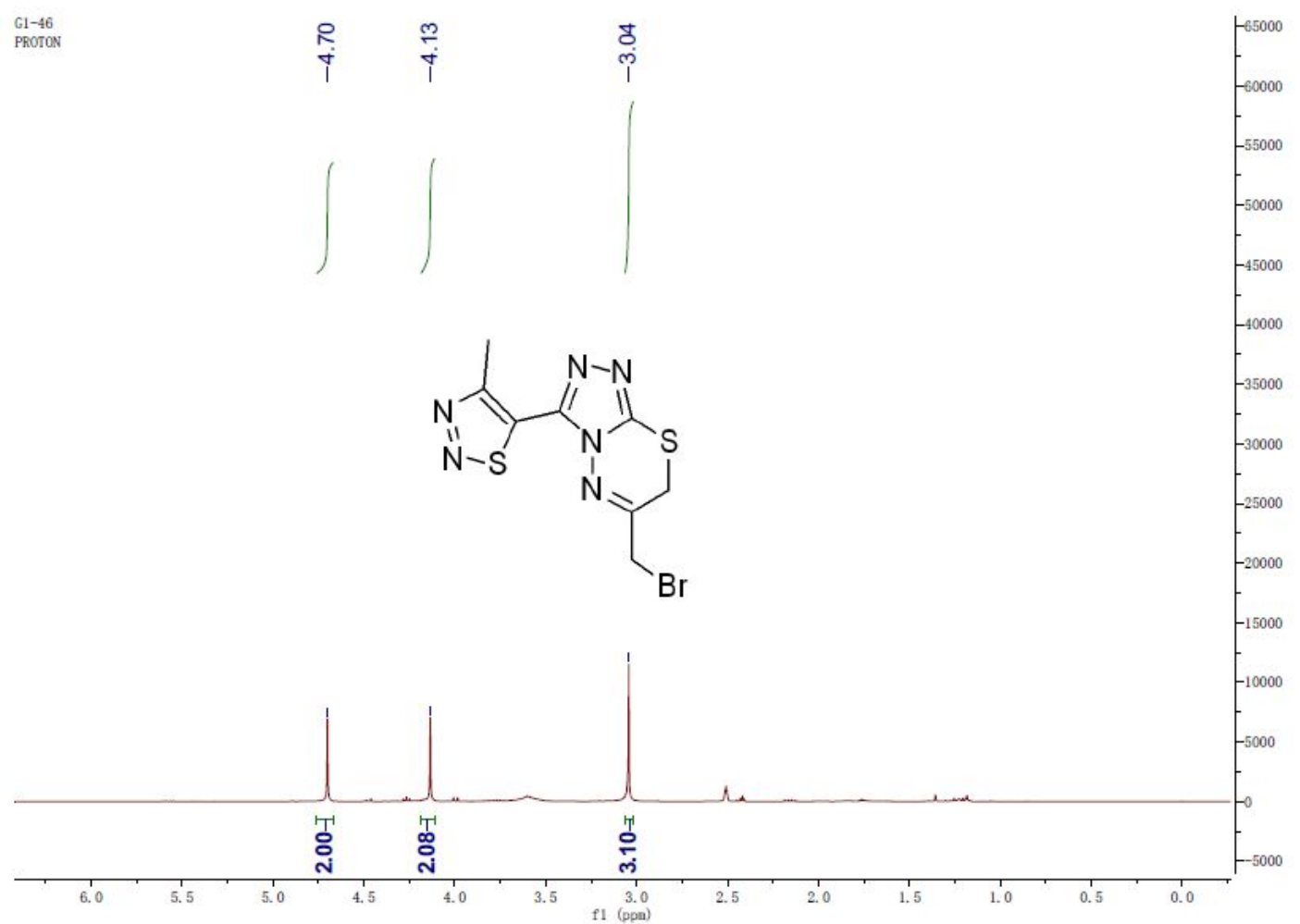

Figure C40. The ${ }^{1} \mathrm{H}$ NMR $\left(400 \mathrm{MHz}, \mathrm{DMSO}-d_{6}\right)$ of compound $6 \mathbf{n}$. 


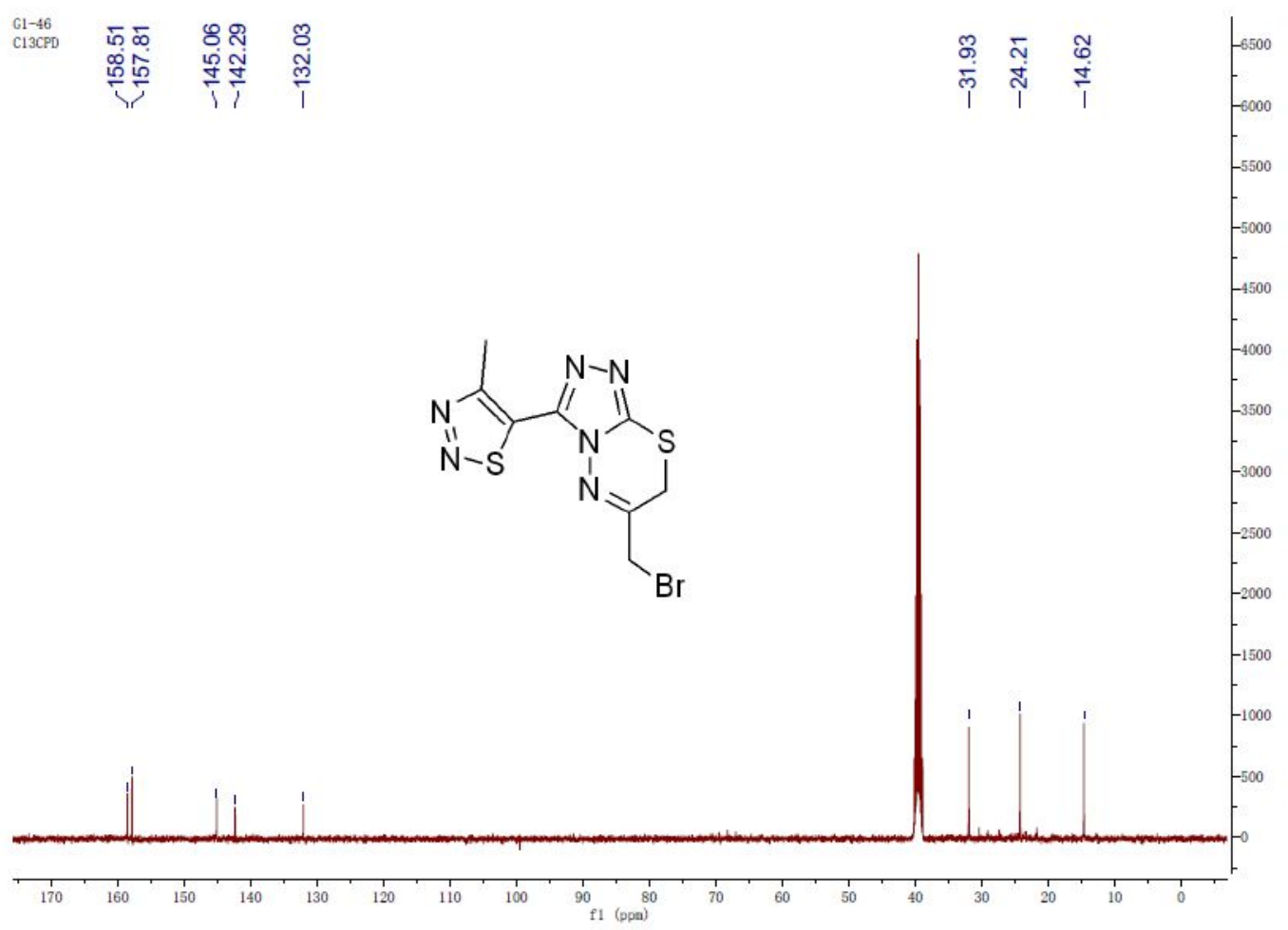

Figure C41. The ${ }^{13} \mathrm{C}$ NMR (400MHz, DMSO- $d_{6}$ ) of compound $\mathbf{6 n}$.

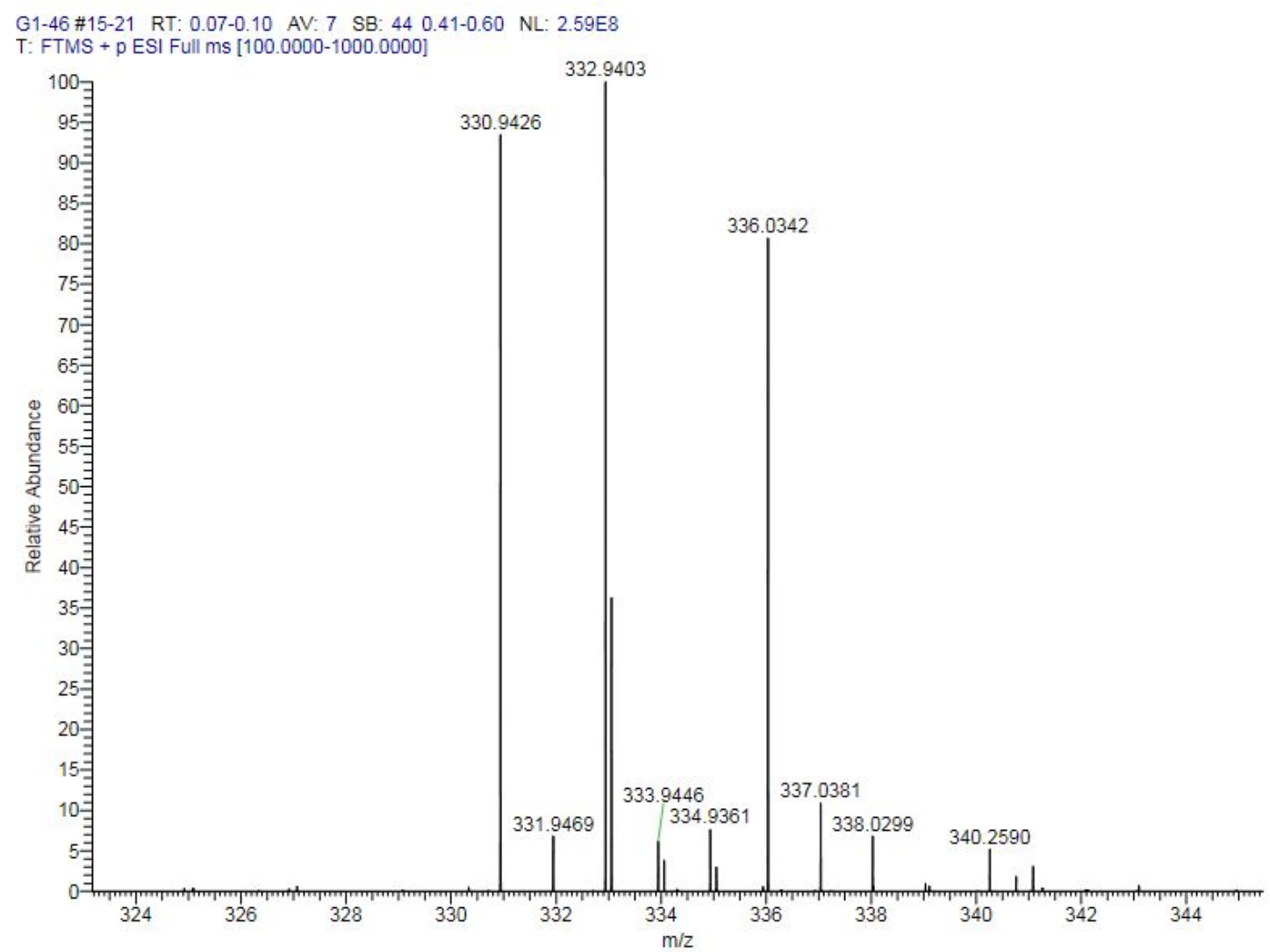

Figure C42. The HRMS of compound $\mathbf{6 n}$. 


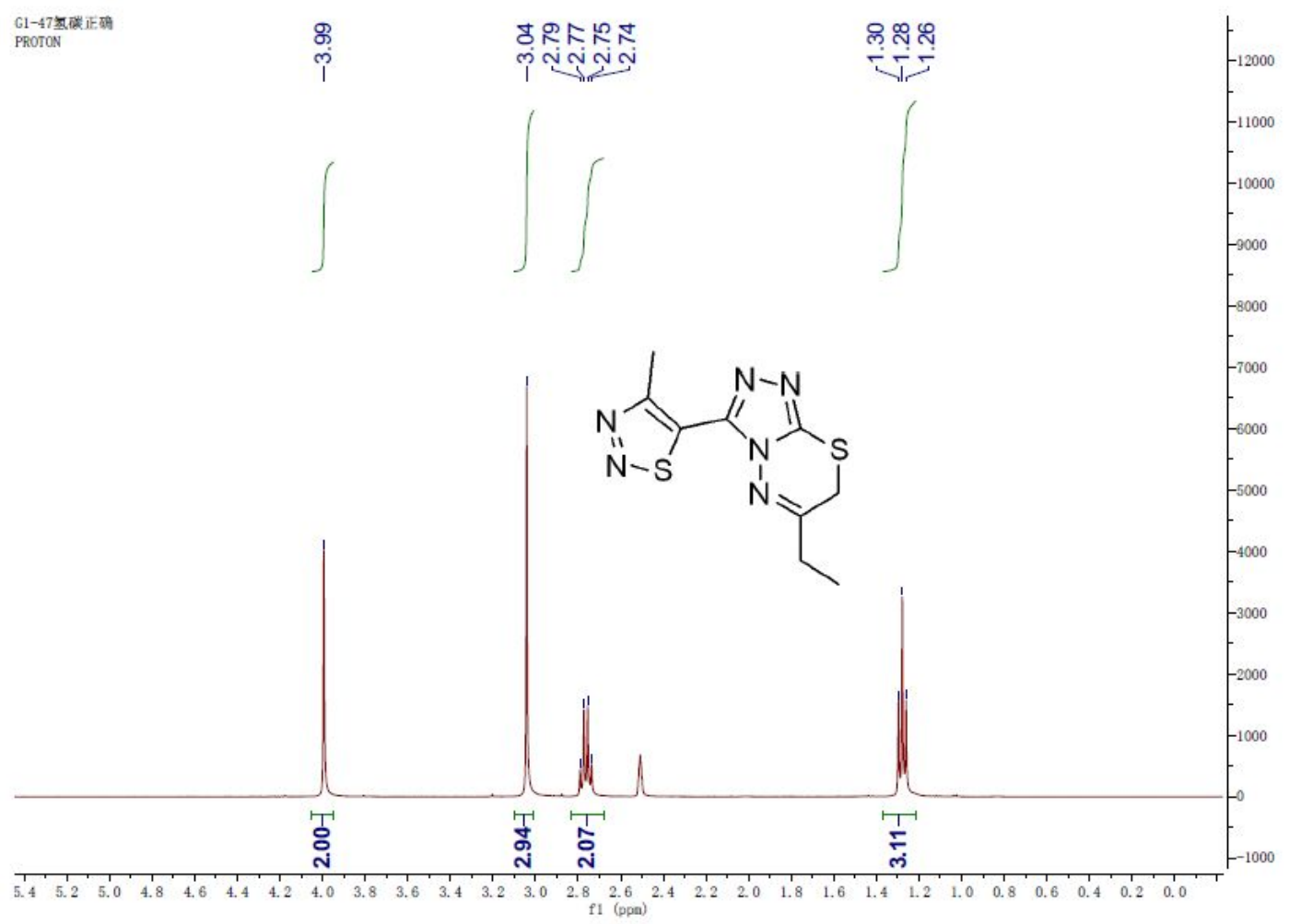

Figure C43. The ${ }^{1} \mathrm{H}$ NMR $\left(400 \mathrm{MHz}, \mathrm{DMSO}-d_{6}\right)$ of compound $6 \mathbf{6}$.

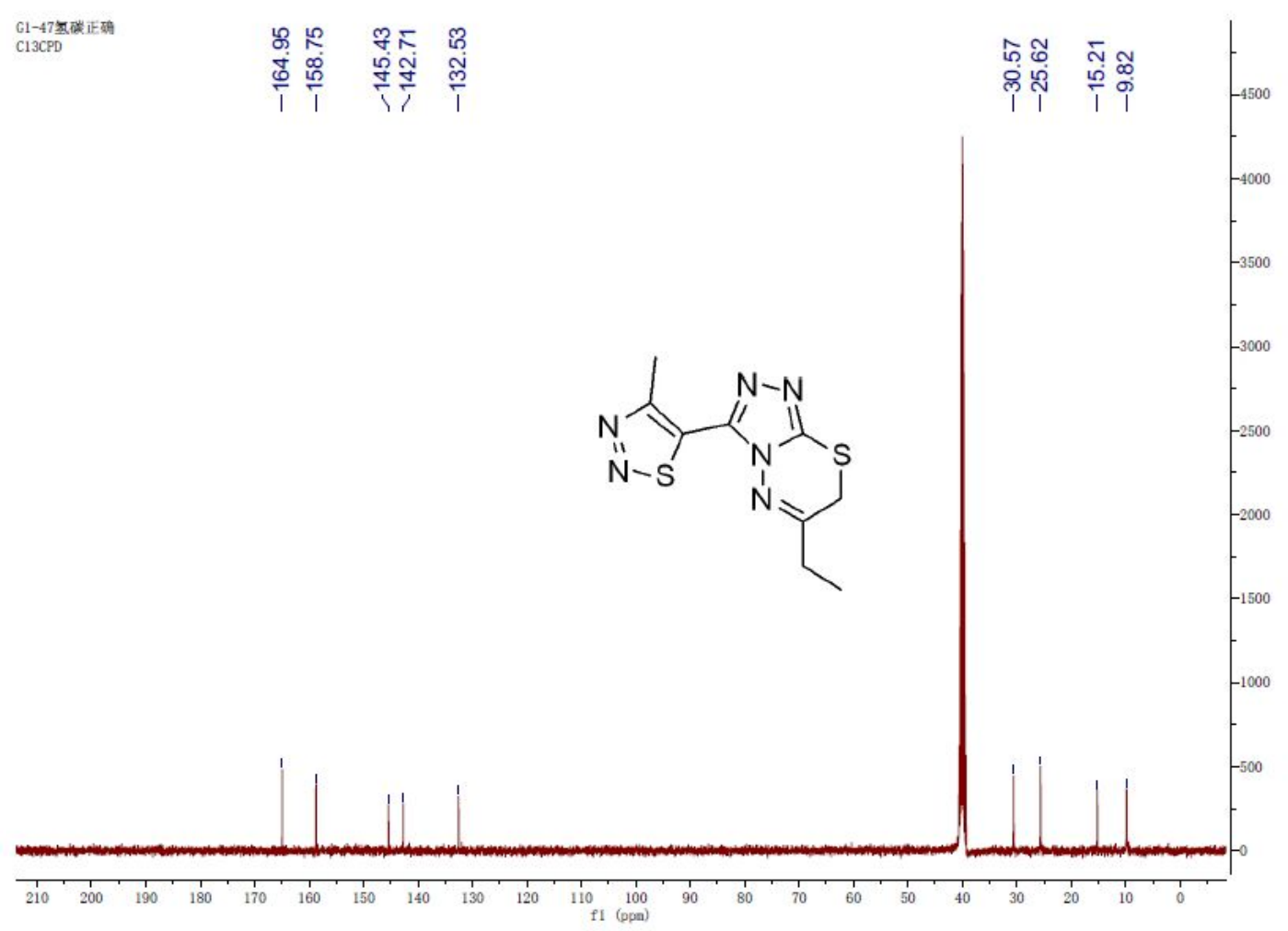

Figure C44. The ${ }^{13} \mathrm{C}$ NMR (400MHz, DMSO- $d_{6}$ ) of compound 60. 


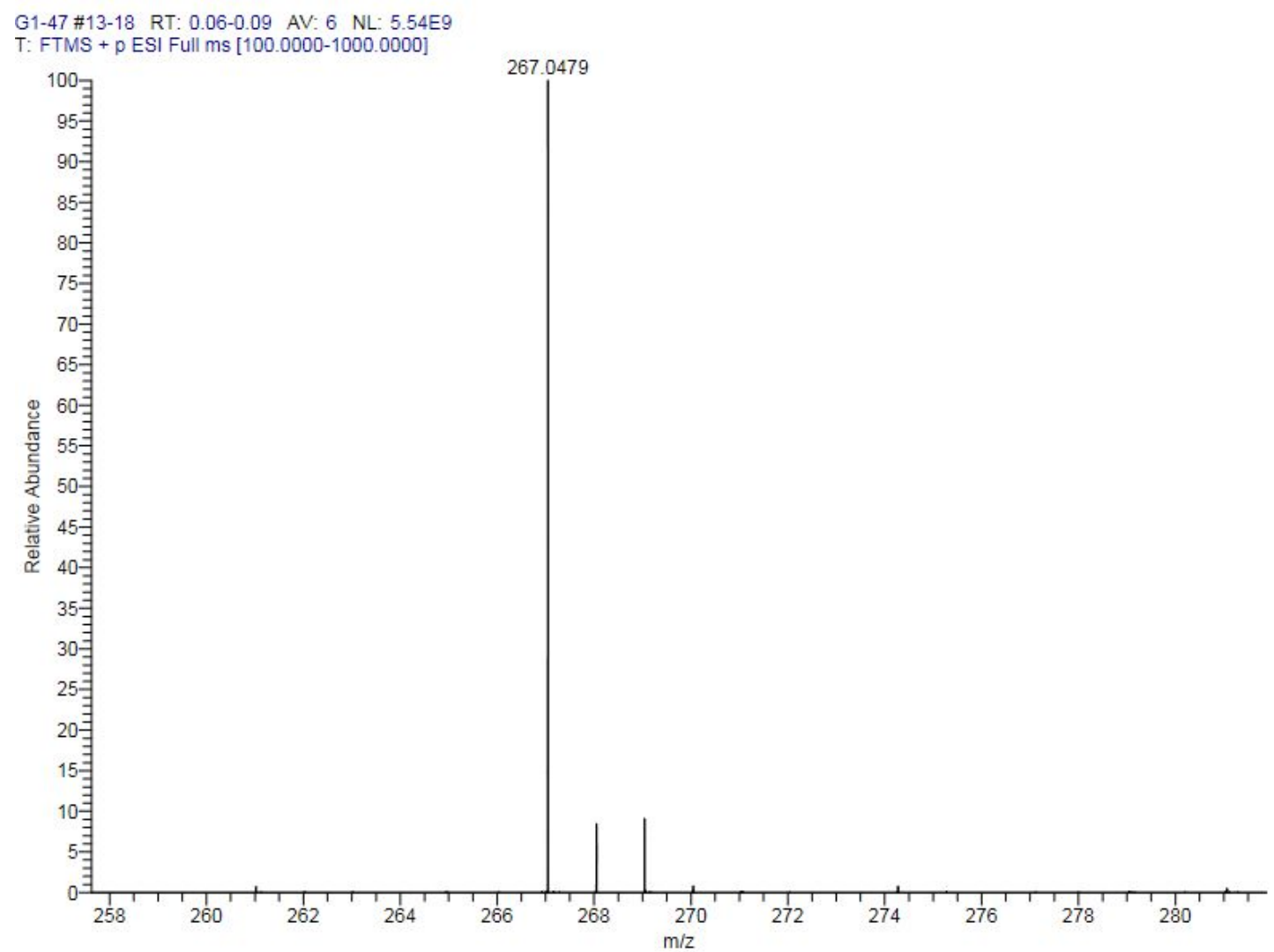

Figure C45. The HRMS of compound $6 \mathbf{o .}$

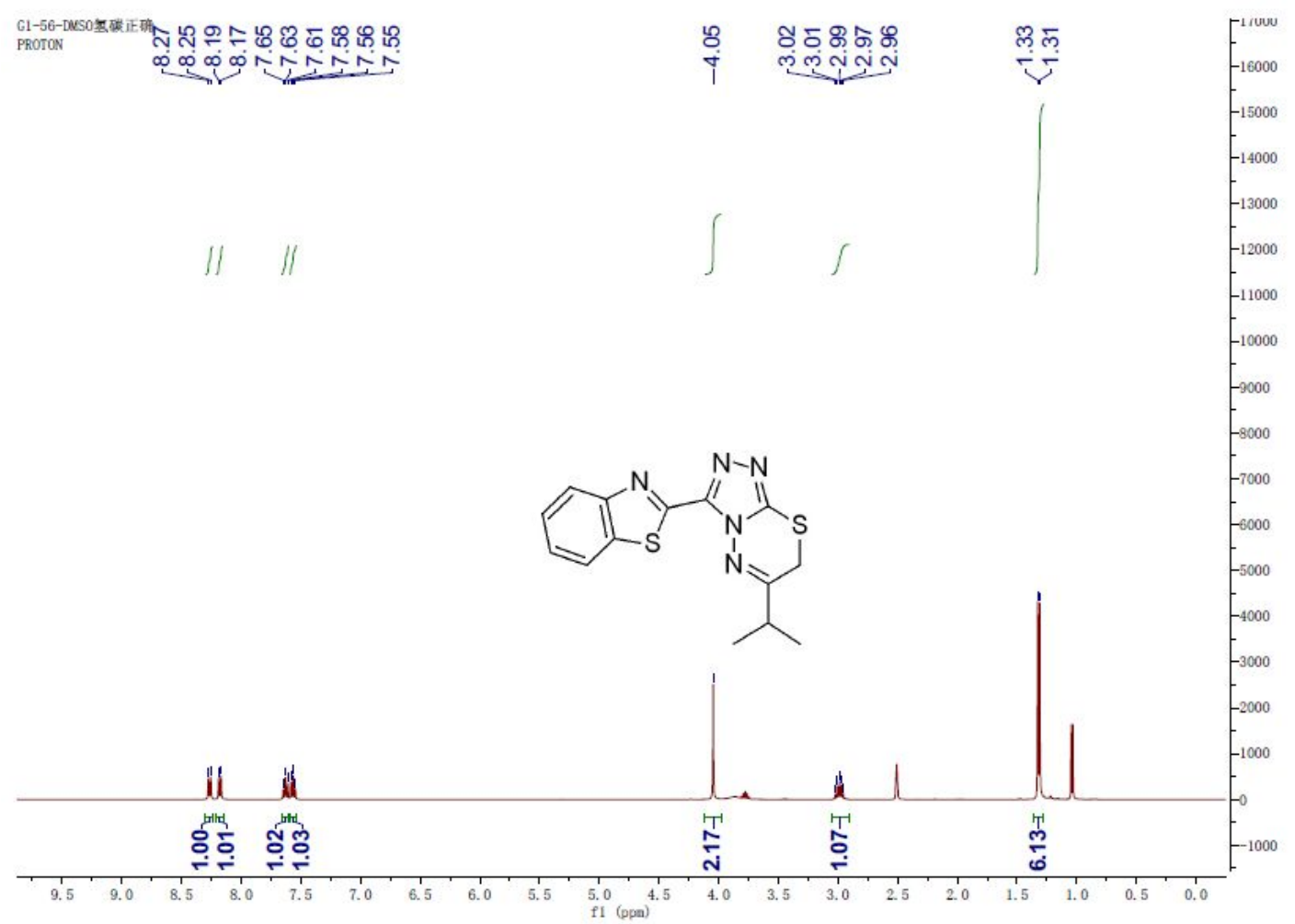

Figure $C 46$. The ${ }^{1} \mathrm{H}$ NMR (400MHz, DMSO- $d_{6}$ ) of compound $\mathbf{6 p}$. 


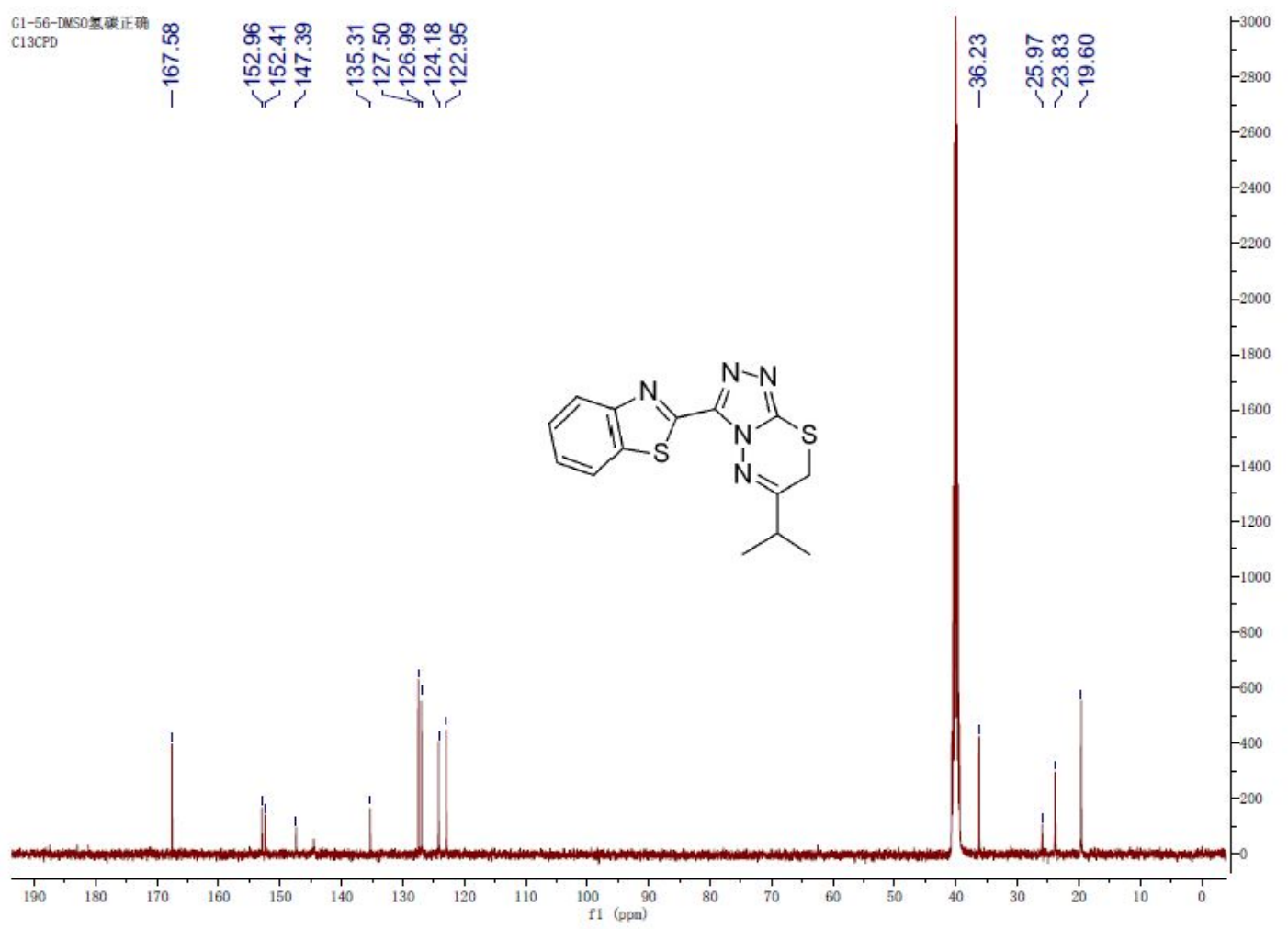

Figure C47. The ${ }^{13} \mathrm{C}$ NMR (400MHz, DMSO- $d_{6}$ ) of compound $6 \mathbf{p}$.

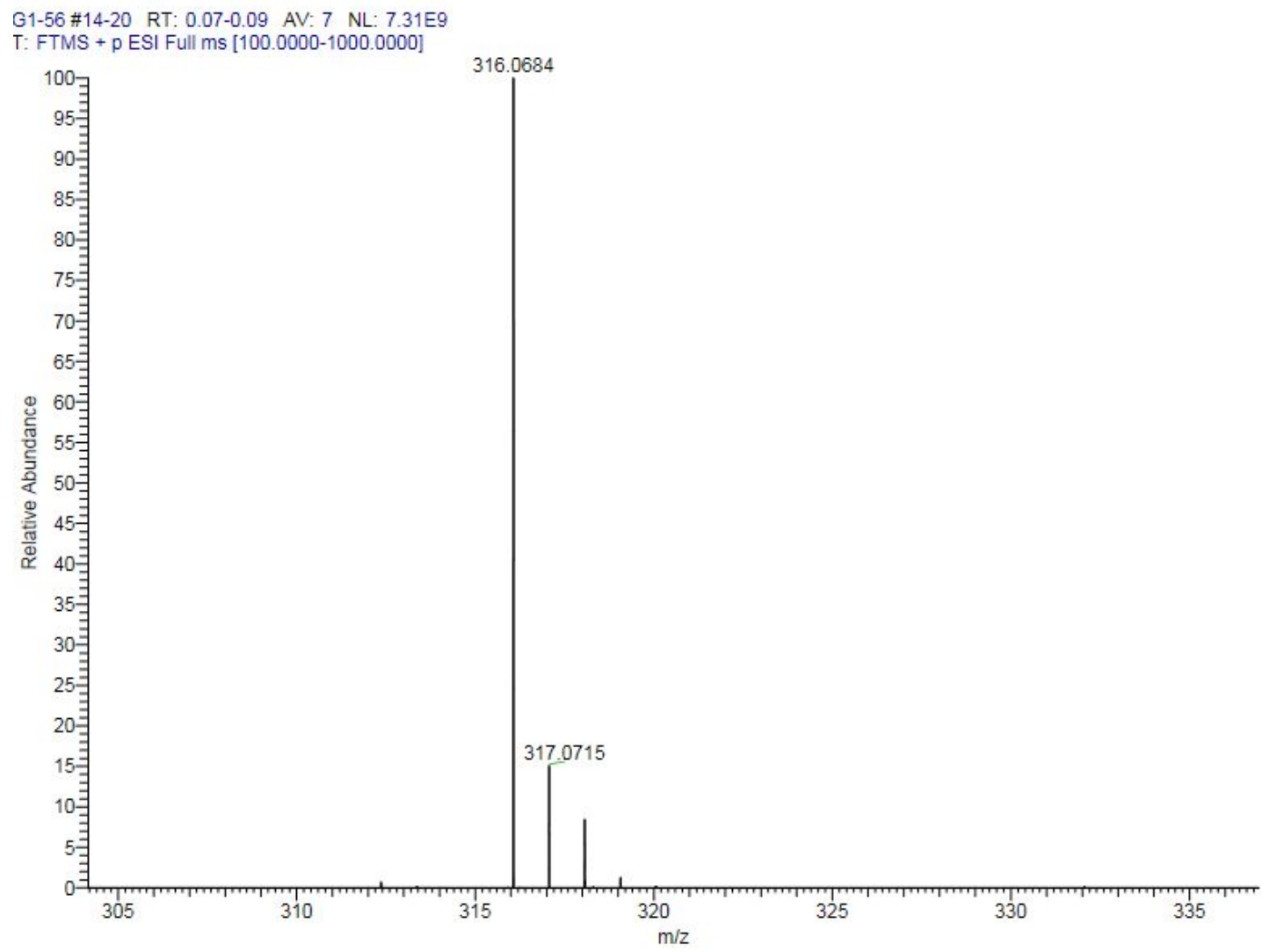

Figure C48. The HRMS of compound $\mathbf{6 p}$. 


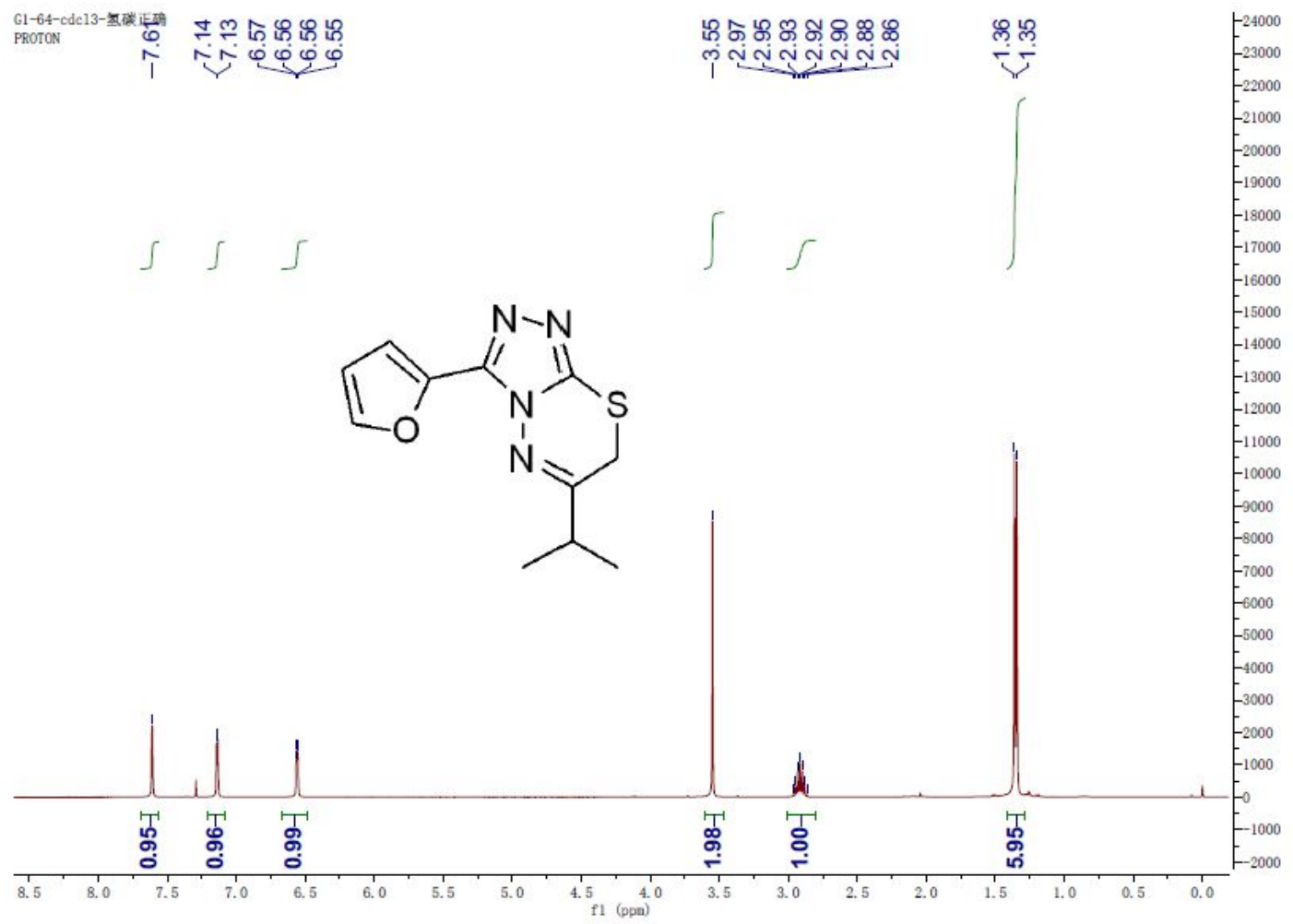

Figure C49. The ${ }^{1} \mathrm{H}$ NMR $\left(400 \mathrm{MHz}, \mathrm{CDCl}_{3}\right)$ of compound $\mathbf{6 q}$.

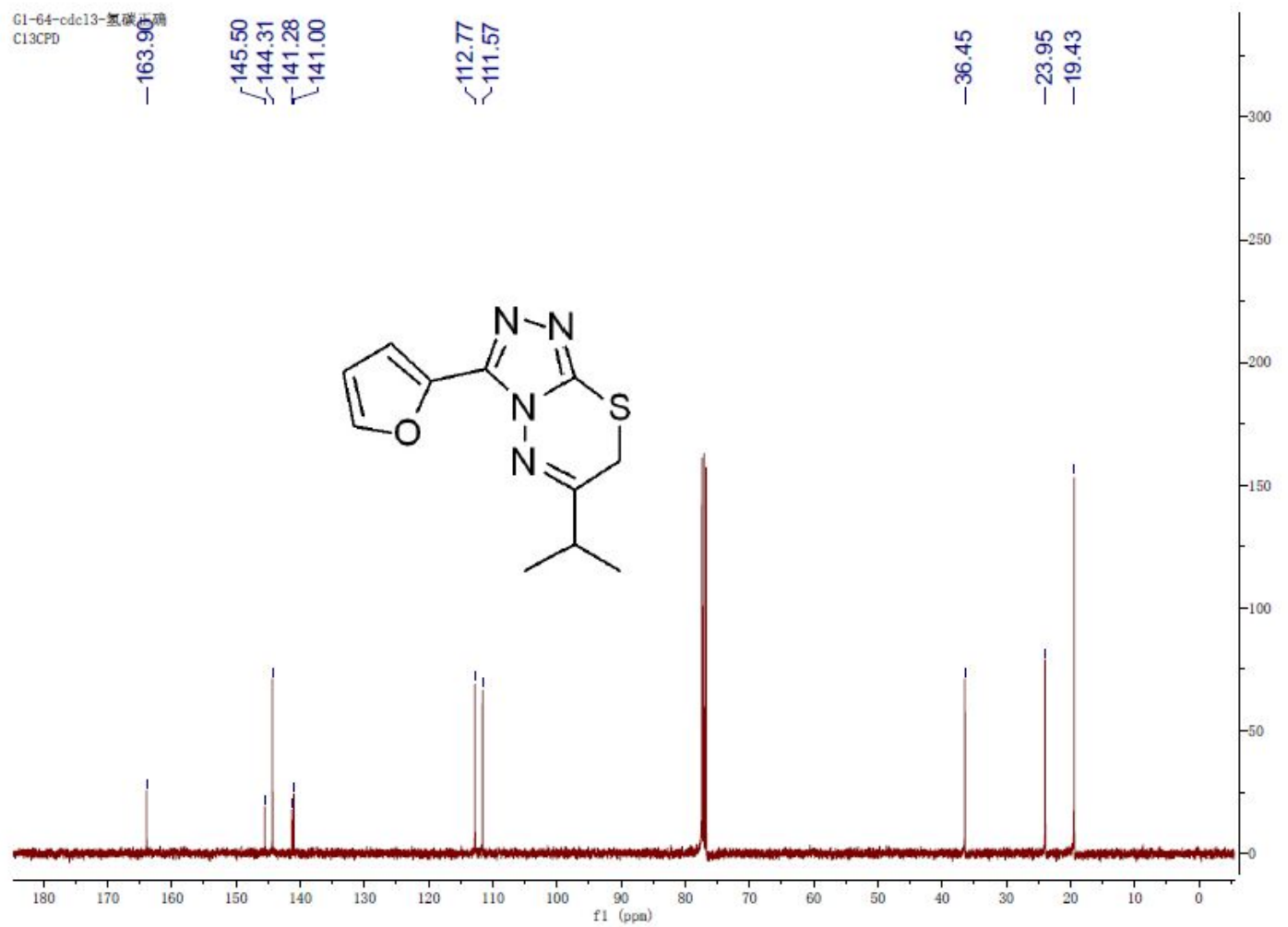

Figure C50. The ${ }^{13} \mathrm{C}$ NMR $\left(400 \mathrm{MHz}, \mathrm{CDCl}_{3}\right)$ of compound $\mathbf{6 q}$. 


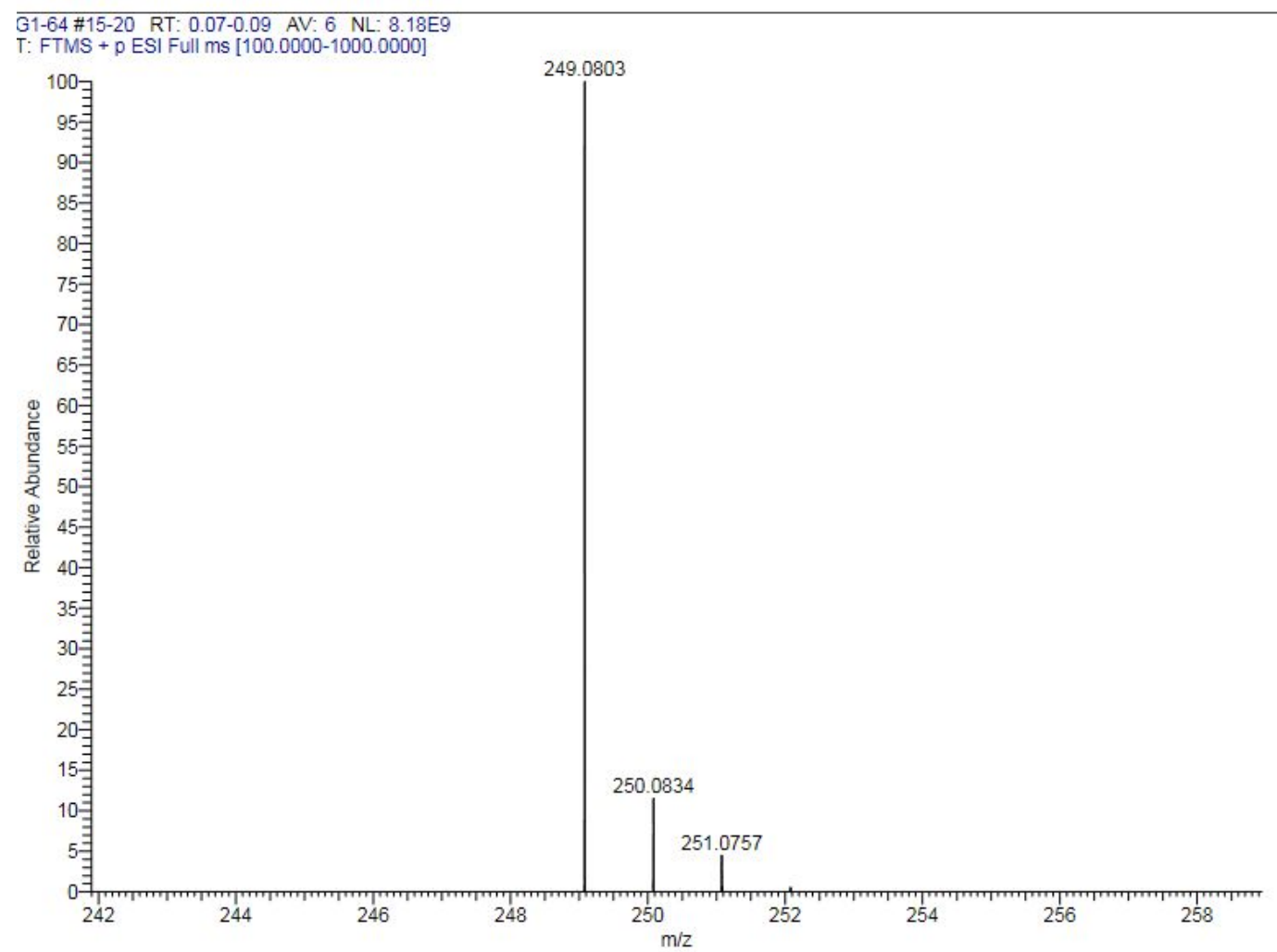

Figure C51. The HRMS of compound 6q.

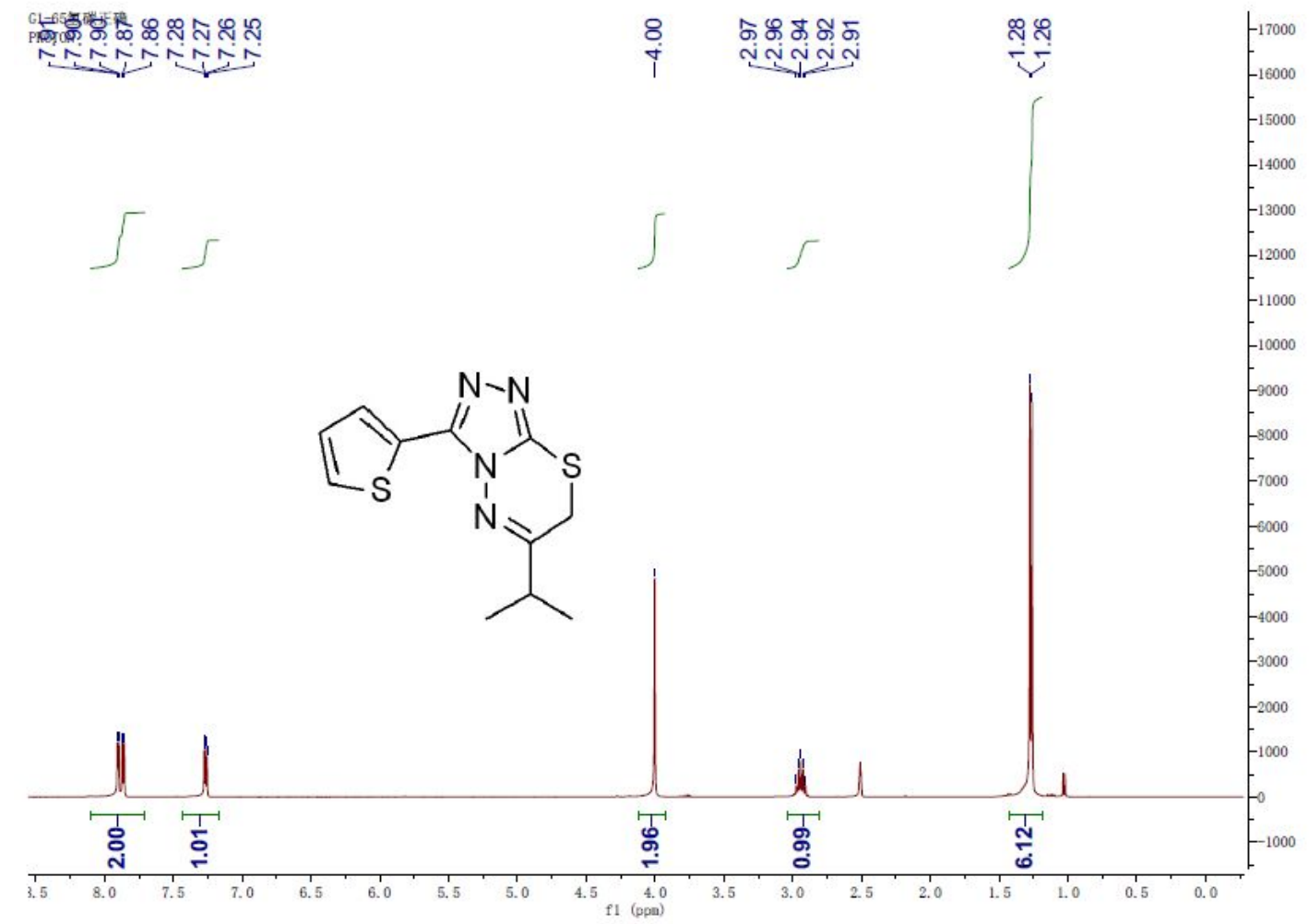

Figure C52. The ${ }^{1} \mathrm{H}$ NMR (400MHz, DMSO- $\left.d_{6}\right)$ of compound $6 \mathbf{r}$. 


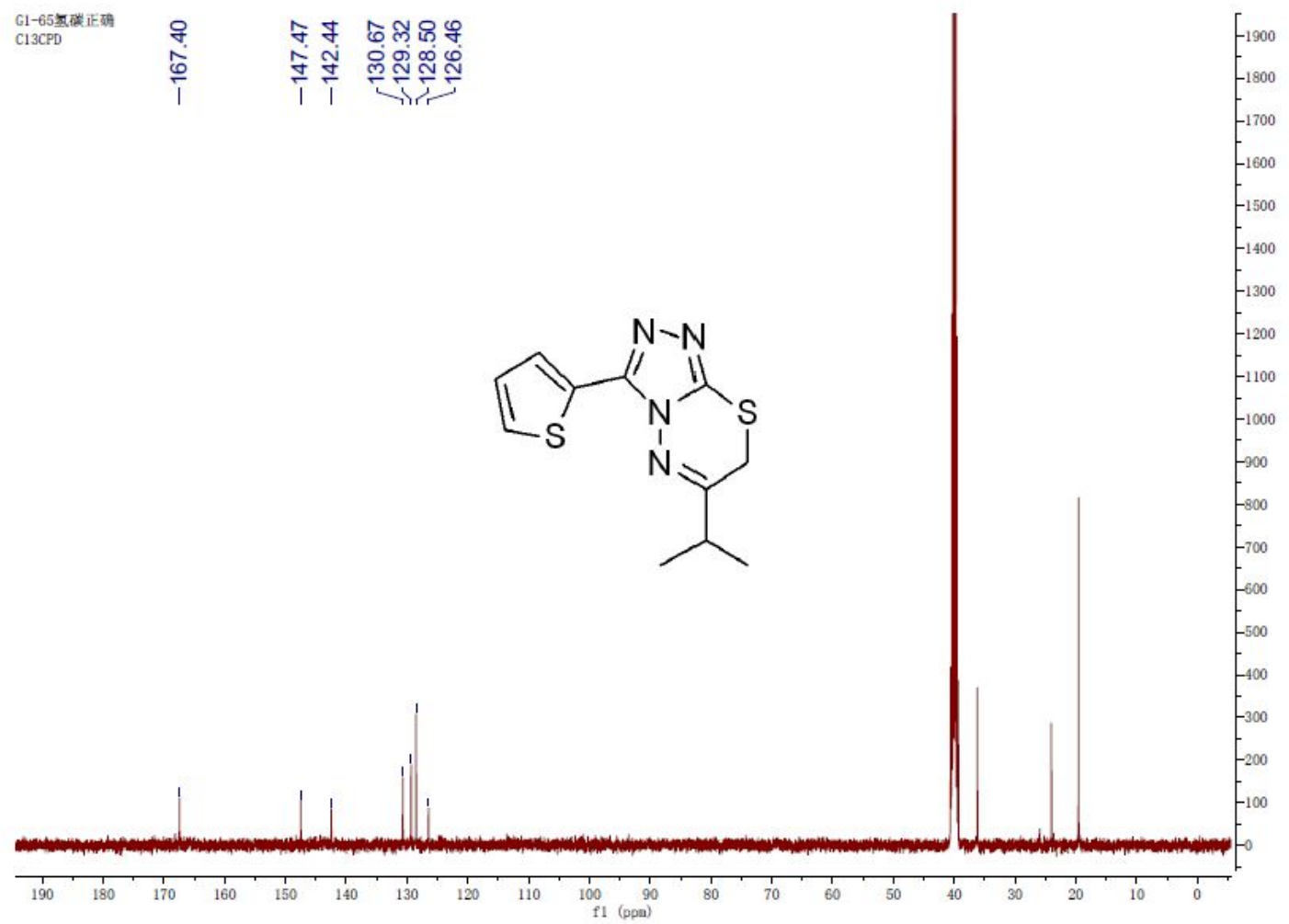

Figure C53. The ${ }^{13} \mathrm{C}$ NMR (400MHz, DMSO- $d_{6}$ ) of compound $6 r$.

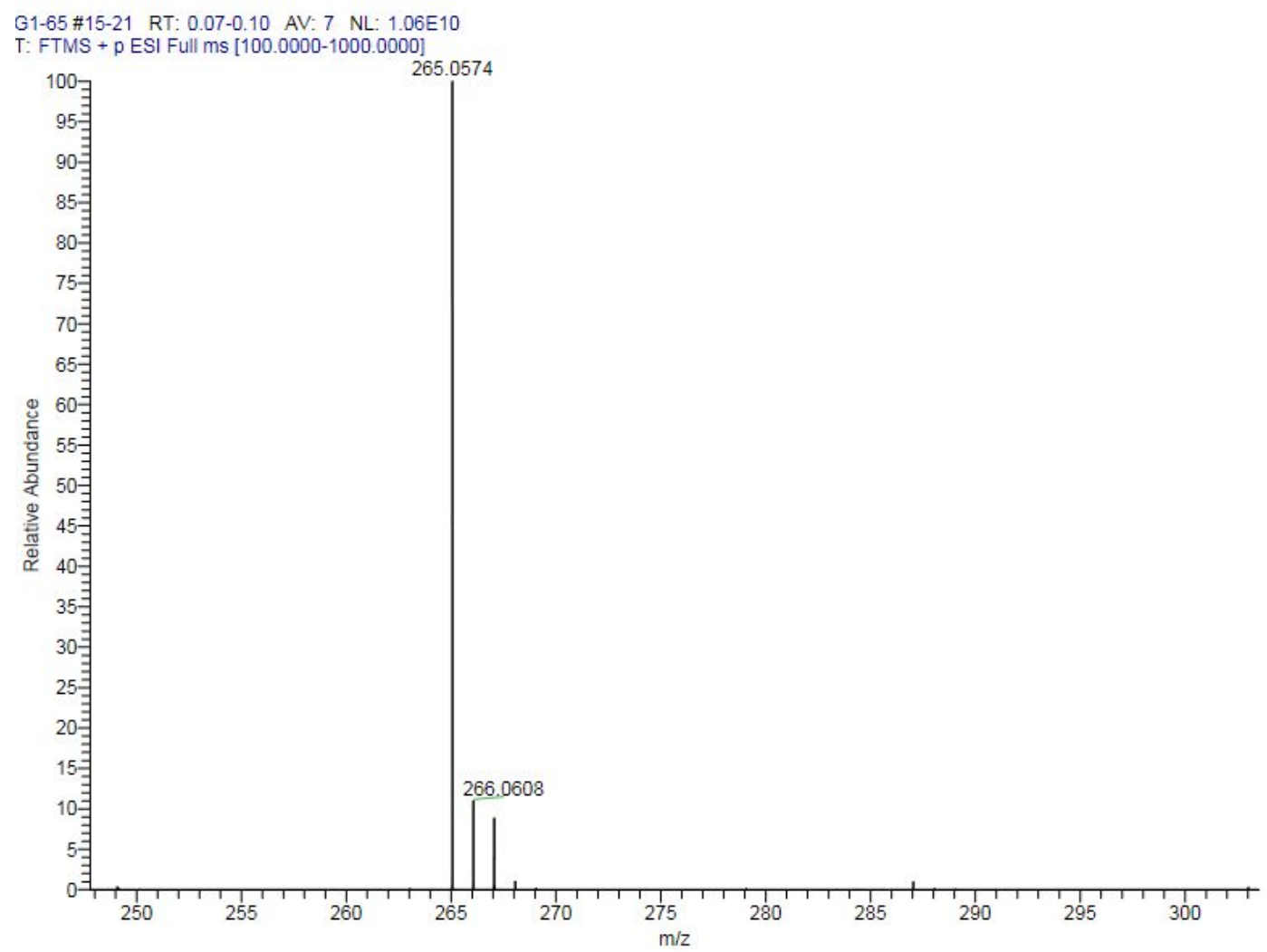

Figure C54. The HRMS of compound $6 \mathbf{r}$. 


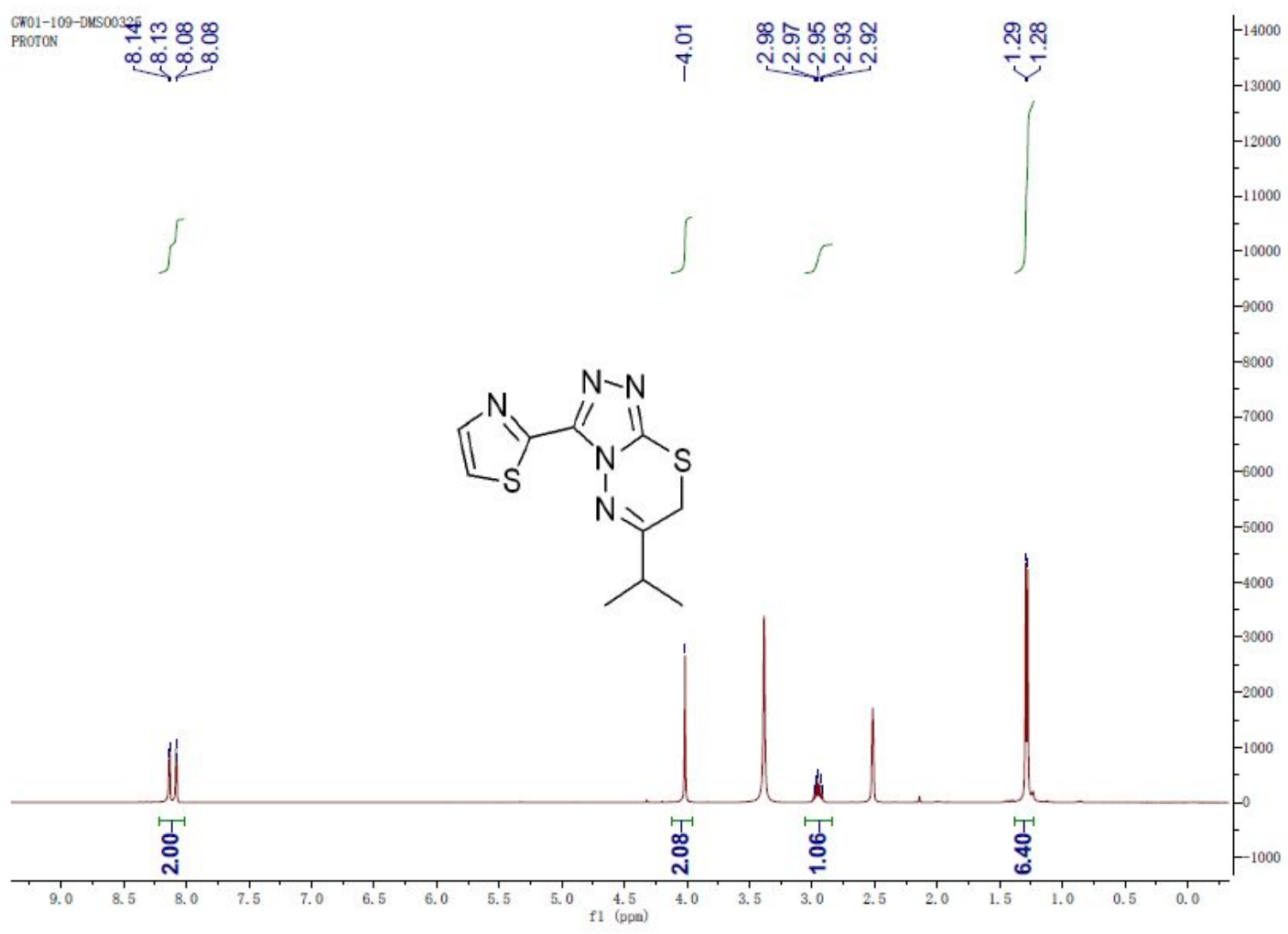

Figure C55. The ${ }^{1} \mathrm{H}$ NMR (400MHz, DMSO- $\left.d_{6}\right)$ of compound $\mathbf{6 s}$.

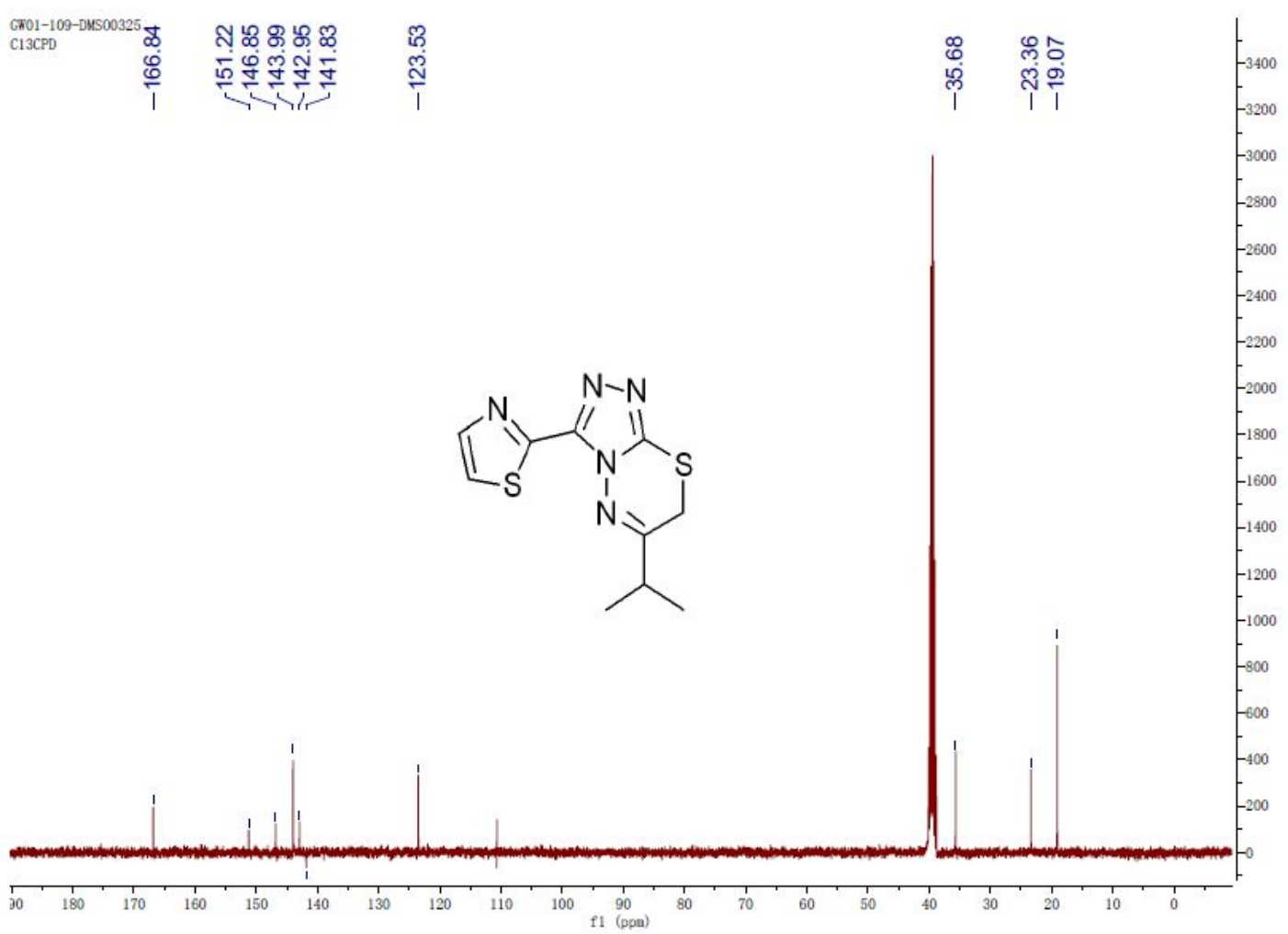

Figure C56. The ${ }^{13} \mathrm{C}$ NMR (400MHz, DMSO- $\left.d_{6}\right)$ of compound $6 \mathbf{s}$. 


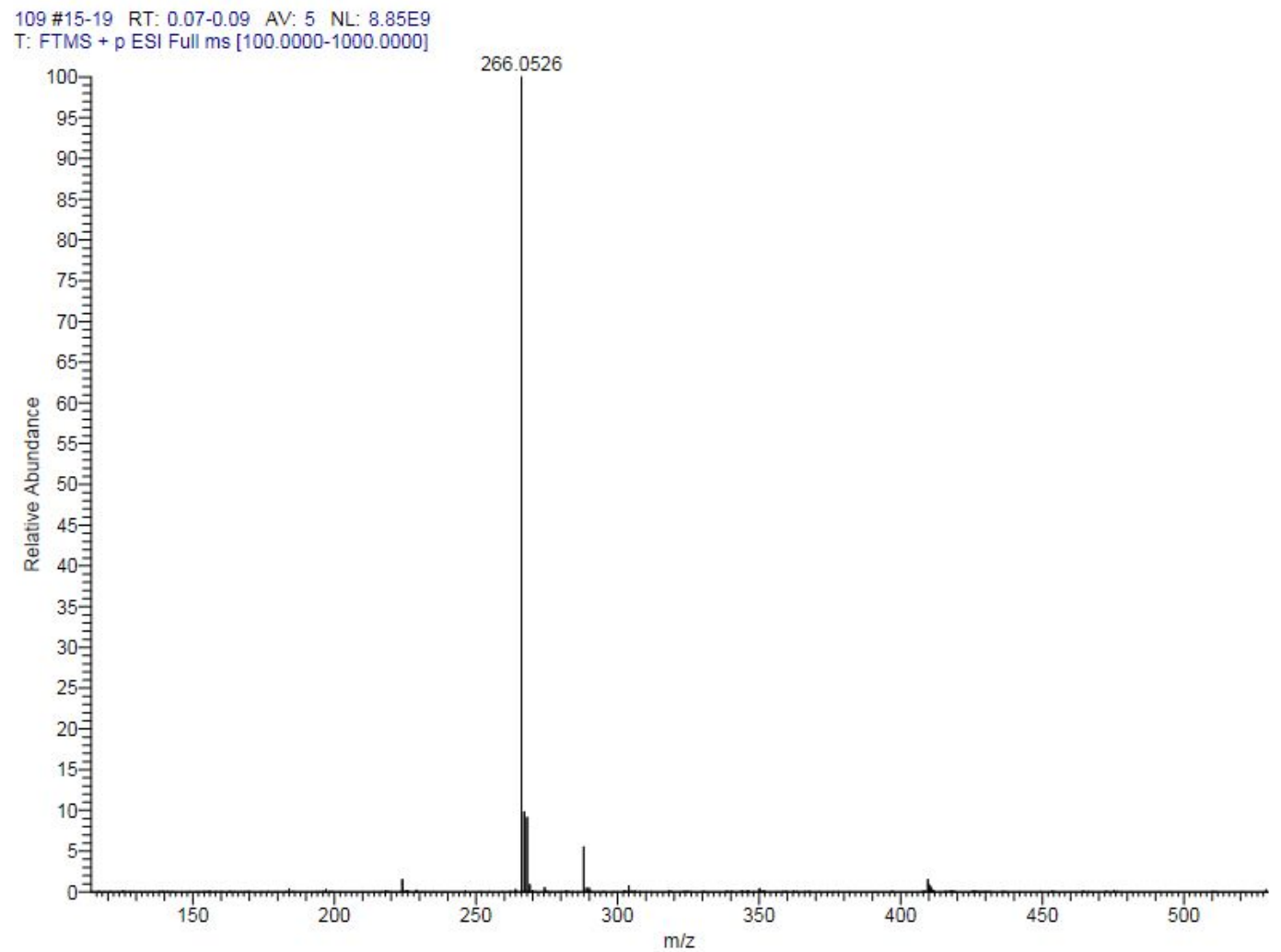

Figure C57. The HRMS of compound 6s.

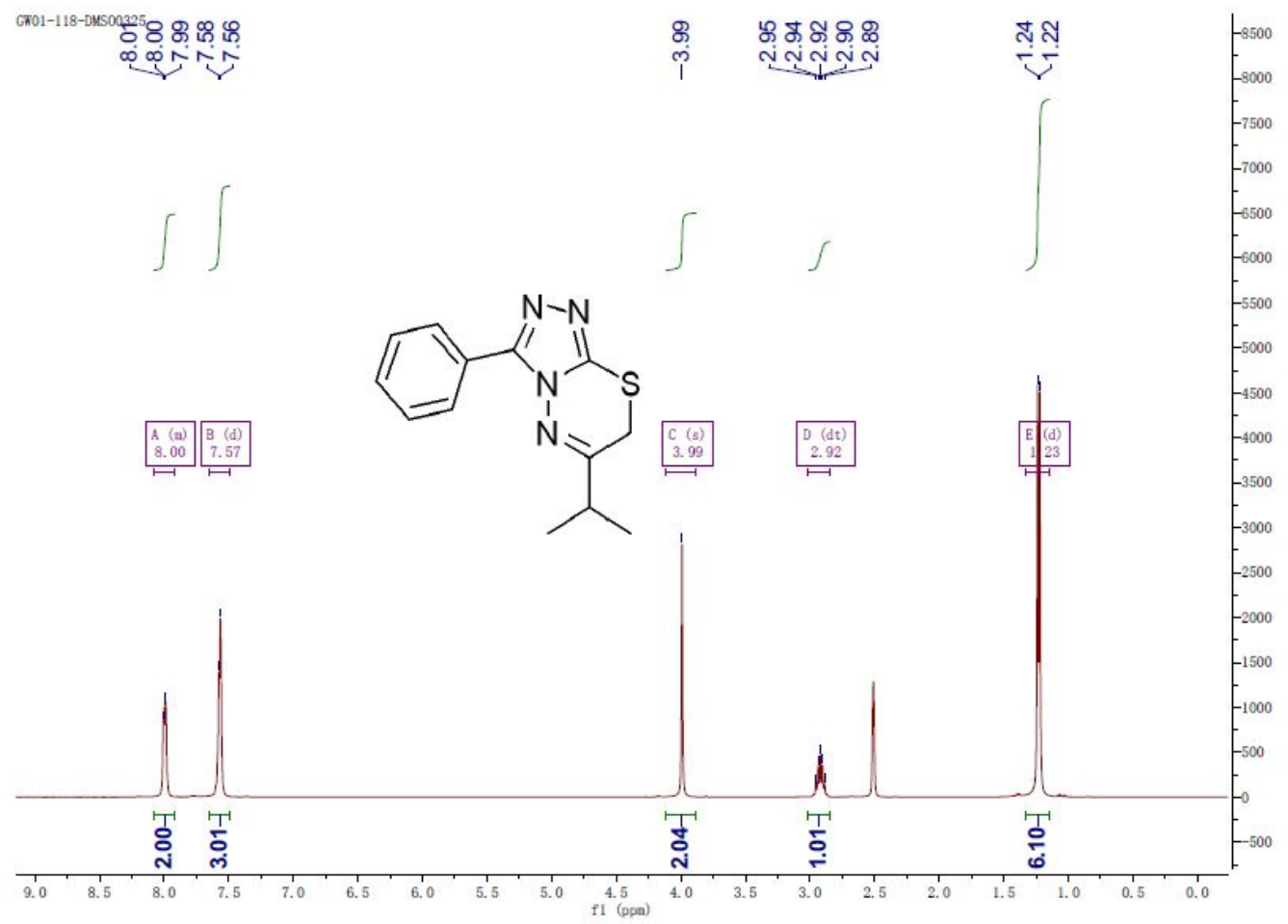

Figure C58. The ${ }^{1} \mathrm{H}$ NMR $\left(400 \mathrm{MHz}\right.$, DMSO- $\left.d_{6}\right)$ of compound 6 t. 


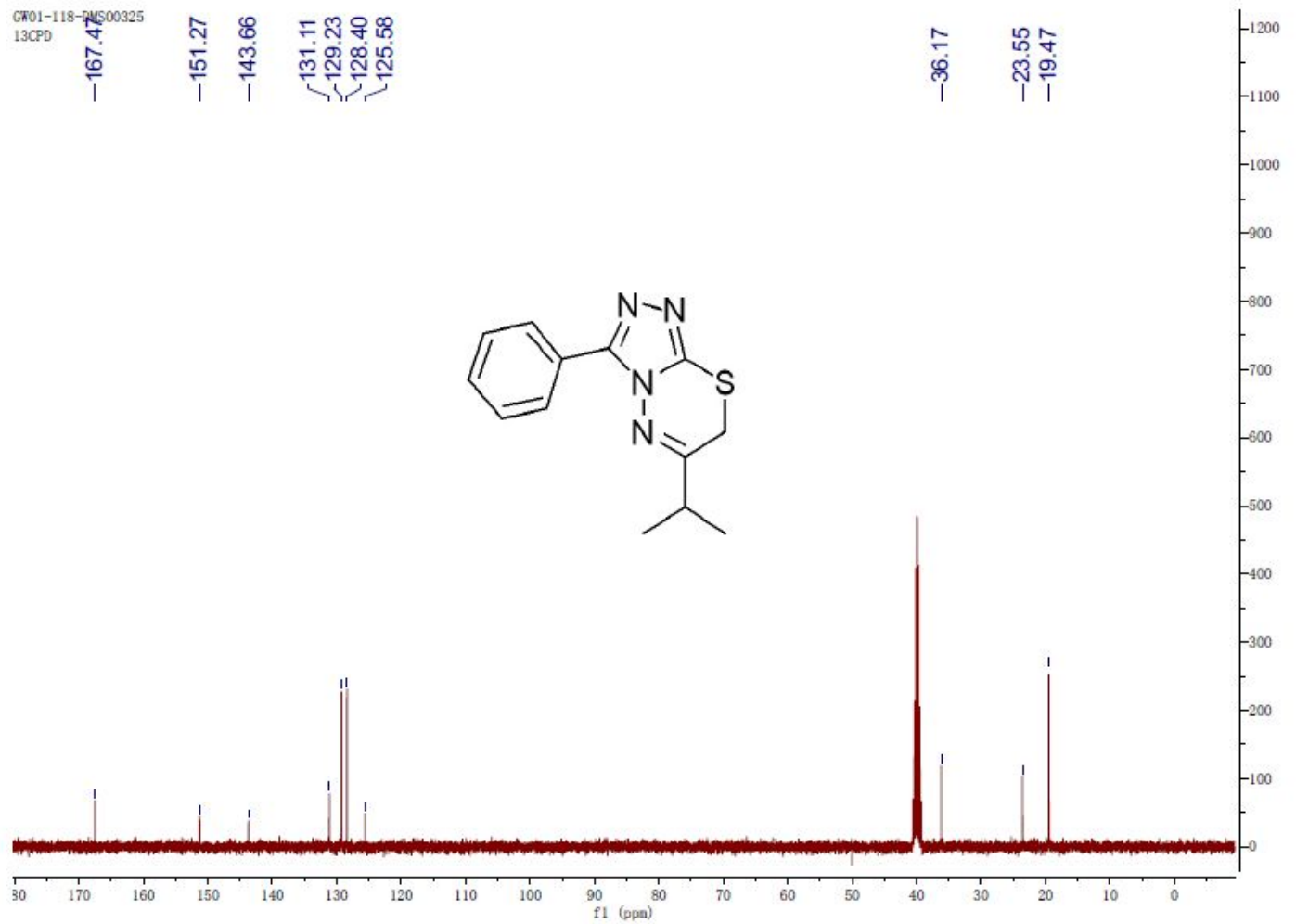

Figure C59. The ${ }^{13} \mathrm{C}$ NMR (400MHz, DMSO- $\left.d_{6}\right)$ of compound 6 t.

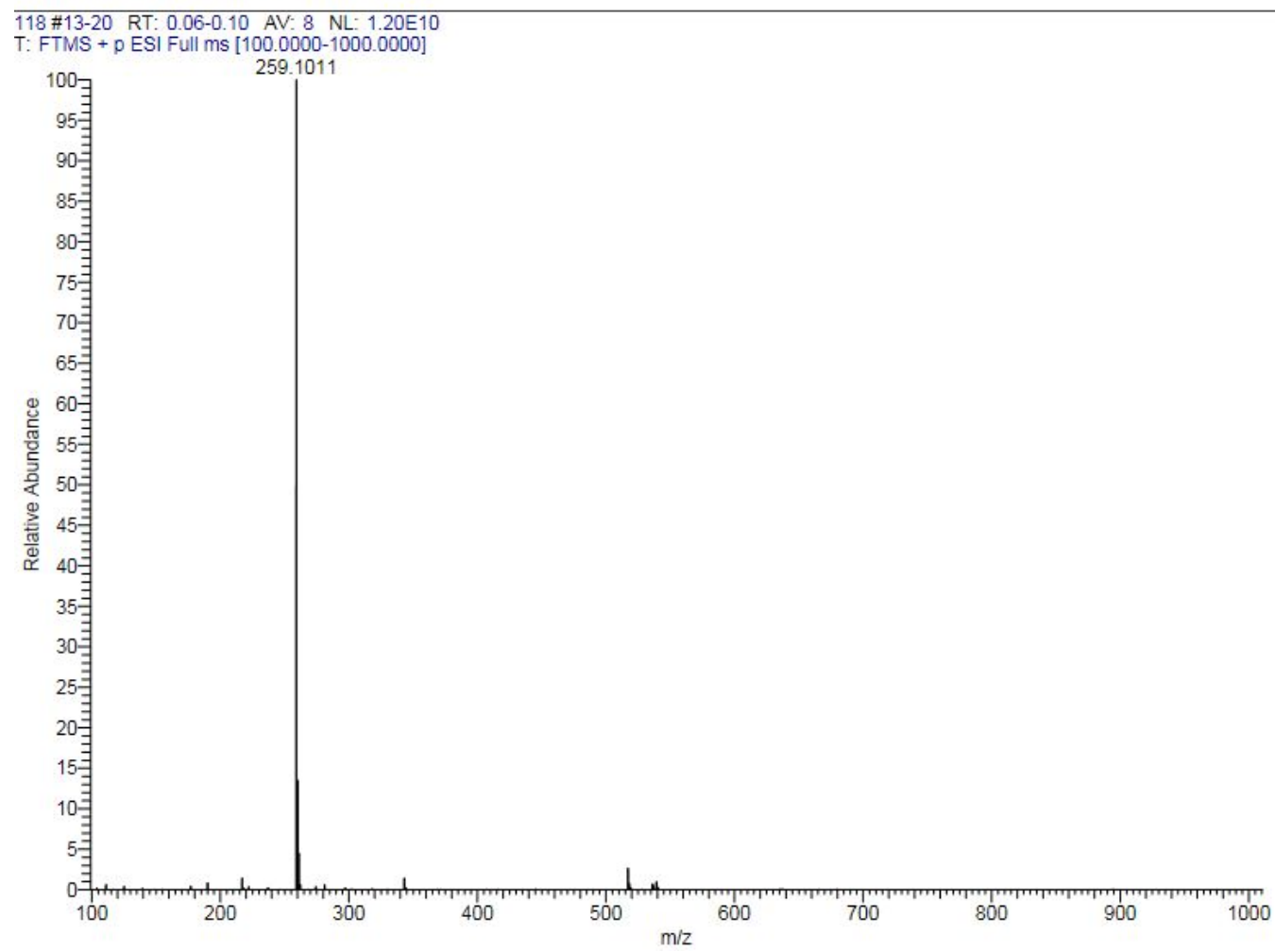

Figure C60. The HRMS of compound $\mathbf{6 t}$. 


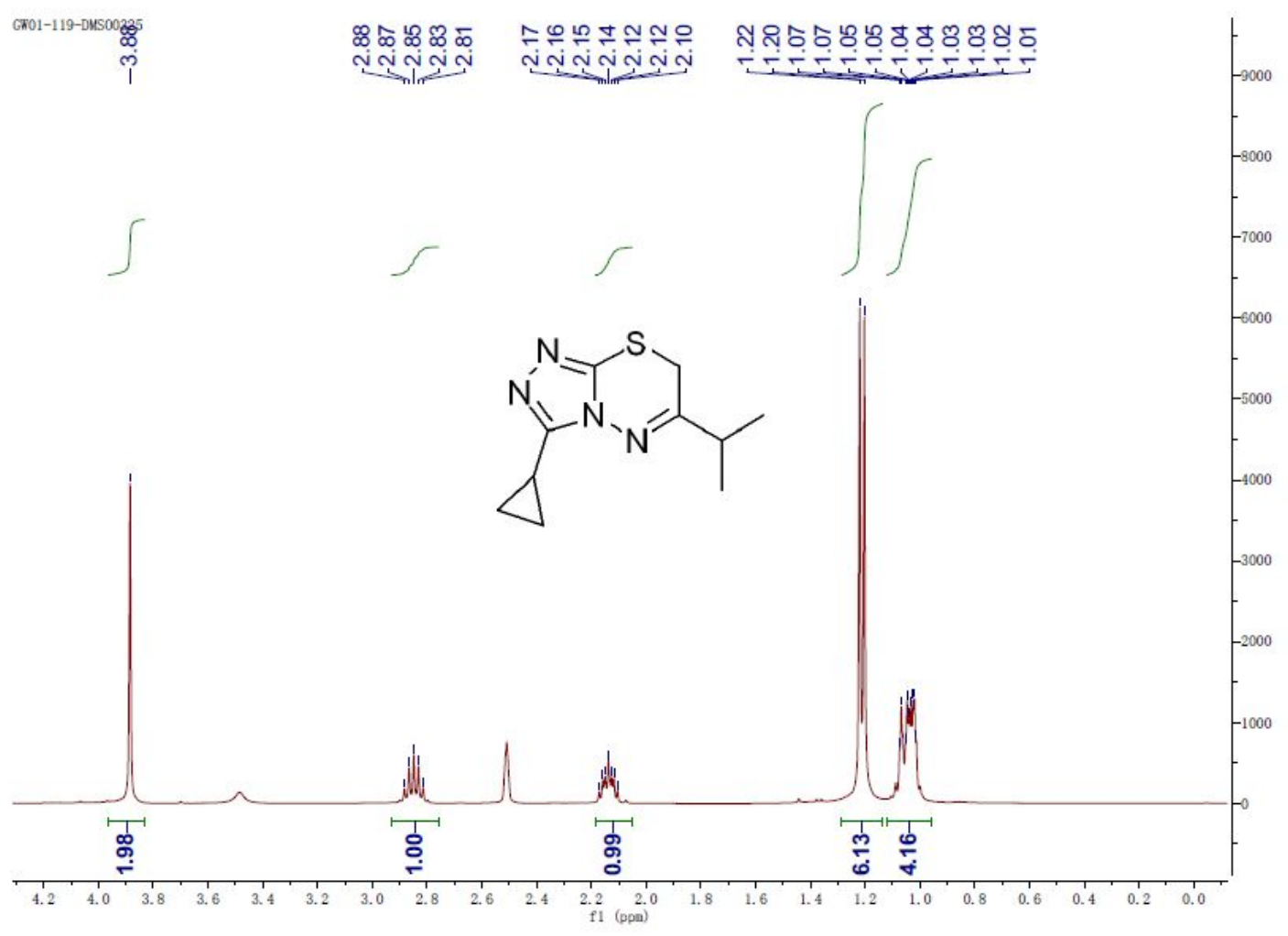

Figure C61. The ${ }^{1} \mathrm{H}$ NMR (400MHz, DMSO- $d_{6}$ ) of compound $6 \mathbf{u}$.

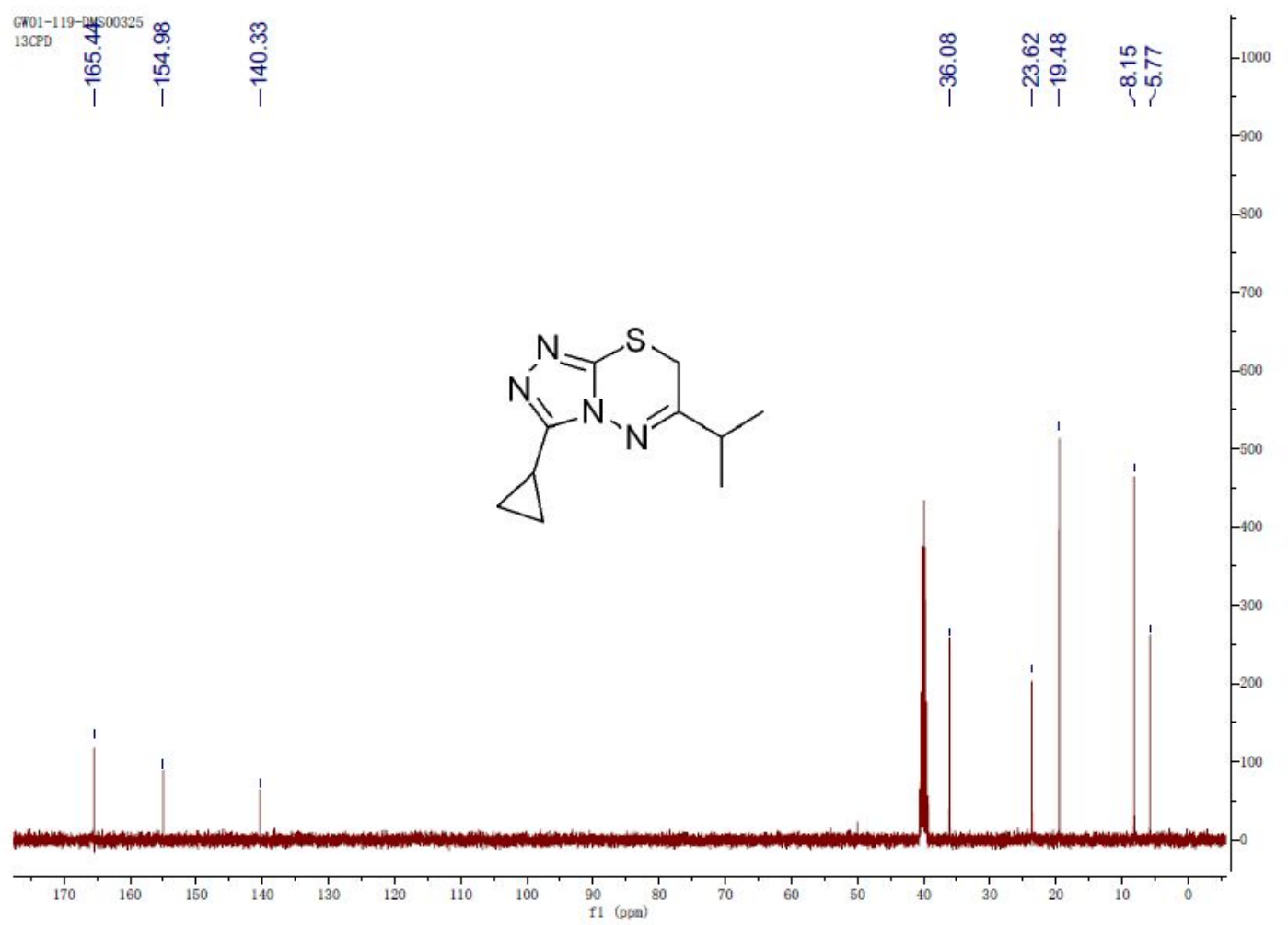

Figure C62. The ${ }^{13} \mathrm{C}$ NMR (400MHz, DMSO- $d_{6}$ ) of compound $6 \mathbf{u}$. 


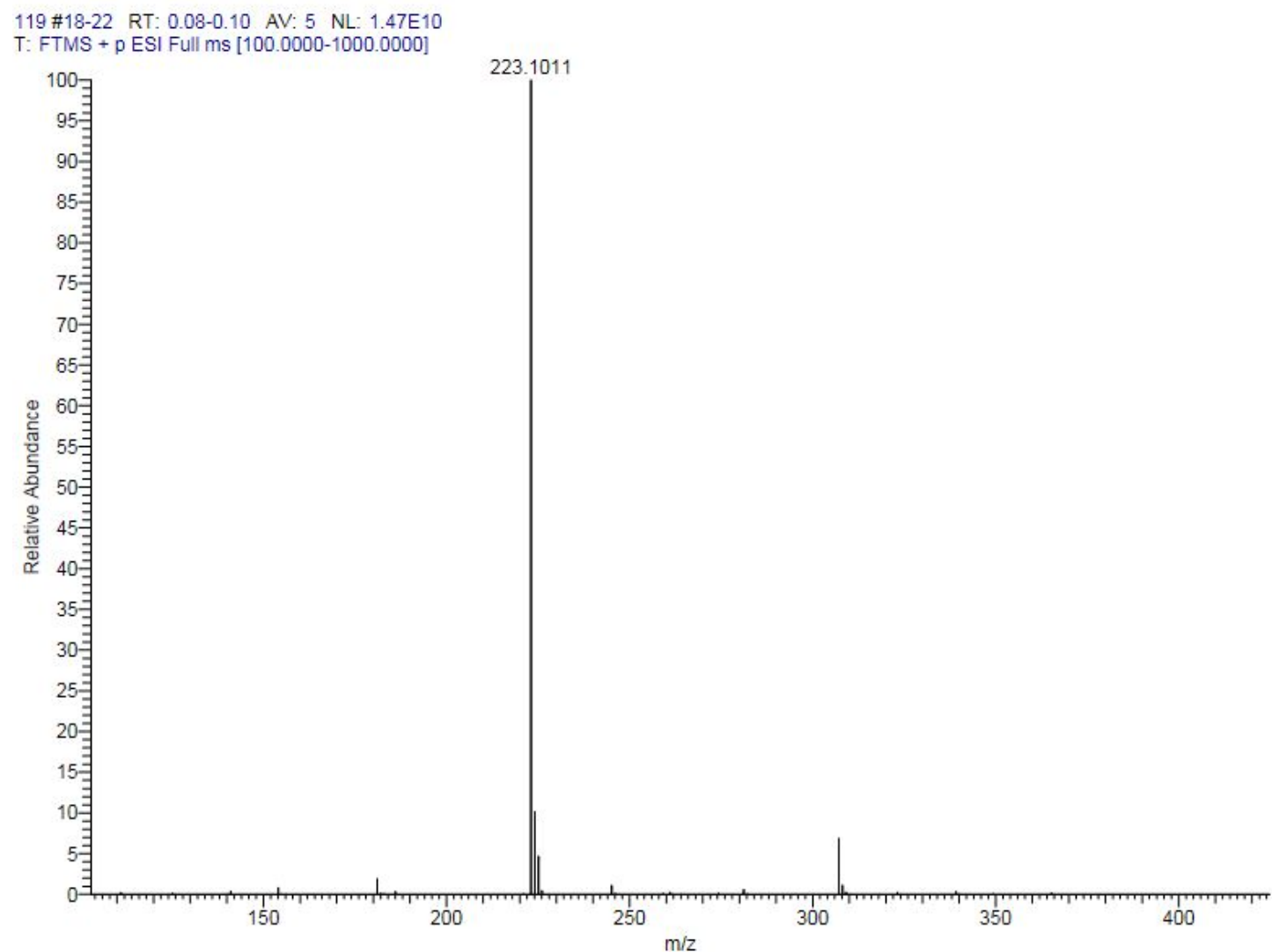

Figure C63. The HRMS of compound $\mathbf{6 u}$. 